(4) 5

\title{
An experimental and theoretical investigation into three-body abrasive wear
}

Martijn Woldman 


\section{An experimental and theoretical investigation into three-body abrasive wear}

Martijn Woldman 
De promotiecomissie is als volgt samengesteld:

prof.dr. G.P.M.R. Dewulf, Universiteit Twente, voorzitter en secretaris prof.dr.ir. E. van der Heide, Universiteit Twente, promotor prof.dr.ir. T. Tinga, Universiteit Twente/Nederlandse Defensie Academie, promotor dr.ir. M.A. Masen, Imperial College London, assistent promotor prof.dr.ir. R.P.B.J. Dollevoet, Technische Universiteit Delft prof.dr.ir. C. van Rhee, Technische Universiteit Delft prof.dr.ir. A.H. van den Boogaard, Universiteit Twente prof.dr.ir. L.A.M. van Dongen, Universiteit Twente

This research was sponsored by the Netherlands Defence Academy (NLDA) and the Netherlands Organisation for Applied Scientific Research (TNO), TNONLDA PhD contract HDO-18

Woldman, Martijn

An experimental and theoretical investigation into three-body abrasive wear $\mathrm{Ph} . \mathrm{D}$. Thesis, University of Twente, Enschede, The Netherlands, April 2014

ISBN: 978-90-365-3621-9

Copyright (C) M. Woldman, Enschede, The Netherlands 


\title{
AN EXPERIMENTAL AND THEORETICAL INVESTIGATION INTO THREE-BODY ABRASIVE WEAR
}

\section{PROEFSCHRIFT}

\author{
ter verkrijging van \\ de graad van doctor aan de Universiteit Twente, \\ op gezag van de rector magnificus, \\ prof.dr. H. Brinksma, \\ volgens besluit van het College voor Promoties \\ in het openbaar te verdedigen \\ op woensdag 23 april 2014 om 14:45 uur
}

door

Martijn Woldman geboren 14 oktober 1985

te Hoogeveen, Nederland 
Dit proefschrift is goedgekeurd door:

de promotoren: prof.dr.ir. E. van der Heide

prof.dr.ir. T. Tinga

de assistent promotor: dr.ir. M.A. Masen 


\section{Summary}

When machines operate under extreme conditions such as sandy and hot environments, they often need to perform to maximum capacity. The high demands cause the amount of wear to increase relative to 'the normal' situation. Moreover, the extreme conditions are typically variable, making it impossible to define fixed maintenance intervals, because the amount of wear cannot be predicted beforehand. When failure of such machines has to be prevented and maintenance is to be performed efficiently, i.e. minimizing downtime and maintenance costs, this means that the amount of wear somehow needs to be calculated based on the use and operating conditions of the machines.

Certainly in the case of machines that work in sandy environments, sand particles entering in between the machines' components in sliding contact cause increased amounts of wear. The wear caused by this sliding movement of hard particles through a softer surface is called abrasion and is a prominent wear mechanism decreasing the life time of e.g. gears and bearings. Traditionally, the amount of wear due to abrasion is estimated with a simple model based on Archard's wear law. Such models, however, are considered too simple and not adequate to calculate abrasive wear rates and predict maintenance intervals. The work presented in this thesis investigates the abrasion mechanism and improves the model for third-body abrasion.

One of the main factors influencing third-body abrasion is formed by the properties of the particles causing the wear. According to the literature, the most important particle properties related to abrasion are the size, shape and hardness. Because the exact influence of particle size and shape on abrasion is not yet fully understood, the relations between these properties and wear have been verified. First, dry sand-rubber wheel experiments were performed to study third-body abrasion and the use of different sand varieties in general. Both the particle size and shape of the sand varieties tested were measured and empirically related to the amount of wear arising. However, because the different properties influence each other, it proved difficult to separate them and study them individually. In a second series of experiments, so-called single asperity scratch tests that take place under more controllable conditions, specifically the effect of the particle size on abrasion was determined. According to the single asperity scratch tests, wear increases with decreasing particle size. Moreover, the experiments revealed a new regime for plastic deformation at typically low loads and indentation depths. 
New parameters were derived to describe the shape of particles in general. Because shape can be described on different levels, a combination of the global regularity parameter and the local sharpness parameter is needed to fully define the particle shape. A numerical finite element model in Abaqus for a tip with a predefined shape sliding through a surface (reproducing the single asperity scratch experiments) was set up to simulate the wear types associated to abrasion and further establish the relation between abrasive wear and particle shape and size.

With the relations between the important particle properties and abrasion derived and the model for third-body abrasion improved, the results were then implemented in a predictive maintenance setup for vehicles operating in sandy environments. The new setup was tested for the CV90 military infantry vehicle, whose sprocket wheels are known to suffer from abrasion. Verification of the improved maintenance strategy with both predefined usage profiles and usage data of the military vehicle showed that the wear model supports the determination of interval lengths and is valuable in scenario analyses.

This thesis describes a combined experimental and theoretical approach aiming to derive the relations between particle properties and abrasion, in order to improve the maintenance strategy for a machine suffering from abrasive wear. 


\section{Samenvatting}

Wanneer machines onder extreme omstandigheden opereren, bijvoorbeeld in zanderige en hete omgevingen, moeten deze vaak op hun maximale capaciteit presteren. De hoge eisen zorgen er voor dat de hoeveelheid slijtage van dergelijke machines toeneemt ten opzichte van 'normaal' gebruik. Bovendien zijn de extreme condities vaak variabel, wat het onmogelijk maakt de optredende slijtage op voorhand te voorspellen. Als voorkomen moet worden dat deze machines falen en bovendien het onderhoud efficiënt moet worden uitgevoerd, wat betekent dat de reparatietijd en onderhoudskosten worden geminimaliseerd, moet de hoeveelheid slijtage worden berekend op basis van het gebruik en de operationele condities van de machines.

Vooral voor machines die in zanderige omgevingen actief zijn, zorgen de zandkorrels die binnendringen in de machinecomponenten en die in glijdend contact zijn voor een verhoogde hoeveelheid slijtage. De slijtage die wordt veroorzaakt door deze beweging van harde korrels door een zachter oppervlak wordt abrasie genoemd en is een prominent slijtagemechanisme dat de levensduur van bijvoorbeeld tandwielen en lagers verkort. Traditioneel gezien wordt de hoeveelheid slijtage ten gevolge van abrasie afgeschat met behulp van een simpel model dat is gebaseerd op Archard's slijtagewet. Deze modellen worden echter als te eenvoudig en niet adequaat beschouwd voor het daadwerkelijk berekenen van abrasieve slijtagesnelheden en het voorspellen van onderhoudsintervallen. Het werk dat wordt gepresenteerd in dit proefschrift onderzoekt en verbetert het model voor 'derde-lichaam' abrasieve slijtage.

Eén van de belangrijkste invloedsfactoren van 'derde-lichaam' abrasie zijn de eigenschappen van de korrels die de slijtage veroorzaken. Volgens de literatuur zijn de grootte, vorm en hardheid de meest belangrijke eigenschappen die gerelateerd zijn aan abrasie. Omdat de precieze invloed van de korrelgrootte en -vorm op abrasie niet volledig werden begrepen, zijn de relaties tussen de eigenschappen en slijtage geverifieerd. Eerst zijn er zogenaamde 'dry sandrubber wheel' tests uitgevoerd om 'derde-lichaam' abrasieve slijtage en het gebruik van verschillende zandsoorten in het algemeen te bestuderen. Zowel de korrelgrootte en -vorm van de geteste zandsoorten zijn gemeten en er is een empirische relatie afgeleid tussen de eigenschappen en de optredende slijtage. Echter, omdat de verschillende eigenschappen elkaar beïnvloeden, bleek het ingewikkeld ze te scheiden en afzonderlijk te bestuderen. In een tweede serie van experimenten onder beter controleerbare omstandigheden, de zogenaamde 'single asperity scratch tests', is de korrelgrootte afzonderlijk bestudeerd en de relatie met abrasie afgeleid. Volgens deze experimenten neemt de slijtage toe als 
de korrelgrootte afneemt. Bovendien hebben de experimenten een nieuw regime van plastische deformatie bij typisch lage belastingen en indentatiedieptes aan het licht gebracht.

Nieuwe parameters voor de beschrijving van de korrelvorm in het algemeen zijn afgeleid. Omdat de vorm op meerder lengteschalen kan worden beschreven is er een combinatie van de 'global regularity' parameter en de 'local sharpness' parameter benodigd om de korrelvorm volledig te beschrijven. Een numerieke eindige elementen analyse in Abaqus voor een tip met een gedefinieerde vorm die door een zachter oppervlak glijdt (waarbij de single asperity scratch tests worden gesimuleerd) is gebruikt om de soorten slijtage die optreden tijdens abrasie te simuleren en de relatie tussen abrasieve slijtage en de korrelvorm en grootte af te leiden.

$\mathrm{Na}$ het afleiden van de relaties tussen de belangrijke korreleigenschappen en abrasie en het verbeteren van het model voor 'derde-lichaam' abrasie, zijn de resultaten geïmplementeerd in een voorspellend onderhoudsconcept voor machines die in zanderige omgevingen opereren. De nieuwe strategie is toegepast op het CV90 militair infanterievoertuig, waarvan de aandrijfwielen van de rupsbanden last hebben van abrasieve slijtage. De verificatie van de verbeterde onderhoudsstrategie met zowel vooraf gedefinieerde gebruiksprofielen en gebruiksdata van het militaire voertuig toont aan dat de strategie helpt bij het bepalen van de onderhoudsintervallen en waardevol is voor scenario analyses.

Dit proefschrift beschrijft een gecombineerde experimentele en theoretisch aanpak voor het afleiden van de relaties tussen korreleigenschappen en abrasie, teneinde de onderhoudsstrategie voor een machine die onderhevig is aan abrasieve slijtage te verbeteren. 


\section{Contents}

\section{Part I}

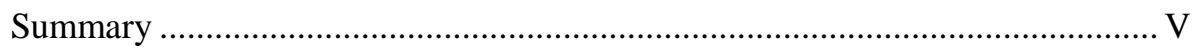

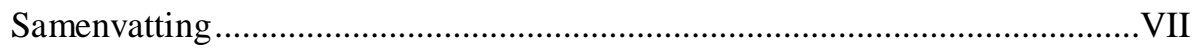

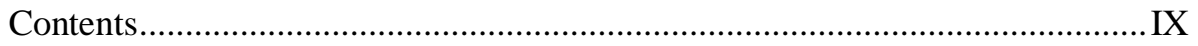

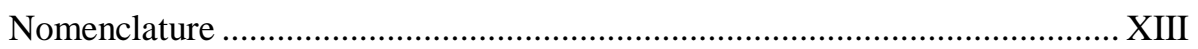

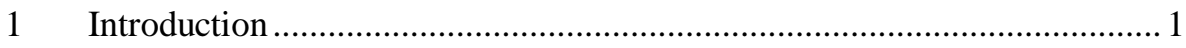

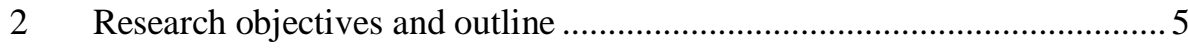

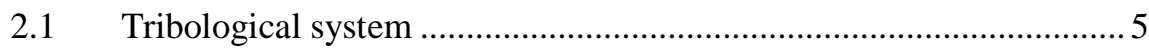

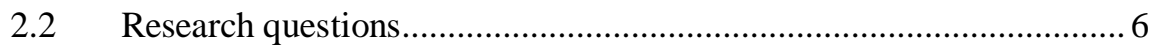

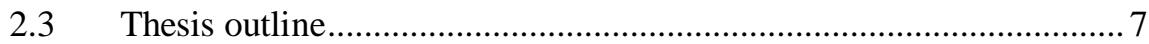

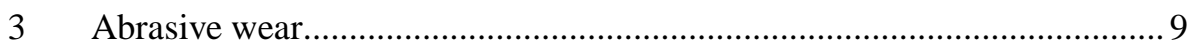

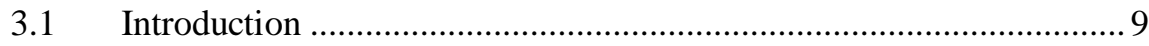

3.2 Modelling abrasive wear............................................................. 10

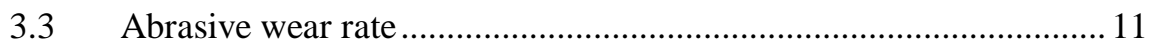

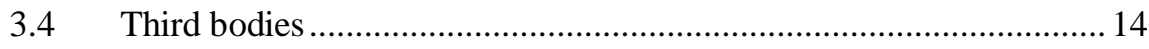

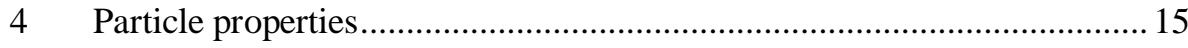

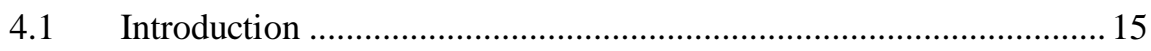

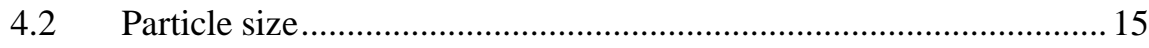

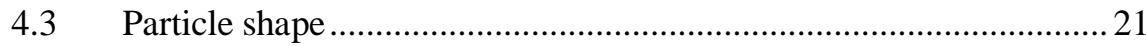

4.3.1 Discretized particles ........................................................... 22

4.3.2 Iterative Closest Point Algorithm.................................................. 23

4.3.3 Particle shape definitions........................................................... 24

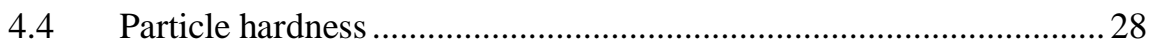

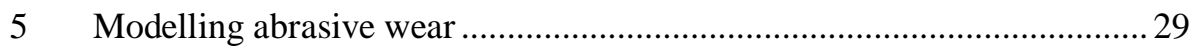

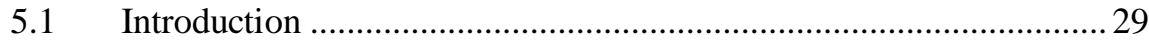

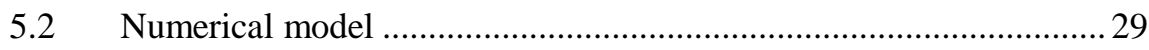

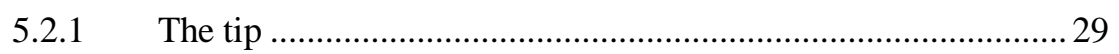




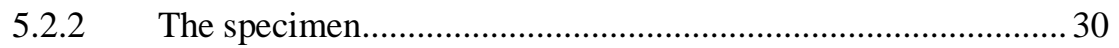

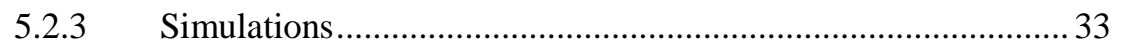

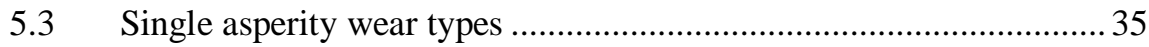

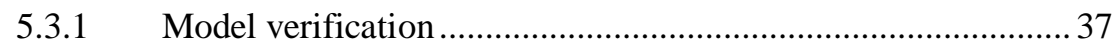

5.4 Application of the model to conical tips ................................................. 39

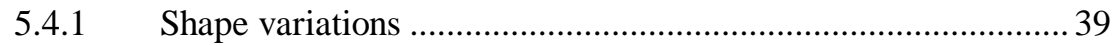

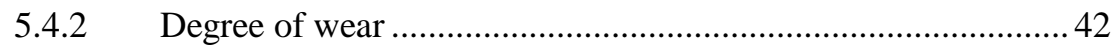

6 Practical application of the wear model ................................................... 43

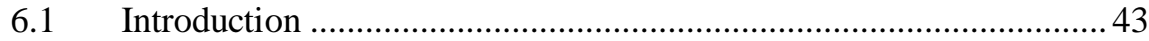

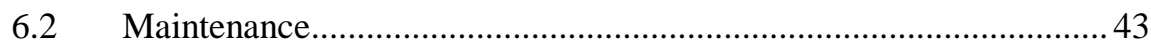

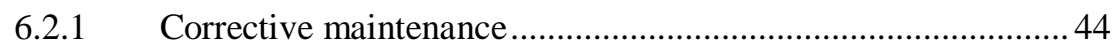

6.2.2 Preventive maintenance............................................................ 44

6.2.3 Reliability centred maintenance …………………................... 45

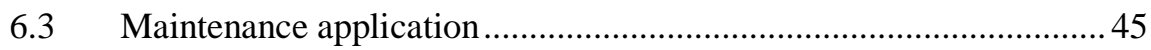

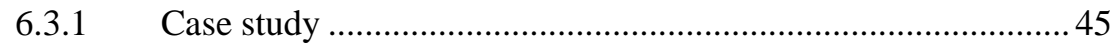

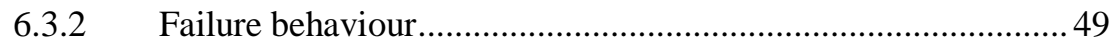

6.3.3 Sprocket service life ............................................................... 50

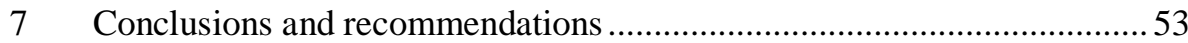

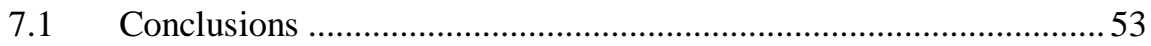

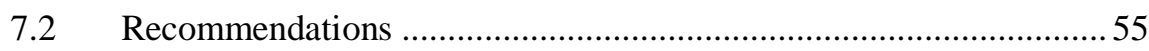

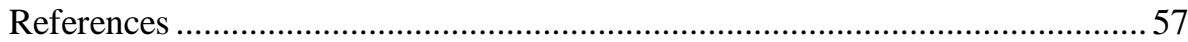

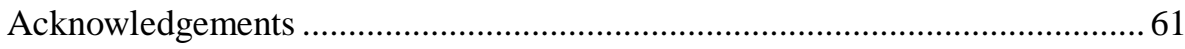




\section{Part II}

Paper A: Investigating the influence of sand particle properties on abrasive wear behaviour, M. Woldman, E. Van Der Heide, D.J. Schipper, T. Tinga and M.A. Masen, Wear, 2012, Volume 294-295, Pages 419-426.

Paper B: The influence of abrasive body dimensions on single asperity wear, M. Woldman, E. Van Der Heide, T. Tinga and M.A. Masen, Wear, 2013, Volume 301, Issues 1-2, Pages 76-81.

Paper C: Classification of Particle Shapes in 3D, M. Woldman, E. Van Der Heide, T. Tinga and M.A. Masen, submitted to Applied Mathematical Modelling (5-2013).

\section{Paper D:}

A Finite Element approach to Modelling Abrasive Wear Modes, M.Woldman, E. van der Heide, T. Tinga, G. Limbert and M.A. Masen, submitted to Tribology Transactions (1-2014).

Paper E: Implementation of an abrasive wear model in a predictive maintenance concept for systems operated in sandy conditions, M. Woldman, T. Tinga, E. Van Der Heide and M.A. Masen, submitted to Engineering Failure Analysis (1-2014). 
Conference contributions:

1. The influence of sand particle properties on abrasive wear, $\mathbf{M}$. Woldman, E. Van Der Heide, D.J. Schipper, T. Tinga and M.A. Masen, presented at the International Joint Tribology Conference, Los Angeles, USA, 2011.

2. Sand particles and the abrasive wear they cause, M. Woldman, E. Van Der Heide, D.J. Schipper, T. Tinga and M.A. Masen, in M. Scherge \& M. Dienwiebel (Eds.), Friction, Wear and Wear Protection, Karlsruhe, Germany, 2011.

3. Performing wear tests to predict three body abrasive wear rates, M. Woldman, In M.A. Masen (Ed.), Proceedings of the 29th meeting of the IRG-WOEM IRG-OECD, Amsterdam, The Netherlands, 2012.

4. Single asperity abrasive wear and the influence of abrasive body dimensions, M. Woldman, presented at the International Conference on Sustainable Construction \& Design,

Ghent, Belgium, 2013.

5. The influence of abrasive body dimensions on single asperity wear, M. Woldman, presented at the $19^{\text {th }}$ International Conference on Wear of Materials, Portland, USA, 2013.

6. A Particle Shape Definition Related to Third-body Abrasive Wear, M. Woldman, presented at the $5^{\text {th }}$ World Tribology Congress, Turin, Italy, 2013. 


\title{
Nomenclature
}

\author{
Abbreviations
}

2D

3D

CBM

CFA

CMMS

CV90

DIN

FEA/FEM

FMECA

MTBF

$\max$

n.a.

ref

$\mathrm{RCM}$
Two-dimensional space

Three-dimensional space

Condition-Based Maintenance

Cone Fit Analysis

Computerized Maintenance Management System

Combat Vehicle 90

Deutsches Institut für Normung

Finite Element Analysis/Finite Element Method

Failure Mode Effects and Criticality Analysis

Mean Time Between Failures

maximum

not applicable

reference

Reliability Centred Maintenance

\section{Greek symbols}

$\begin{array}{ll}\alpha_{1-3} & - \\ \beta & \circ \\ \beta_{\text {asp }} & \circ \\ \beta_{\text {eff }} & \circ \\ \delta & - \\ \Delta \varepsilon & - \\ & \\ \varepsilon^{\mathrm{f}} & - \\ \dot{\varepsilon} & - \\ \dot{\varepsilon}_{0} & - \\ \dot{\varepsilon}^{*} & - \\ \sigma^{*} & - \\ \eta_{\text {asp }} & - \\ \eta_{\text {eff }} & - \\ \theta & \circ \\ \rho & \mathrm{kg} / \mathrm{m}^{3} \\ \sigma_{\mathrm{m}} & \mathrm{N} / \mathrm{m}^{2} \\ \bar{\sigma} & \mathrm{N} / \mathrm{m}^{2}\end{array}$

fitting parameters wear model semi-angle cone semi-angle single asperity effective semi-angle degree of wear increment of equivalent plastic strain, one integration cycle equivalent fracture strain strain rate initial strain rate dimensionless strain rate pressure-stress ratio cutting efficiency single asperity effective cutting efficiency contact angle material density average normal stress equivalent von Mises stress 


\section{Roman symbols}

$\begin{array}{lll}A_{\mathrm{c}} & \mathrm{m}^{2} & \text { surface area spherical cap } \\ A_{\mathrm{g}} & \mathrm{m}^{2} & \text { groove area } \\ A_{\mathrm{s}} & \mathrm{m}^{2} & \text { shoulder area } \\ a & \mathrm{~m} & \text { asperity contact radius } \\ c & \mathrm{~m} / \mathrm{s} & \text { wave speed along an element } \\ D & - & \text { damage parameter } \\ D_{p} & - & \text { degree of penetration } \\ d & \mathrm{~m} & \text { indentation depth } \\ E & \mathrm{~N} / \mathrm{mm}^{2} & \text { Young's modulus } \\ \text { feedrate } & - & \text { particle feed rate } \\ H & \mathrm{~N} / \mathrm{m}^{2} & \text { hardness } \\ i & - & \text { index sand variety } \\ J_{1-4} & - & \text { model parameters Johnson-Cook } \\ K & - & \text { wear coefficient } \\ k & \mathrm{~mm} / \mathrm{N} \cdot \mathrm{m} & \text { specific wear rate } \\ l & \mathrm{~m} & \text { smallest element length } \\ N & \mathrm{~N} & \text { normal load } \\ N_{\text {asp }} & \mathrm{N} & \text { normal load one asperity } \\ P & \mathrm{~N} / \mathrm{m}^{2} & \text { contact pressure } \\ Q & \mathrm{~m} & \text { wear volume } \\ q_{\text {asp }} & \mathrm{m}^{3} & \text { wear volume for one asperity } \\ R & \mathrm{~m} & \text { contact radius/tip radius } \\ R_{\mathrm{a}} & - & \text { surface roughness, arithmetic average } \\ R_{\mathrm{q}} & - & \text { surface roughness, root mean square } \\ r_{\mathrm{g}} & - & \text { global regularity parameter } \\ s & \mathrm{~m} & \text { sliding distance } \\ s_{1} & - & \text { local sharpness parameter } \\ s h a p e & - & \text { particle shape } \\ \text { size } & \mu \mathrm{m} & \text { particle size } \\ T & \mathrm{~N} & \text { traction/sliding load } \\ \Delta t_{\mathrm{cr}} & \mathrm{s} & \begin{array}{l}\text { critical time increment } \\ \text { contact width }\end{array} \\ \mathrm{W} & \mathrm{m} & \end{array}$




\section{Introduction}

Anybody who has ever spent a day at the beach will probably remember their sandwiches being extra crunchy because of the additional topping of sand and that sand remained between their toes, even several hours after leaving. It is therefore not hard to imagine that in a sandy environment as shown in Figure 1.1 (a), the sand will end up going places where it actually is not intended to go. Though a little annoying, this could easily be considered one of the charming aspects of a seaside trip. In the case of machinery and equipment, however, the entrapment of sand can lead to increased wear and even preliminary failure of the machine components, for instance when sand enters a hydraulic cylinder, causing the cylinder to leak. This kind of wear, where the displacement of hard particles like the sand particles depicted in Figure 1.1 (b) causes wear on a softer surface, is called abrasion and can ultimately cause the early onset of failure of the machine in question.

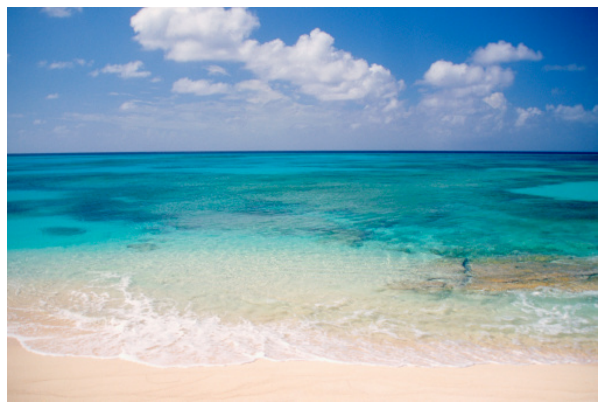

(a)

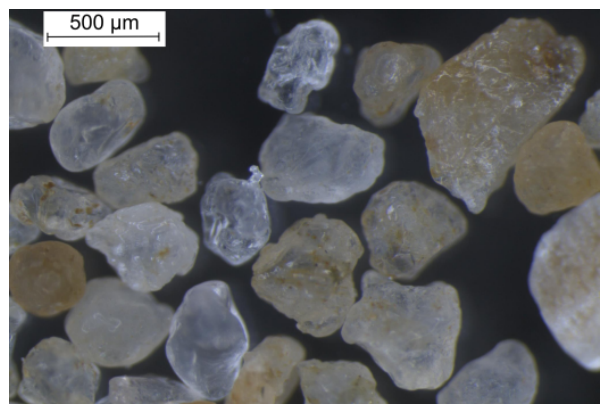

(b)

Figure 1.1: Pictures of a beach (a) and the sand particles typically giving problems (b).

The work presented in this thesis aims to study abrasive wear in the contact between two surfaces. Abrasive wear is caused by hard particles, such as soot, rust, sand or highly deformed wear particles originating from a previous wear process, that become trapped between the surfaces. The system that will be considered is that of wear of construction steel, caused by sand particles. Whereas our toes can relatively easily be cleaned to prevent irritation, for engineering systems this is typically a labour-intensive activity. The parts will first need to be disassembled, then cleaned or replaced before the system can be re-assembled. During this time the equipment is not available for operation. Because it is inefficient to repeat this process every time the machine operates 
under sandy conditions, parts are allowed to wear to some extent before maintenance is performed. Then, failure of machinery can be prevented by repairing or replacing damaged components on time. However, this requires knowledge on the evolution of the damage and the expected remaining lifetime of the component, while it is often difficult to determine if a machine component is about to fail.

Hence, maintenance intervals are established based on an estimate of the lifetime of components. This expected lifetime depends on the usage conditions, such as the applied forces and torques and the power throughput as well as the environment. For machines that operate in a sandy environment, as illustrated in Figure 1.2, the conditions can be considered extreme and because these conditions fluctuate it is currently still challenging to make a reliable estimate of the lifetime of a component. In such cases, it is better to monitor the operating conditions of the machine while it is in use. Based on the usage of the system, for instance rotational velocities, loads, lubricating conditions, as well as the environmental conditions like the humidity and temperature, the amount of wear can be calculated at all times and maintenance performed when needed. Implementing such a strategy for predictive maintenance is not straightforward, because the 'usage' of the machine needs to be translated into wear, meaning that the properties influencing abrasive wear should be known and the quantitative relations have to be derived.

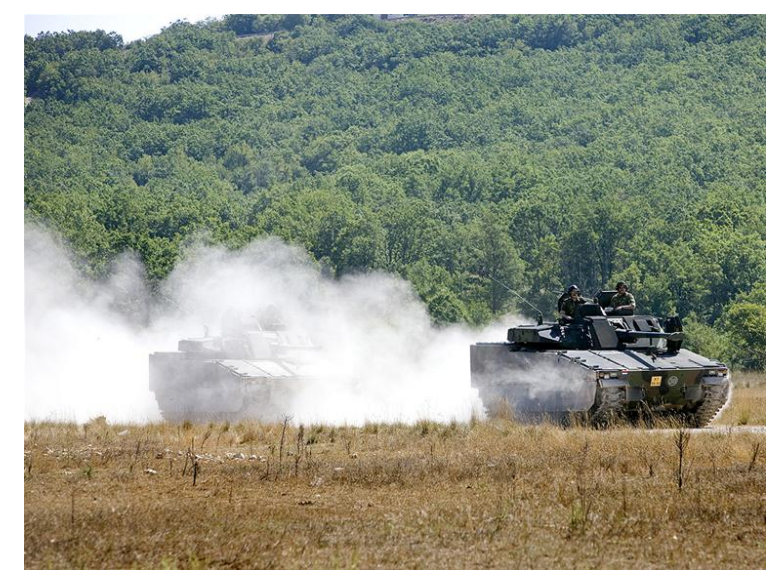

Figure 1.2: A military vehicle being tested under simulated sandy conditions. Source: Dutch Ministry of Defence. 
There is a wide range of parameters that have an influence on the abrasive wear that occurs in an engineering system due to hard particles. Examples are the applied load, the sliding velocity of the two materials in contact, the hardness of the contacting materials and the characteristics of the particles that cause the wear. The influence of the particle characteristics on the wear is significant, and has been recognized by many researchers [1-8]. However, at present there are no adequate quantitative models that describe the relationship between the properties of the particles and the resulting amount of abrasive wear. An important step in the development of a reliable system for predictive maintenance is the establishment of these relationships. A key element in this is a deeper understanding of the mechanisms that govern abrasion. 


\section{Research objectives and outline}

\subsection{Tribological system}

The field of tribology concerns the science and technology of interacting surfaces in relative motion [9]. Friction and wear are generally not determined by single surface properties but depend on the nature of the interaction. The contact behaviour is typically described using a systems approach [10], taking into account the contacting surfaces, the lubricant present in the contact and the environment surrounding the contact. As will be explained in Section 3, the tribological system selected for this work is constrained to unlubricated threebody abrasion. Hence, Figure 2.1 comprises the third body -the particles that actually cause the abrasive action- as well. The input to the system is formed by the operating conditions of the components, with friction and wear of the surfaces as output.

\section{Tribological system}

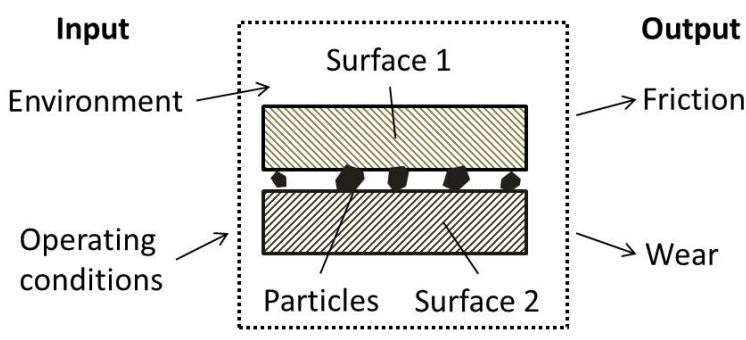

Figure 2.1: Schematic overview of the tribological system for abrasion.

The structure of the tribo-system, the type of motion and the type of work are combined in DIN 50320 [11] with four wear mechanisms: tribochemical wear, surface fatigue, adhesive wear and abrasive wear.

Tribochemical or corrosive wear is a wear process in which chemical or electrochemical reaction with the environment predominates [9]. Removal of chemical reaction products by the tribological action give rise to wear. An example of tribochemical wear (corrosion) is shown in Figure 2.2 (a). Surface fatigue, see Figure 2.2 (b), arises from cyclic stress variations [9]. The stress variations ultimately lead to delamination, particle detachment and crack formation and growth. Surface fatigue typically appears in rolling contacts like roller bearings and gears. 


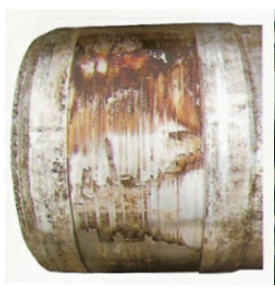

(a)

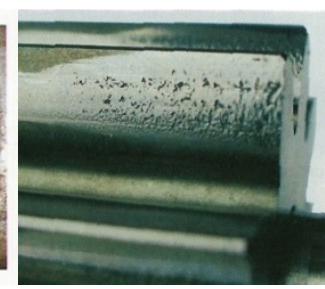

(b)

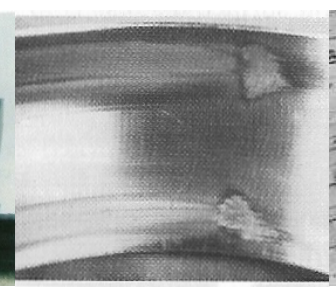

(c)

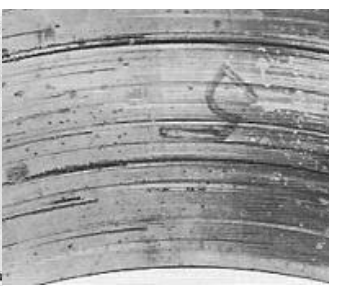

(d)

Figure 2.2: Typical examples of (a) tribochemical wear, (b) surface fatigue, (c) adhesive wear and (d) abrasive wear.

According to [9], adhesive wear concerns transference of material from one surface to another during relative motion, due to a process of solid-phase welding. Particles that are removed from one surface are either temporarily or permanently attached to the other surface. Figure 2.2 (c) shows an example of adhesive wear. The wear mechanism of abrasion, wear by displacement of material caused by hard particles or hard protuberances, is described in more detail Section 3. An example of the abrasive action is shown in Figure 2.2 (d).

These four basic mechanisms or any combination of them are involved in wear processes. DIN 50320 [11] uses the type of motion to distinguish the wear processes: sliding wear, oscillation wear, erosive wear, impact wear and rolling wear. The work presented in this thesis is constrained to the wear mechanism abrasive wear and to the wear process sliding wear.

\subsection{Research questions}

The objective of this research is to develop an improved strategy for the maintenance of a machine suffering from sliding wear caused by the abrasive action of sand particles. Based on the current state of the art presented in the literature, four research questions are formulated:

- Which sand particle properties are influencing abrasive wear?

- Why do these properties influence abrasion and how can their influence be quantified?

- How to extend current 2D particle shape functions in 3D?

- How to relate the operating conditions of a machine to the amount of abrasive wear it suffers for application in a predictive maintenance strategy? 
The work conducted in relation to these questions is described in the next chapters, the progress is summarized by the conclusions and accompanied by a description of the remaining work given in the recommendations.

\subsection{Thesis outline}

This thesis is divided into two parts: Part I summarizes the research, Part II contains the set of papers which constitute the scientific work on which this thesis is based. In Part I, Chapter 3 describes the abrasive wear mechanism. The important particle properties that influence abrasion are extracted and their relations to wear established in Chapter 4. These relationships are obtained based on two sets of experiments; single asperity scratching tests to study the influence of the asperity size and dry sand-rubber wheel tests to study the global influence of sand particles on wear. Definitions and quantifications of the particle shape are derived to parameterize shape in 3D and on different length scales. The relationship between particle shape and abrasion is verified with a numerical model described in Chapter 5, simulating the scratching movement of asperities with a range of predefined shapes through a softer surface. Finally, in Chapter 6, the derived wear relations are implemented into a maintenance setup of a machine component. Here, lifetime predictions are derived to support a predictive maintenance approach that can be used to optimize the maintenance intervals of a machine.

A schematic overview of this thesis is shown in Figure 2.3. This figure also shows the connections between the chapters in Part I and the corresponding papers in Part II.

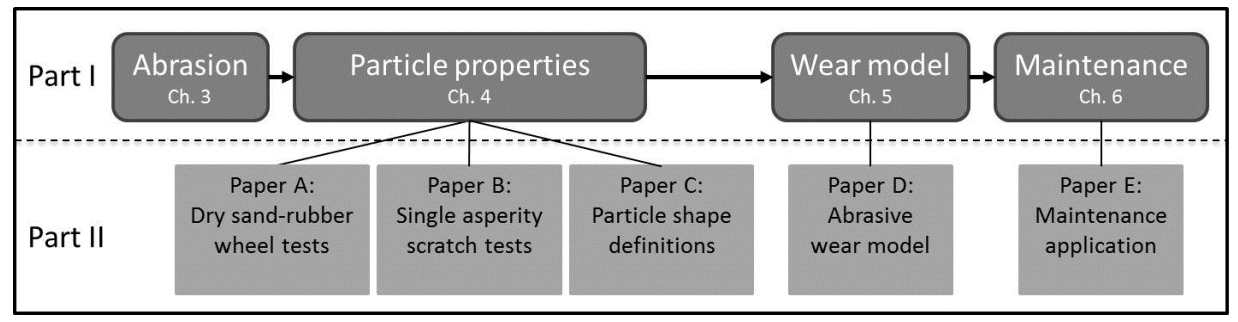

Figure 2.3: Schematic overview of the thesis. 


\section{Abrasive wear}

\subsection{Introduction}

When wear arises due to the sliding movement of hard particles or protuberances along a softer surface, this is referred to as abrasion. Two types can be distinguished; two- and three-body abrasion. In two-body abrasion, a softer surface wears because it is scratched by harder asperities of another surface. In three-body abrasion, particles are present in the interface between the surfaces and are either embedded in one of the surfaces or are free to roll and slide as shown in Figure 3.1. When particles embed, they will generally do so in the softer of the contacting materials, causing wear to the harder surface. Referring to Figure 3.1, the embedded particle will cause a scratch and the rolling particles will cause repeated indentations to the surfaces in contact. Although two- and three-body abrasion are sometimes difficult to distinguish visually, embedded particles are indications of three-body abrasion. Also, the amount of wear observed in three-body abrasion is typically one order of magnitude lower than that observed in two-body abrasion [1]. In manufacturing, an example of two-body abrasion is grinding, whereas polishing with e.g. diamond paste is an example of three-body abrasion.

This section treats a simple model for abrasion, in order to identify the parameters influencing abrasive wear and give an idea about the relations between the parameters and abrasion.

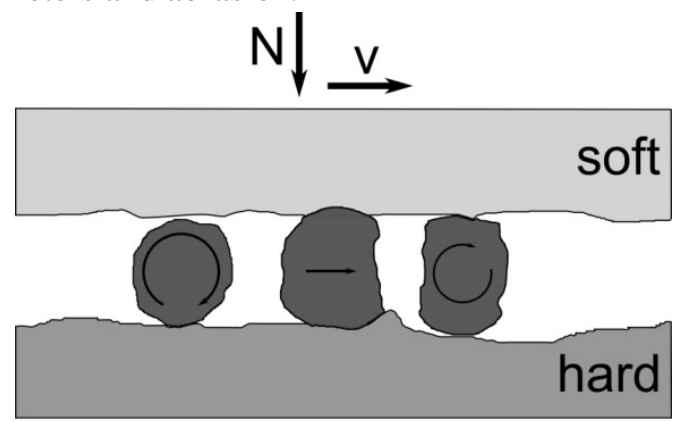

Figure 3.1: Schematic representation of the third-body abrasive wear process. The upper surface slides with a velocity $\mathrm{v}$ to the right at a normal force $\mathrm{N}$, causing third bodies to roll or slide and generate local wear to the surfaces. 


\subsection{Modelling abrasive wear}

For ductile materials, abrasion means that material is removed because hard particles scratch and cut through a surface that is less hard than the particles. A model referring to this kind of wear can be derived similarly to the model defined by Archard [12]. According to Archard, the total volume $Q$ worn away by the scratching movement of e.g. particles is expressed by:

$$
Q=\frac{K \cdot N \cdot s}{H}
$$

with $K$ the wear coefficient (-), $N$ the total normal load (N), $s$ the sliding distance $(\mathrm{m})$ and $H$ the hardness of the abraded material $\left(\mathrm{N} / \mathrm{m}^{2}\right)$. In order to obtain this result, the hardness of the abraded material is assumed to be equal to the contact pressure. The wear coefficient $K$ comprises the material and geometrical properties of the abrading particles. To give an idea about the actual values, the wear coefficient has typical values of $5 \cdot 10^{-3}$ to $5 \cdot 10^{-2}$ (-) for twobody abrasion. In three-body abrasion, the wear coefficient is generally smaller by one order of magnitude [1], typically ranging between $5 \cdot 10^{-4}$ and $5 \cdot 10^{-3}(-)$.

According to [13], most wear processes stabilize in time when the operational conditions are constant. This leads to an equilibrium, with the volume of material worn away proportional to either process time or the sliding distance. Consequently, the wear volume can be related to a specific wear rate $k\left(\mathrm{~mm}^{3} / \mathrm{N} \cdot \mathrm{m}\right)$ :

$$
Q=k \cdot N \cdot s
$$

Comparing Equations 3.1 and 3.2, the specific wear rate $k$ is equal to the wear coefficient $K$ divided by the hardness $H$ :

$$
k=\frac{K}{H}
$$

The values for the specific wear range from virtually unaffecting, with values of around $1 \cdot 10^{-9} \mathrm{~mm}^{3} / \mathrm{N} \cdot \mathrm{m}$ for lubricated contacts, to $1 \cdot 10^{-6} \mathrm{~mm}^{3} / \mathrm{N} \cdot \mathrm{m}$ for dry sliding and $1 \cdot 10^{-2} \mathrm{~mm}^{3} / \mathrm{N} \cdot \mathrm{m}$ for grinding $[13,14]$. 
The equations described above show that the wear volume is directly proportional to both sliding distance and normal load. Furthermore, they suggest that the wear volume is inversely proportional to the material hardness. In reality, however, the hardness of the surface will be different from the bulk hardness, for instance due to the large amounts of strain hardening observed during abrasion of some materials. This increases the flow stress and hardness of the surface with respect to the bulk and consequently, the hardness of the bulk material can no longer rightfully be used to calculate the wear volume.

\subsection{Abrasive wear rate}

The abrasive wear mechanism can be studied using a simple model. It helps to clarify the wear process as well as the parameters influencing abrasion. An initial model for two-body abrasion can be constructed, considering a contact situation of asperities with a predefined shape sliding over a surface. This model is based on the following assumptions:

- actual contacts arise at locations where the asperities of the interacting surfaces touch;

- the real area of contact is equal to the sum of the individual asperity contact areas, and;

- asperities are rigid and the asperity contact is circular with radius $a(\mathrm{~m})$.

Starting with a single asperity with a conical shape as shown in Figure 3.2, the normal load $N_{\text {asp }}(\mathrm{N})$ supported by this single asperity is equal to:

$$
N_{\text {asp }}=P \cdot \frac{\pi \cdot a^{2}}{2}
$$

with $P$ the contact pressure (Pa). Because the cone has a semi-angle $\beta$ (varying between 0 and $90^{\circ}$ ) and penetration depth $d(\mathrm{~m})$ according to Figure 3.2, this equation can be rewritten:

$$
N_{\text {asp }}=P \cdot \frac{\pi \cdot\left(x \cdot \tan \beta_{\text {asp }}\right)^{2}}{2}=\frac{\pi}{2} \cdot P \cdot d^{2} \cdot \tan ^{2} \beta_{\text {asp }}
$$




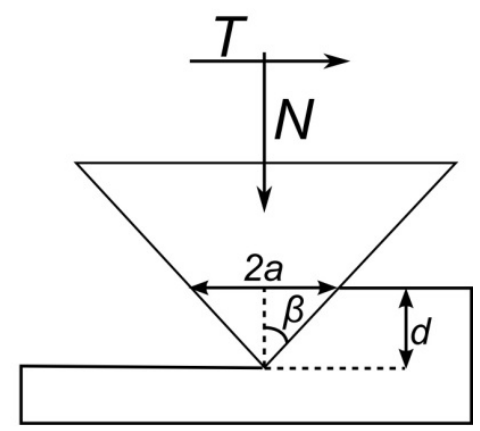

Figure 3.2: Schematic representation of a scratching conical particle.

Not all material displaced by one pass of the cone will actually be removed. Based on e.g. the material properties of the tip, the abrasion can lead to different wear types, varying from ploughing to cutting. Hence, the material volume $q_{\text {asp }}\left(\mathrm{m}^{3}\right)$ worn away by the sliding movement of the conical particle over a distance $s$ is equal to:

$$
q_{\text {asp }}=\eta_{\text {asp }} \cdot s \cdot a \cdot d=\eta_{\text {asp }} \cdot s \cdot d^{2} \cdot \tan \beta_{\text {asp }}
$$

with $\eta_{\text {asp }}$ the fraction of the material actually removed, $a \cdot d$ the frontal area of the groove $\left(\mathrm{m}^{2}\right), s$ the length of the groove produced $(\mathrm{m})$ and a purely plastic situation assumed. Rewriting Equation 3.5 in terms of $d^{2}$ and substituting gives:

$$
q_{\mathrm{asp}}=\frac{2 \cdot \eta_{\mathrm{asp}} \cdot s \cdot N_{\mathrm{asp}}}{\pi \cdot P \cdot \tan \beta_{\mathrm{asp}}}
$$

Because the situation involves plastic deformation, the contact pressure is approximately equal to the hardness $H$ of the abraded surface. Summing the equation over all relevant particles in the contact, the total volume worn away per sliding distance is expressed by:

$$
Q=\frac{2 \cdot \eta_{\mathrm{eff}} \cdot N \cdot s}{\pi \cdot H \cdot \tan \beta_{\mathrm{eff}}}
$$

with $\eta_{\text {eff }}$ the effective cutting efficiency of all the particles combined and $\beta_{\text {eff }}$ the semi-angle which represents the sharpness of the scratching particles. 
Comparing Equations 3.1 and 3.8, the wear coefficient $K$ equals:

$$
K=\frac{2 \cdot \eta_{\mathrm{eff}}}{\pi \cdot \tan \beta_{\mathrm{eff}}}
$$

Hence, the wear coefficient depends on the fraction $\eta$ of the material removed and the geometry (semi-angle $\beta$ ) of the abrading particles.

This model essentially applies to two-body abrasion. However, the most severe situation in three-body abrasion arises when particles embed in one of the surfaces and cause wear to the other surface. This process can be simulated adequately with the model derived above. Extending the model for two-body abrasion to incorporate other third-body effects would include the degrees of freedom of the third-body, e.g. rotational behaviour, the hardness difference between the abraded surface and the third-bodies and the properties of the thirdbodies that relate to abrasive wear. 


\subsection{Third bodies}

As this thesis studies three-body abrasion, it is clear that the nature of the particles and the way these particles can move within the tribological contact are of high importance. The influence of the particles on abrasive wear has been reported in the literature extensively [1-6, 15-25], however, the relations between abrasion and the most important particle properties are still debatable, e.g. $[2,5]$. Hence, the work reported in this thesis deals with the study of the influence of particle properties on abrasion, a brief description of which will be given here. The properties treated are particle size, shape and hardness, because according to the literature they are the dominant properties influencing abrasion. Moreover, the techniques applied to measure the particle properties themselves are treated (Section 4), as well as the experiments (Section 4) and the model (Section 5) used to study the relations between the properties and abrasion. 


\section{Particle properties}

\subsection{Introduction}

One of the main factors influencing abrasion is associated with the properties of the particles causing the third-body wear. A distinction can be made between mechanical and geometrical properties. Among the mechanical properties, according to the modified Archard wear equation for abrasion (Equation 3.8), the most important property that possibly influences abrasion is the particle hardness $[19,23]$. The geometrical properties that affect abrasive wear are the particle size and shape $[19,23]$. Additional to the particle size effect, the number of particles in the contact also has an influence on abrasion.

\subsection{Particle size}

Although it is generally accepted that particle size influences abrasion [1-6], it still is a subject to debate. It has been shown that the wear rate increases with abrasive medium size up to around $100 \mu \mathrm{m}$ [4] and several phenomena are held responsible for this particle size effect in abrasion. The two most plausible explanations from the literature are treated here, as well as the observation based on the experiments reported in Paper B.

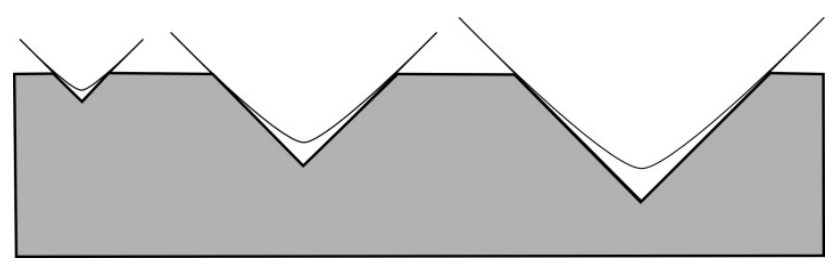

Figure 4.1: Illustration of relative bluntness.

First, the 'relative bluntness' effect as discussed by Gåhlin et al. [6] states that the penetration depth increases with increasing particle size, making smaller particles blunter compared to larger ones. This is illustrated by Figure 4.1, showing the same rounded conical indenter at three indentation depths. For small indentations the bluntness of the rounded tips is relatively important, whereas for large indentations it is not. The relative bluntness effect does not apply to ideally sharp particles. 


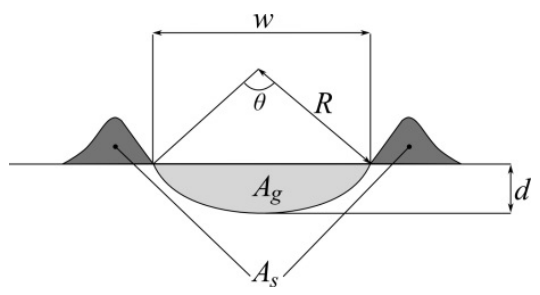

Figure 4.2: Schematic cross section of a typical groove, showing contact radius $R$ and angle $\theta$.

When the relative bluntness is to be incorporated into the method to account for the size effect, it has to be quantified. This can be done by the calculation of the ratio between the cross-sectional area of the groove and the contact area of the particle [6]. For a spherical indentation as shown in Figure 4.2, the area of the groove is equal to:

$$
A_{g}=\frac{R^{2}}{2}(\theta-\sin \theta)
$$

with $R$ the contact radius (m) and the contact angle $\theta$ equal to:

$$
\theta=2 \cos ^{-1}\left(\frac{R-d}{R}\right)
$$

The contact area on the spherical particle can be calculated by using the surface area of a spherical cap:

$$
A_{c}=2 \pi R d
$$

The ratio of $A_{\mathrm{g}}$ over $A_{\mathrm{c}}$ is a measure of the particle shape and by plotting this ratio against the penetration depth $d$, Figure 4.3 is found. This ratio increases with increasing indentation depth, and thus with increasing particle size. As the indentation depth increases, the relative bluntness decreases, rendering the particle to effectively be sharper. The amount of wear is proportional to the groove area, and thus it can be concluded that a decrease in relative bluntness indeed leads to an increase of the amount of abrasive wear. 


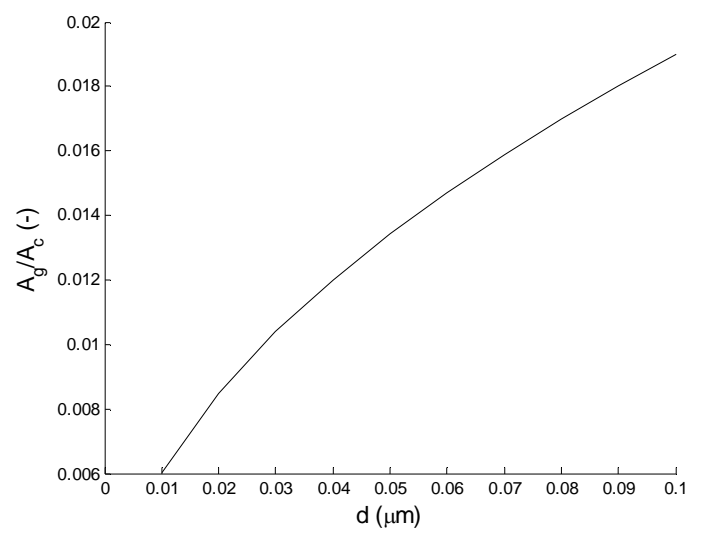

Figure 4.3: Ratio of groove area over contact area $\left(A_{\mathrm{g}} / A_{\mathrm{c}}\right)$, plotted against penetration depth $d$.

The second common explanation for the particle size effect is clogging [6]. When wear debris becomes trapped between the contacting surfaces and sticks to either the surface or the abrasive, this is referred to as clogging. Clogged debris can make the abrasive blunter and the penetration depth lower, thereby decreasing its contribution to the wear rate. Moreover, when the debris is larger than the abrasive particle, it is able to carry part of the load and prevents abrasion from arising. When particle sizes are too large, the debris clogs in the valleys of the abrasive surface. But when particle sizes become smaller, the debris cannot 'shelter' anymore and will stick out. From then, it will carry part of the load and decrease the abrasive wear (rate). This effect of smaller particles allowing the debris to carry part of the load explains the grit size effect.

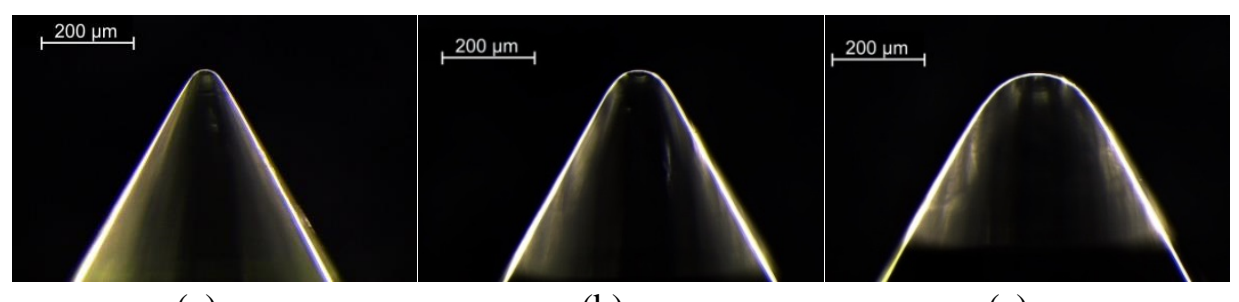

(a)

(b)

(c)

Figure 4.4: Examples of quartz tips used, (a) $R=50 \mu \mathrm{m},(b) R=100 \mu \mathrm{m}$, (c) $R=200 \mu \mathrm{m}$ (Paper B).

The explanations described above may very well give a deeper understanding of the mechanisms behind the particle size effect, but do not give adequate quantitative relations between particle size and abrasion. In a series of single 
asperity scratch experiments reported in Paper B, such a relation is obtained. Quartz is the main component of sand and hence, by using quartz tips the material properties of sand are represented. Different values for the tip radius allow for studying the influence of the asperity size on the cutting part of abrasion. Examples of the quartz tips used for the scratch tests are shown in Figure 4.4. Because cutting is the dominant part in three-body abrasion (over rolling of the particles), it is assumed that such experiments apply to three-body abrasion too.

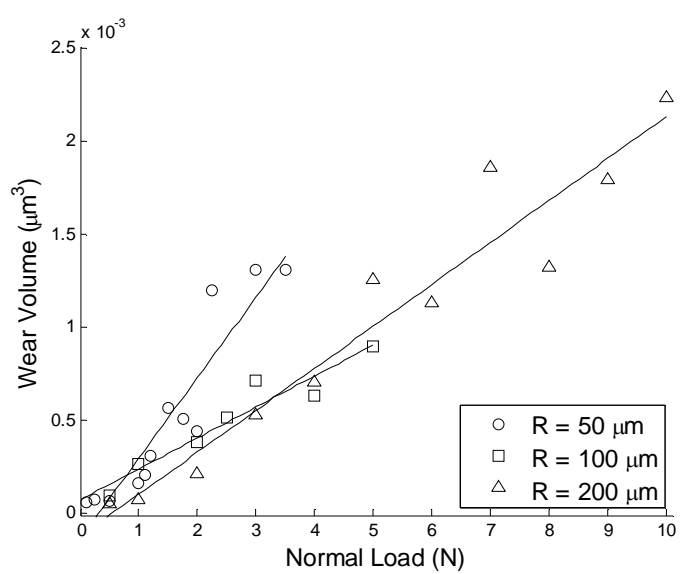

Figure 4.5: Results single asperity scratch tests, representative wear volume versus the normal load.

According to Figure 4.5, the smaller tip results in a higher wear rate than larger tips do. This can be explained by a geometrical analysis. In Figure 4.2 a schematic cross section of a typical wear scar is shown, caused by the scratching movement of a tip with radius $R$. This scratching movement causes a groove with cross-sectional area $A_{\mathrm{g}}$. The material in the groove will partly be pushed into the shoulders, quantified by the cross-sectional area $A_{\mathrm{s}}$ and the rest of the material is removed as wear debris. Referring to Figure 4.2, the groove area $A_{\mathrm{g}}$ can be calculated with Equation 4.1.

In plastically deforming contacts, the contact pressure equals the hardness of the deforming material and thus the size of the contact area can be expressed as the ratio of the applied normal load and the hardness. Hence, the contact area is independent of the tip radius. The resulting wear volume can be plotted against the contact area for the different tip radii as in Figure 4.6. This figure shows that for a constant contact area, and thus a constant load, the volume of the resulting 
groove increases with decreasing tip radius. Therefore, the wear rate increases with decreasing tip radius at a constant load.

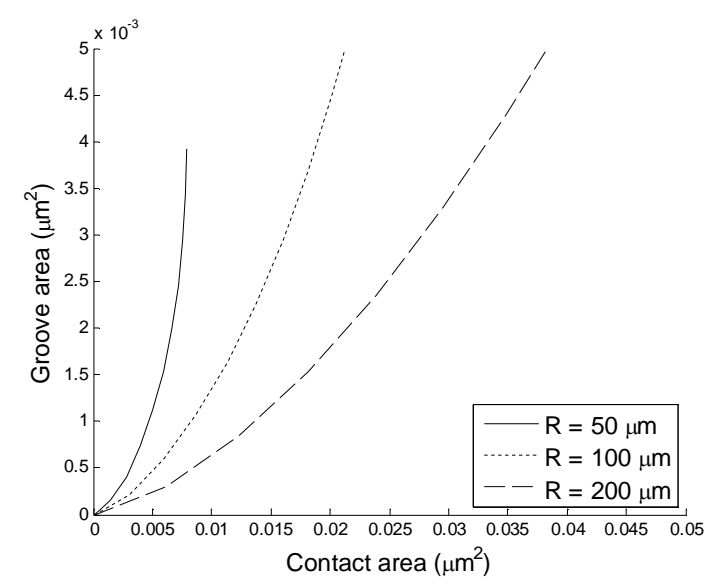

Figure 4.6: Contact area versus groove area, calculated.

This effect for a single tip opposes the size effect reported in the literature, where it is observed that the abrasive wear rate increases with increasing size. A possible explanation is that in the literature the particle size effect is commonly studied using a grid of particles or tips, while in this work the effects of individual tips are studied. When using grids of particles of various sizes and a constant total normal load, the load per tip decreases with decreasing tip size since the number of tips per unit area increases for smaller tips when the height distribution of the bearing area curve of the grid is kept constant. This would result in a decreased amount of wear caused by each single tip. In conclusion, for individual tips the wear rate decreases with increasing tip size.

\section{Dry sand-rubber wheel tests; particle feed rate}

In Paper A, dry sand-rubber wheel tests are performed to study the influence of sand particle properties on abrasion, because these experiments closely resemble the real situation for abrasive wear. Different sand varieties with varying particle properties are used to abrade a steel surface with equipment from TNO Technical Sciences, location de Rondom in Eindhoven, the Netherlands.

The wear rates for the different sand varieties are measured by calculating the slopes of the lines shown in Figure 4.7. The selected particle properties are measured as well and an attempt has been made to relate them to abrasion. It 
turns out that there is another parameter related to the particles that influences abrasion: the particle feed rate. In a dry sand-rubber wheel test the feed rate of sand into the contact is controlled as a constant mass flow of sand, meaning that the number of particles present in the contact zone and which cause abrasive wear depends on the particle size. Moreover, a relation between the particle properties and abrasion can only be derived when the properties are combined into one equation, because the different properties influence each other during a test.

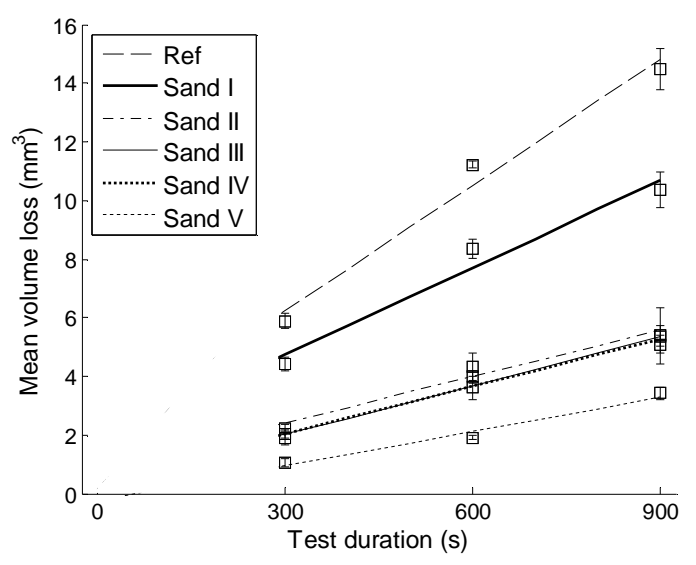

Figure 4.7: Results dry sand- rubber wheel tests; mean volume loss versus test duration for the sand varieties tested.

This equation allows to calculate the actual amount of wear by combining the Archard's law from Equation 3.2 with the empirical equations for the specific wear rate derived in Paper A:

$$
\begin{aligned}
& \frac{k}{k_{\mathrm{ref}}}=\left(\frac{\text { size }_{\mathrm{i}}}{\text { size }_{\mathrm{ref}}}\right)^{\alpha_{1}} \cdot\left(\frac{\text { feedrate }_{\mathrm{i}}}{\text { feedrate }_{\mathrm{ref}}}\right)^{\alpha_{2}} \cdot\left(\frac{\text { sharpness }_{\mathrm{i}}}{\text { sharpnes }_{\mathrm{ref}}}\right)^{\alpha_{3}} \\
& \text { with }\left\{\begin{array}{cl}
\text { size }_{\mathrm{i}}=\text { size }_{\mathrm{i}} & \text { if } \text { size }_{\mathrm{i}}<100 \mu \mathrm{m} \\
\text { size }_{\mathrm{i}}=\text { size }_{\mathrm{ref}} & \text { if } \text { size }_{\mathrm{i}}>100 \mu \mathrm{m}
\end{array}\right.
\end{aligned}
$$


with size $_{\mathrm{i}}(\mu \mathrm{m})$, feedrate $_{\mathrm{i}}(-)$, and sharpness $_{\mathrm{i}}(-)$ the particle property values for the different sand varieties, size $_{\text {ref }}(\mu \mathrm{m})$, feedrate $_{\text {ref }}(-)$, and sharpness $_{\text {ref }}(-)$ the particular values for silversand taken as reference, $k_{\text {ref }}\left(\mathrm{mm}^{3} / \mathrm{N} \cdot \mathrm{m}\right), \alpha_{1}, \alpha_{2}$, and $\alpha_{3}$ (-) the model parameters shown in Table 4-1 and $i$ the index for the different sand varieties.

Table 4-1: Parameter values used to fit Equation 4.4.

\begin{tabular}{|l|c|c|}
\cline { 2 - 3 } \multicolumn{1}{c|}{} & Fit parameter & Value \\
\cline { 2 - 3 } \multicolumn{1}{c|}{} & $k_{\text {ref }}\left(\mathrm{mm}^{3} / \mathrm{Nm}\right)$ & 0.00285 \\
\hline size & $a_{1}(-)$ & 3 \\
\hline feedrate & $a_{2}(-)$ & 1.5 \\
\hline sharpness & $a_{3}(-)$ & 2.5 \\
\hline
\end{tabular}

\subsection{Particle shape}

Besides particle size, the shape of the particle is an important property influencing abrasion. Intuitively, one may suppose that sharper particles cause more wear than blunter particles do. This has also been shown, e.g. by [7, 8], but a definite relation between particle shape and abrasive wear had yet to be derived. Particle shape definitions are usually based on similarities to standard shapes like spheres, hyperboloids, cones and wedges [5, 15, 26]. The relation between these shape factors and abrasion, however, is still not fully described [27]. Though more recent attempts have been made to improve the results, e.g. by deriving techniques like cone fit analysis (CFA) [28] or definitions based on Fourier analysis, fractal dimensions or changes along the particles' outline [15], still more work is needed to obtain adequate relations. An important reason for this is that most existing models are two-dimensional. Hence, only one particle orientation is considered, where other orientations of the same particle may induce different wear behaviour. In third-body abrasion the orientation of the particle can change continuously. Therefore, for a full and appropriate description the three-dimensional geometry has to be known, certainly in three-body abrasion. The shape of a particle can be defined on different levels as illustrated in Figure 4.8; shape itself on the global level (e.g. round, rectangular), sharpness, like irregularities or protrusions, on the local level and roughness on the micro level. This means that a definition of shape 
should either capture all three levels, recognize the dominant one or describe the three levels separately.

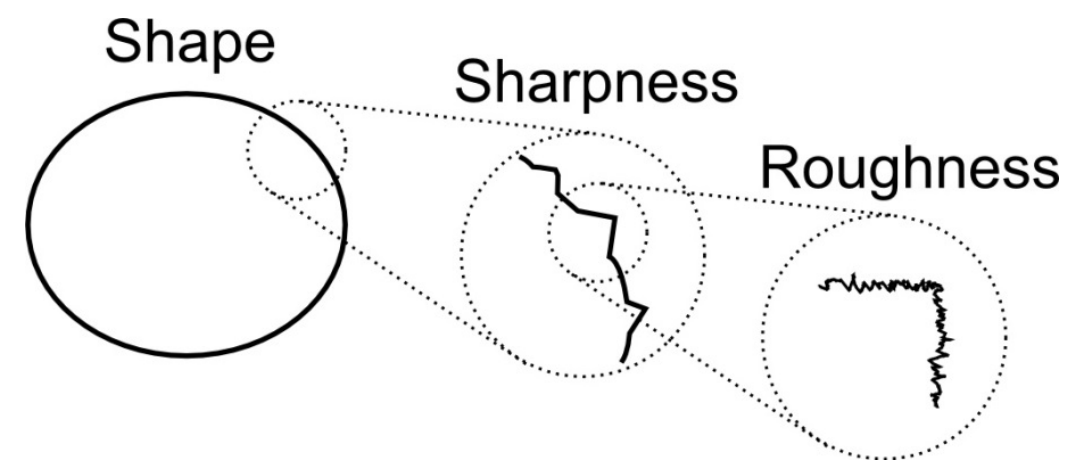

Figure 4.8: Shape levels.

\subsubsection{Discretized particles}

To be able to quantify the shape of a particle, first the particle itself has to be described. For this, the particles are scanned using a confocal microscope. To do so, the device shown schematically in Figure 4.9 is used. This device consists of a shaft supported by ball bearings, fitted with a small wheel and putty rubber at the tip. A sand particle is attached to this putty rubber, making sure the putty overlaps with the particle as little as possible. The wheel is in contact with the xy-stage of the confocal microscope, ensuring that the wheel, and thus the particle rotates when the stage is moved. When a measurement is performed and the wheel rotated repetitively, the particle is measured 360 degrees in circumference. The remaining putty in the measurements can be digitally removed afterwards. Because of the relatively small contact area with the particle this is expected to not influence the results. Moreover, there has to be sufficient overlap in between two consecutive measurements to make sure a proper discretization can be drawn up. This is because an iterative closest point algorithm is used to 'stitch' the separate measurements together (see Section 4.3.2) and this algorithm requires some overlap to work properly. After stitching, the particle is discretized using a Delaunay triangulation, combining the surface points into triangles and appointing these triangles an outward normal direction. With this triangulation no points in the particle set are present in the circles circumscribing the appointed triangles, making sure all points are taken into account. 


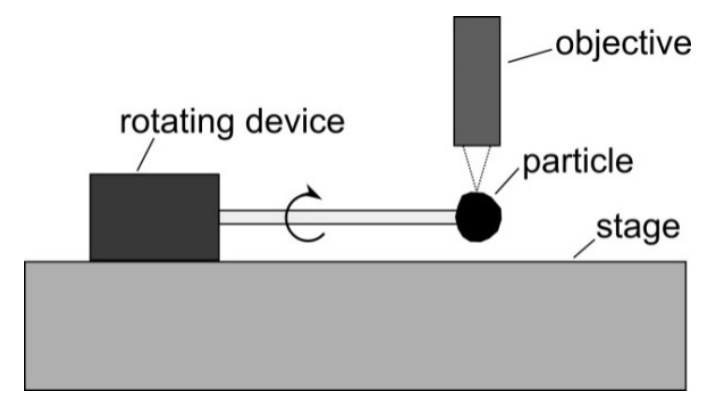

Figure 4.9: Schematic overview of the setup used for scanning particles.

\subsubsection{Iterative Closest Point Algorithm}

It is not possible to obtain a complete particle description with one measurement using a confocal microscope. Hence, separate measurements are performed all around the particle and combined afterwards to acquire a 3D surface. The point clouds obtained from the separate confocal measurements are stitched using an iterative closest point algorithm [29]. This algorithm is based on an overlap between two consecutive measurements, iteratively minimizing the distance between the corresponding points on the two point clouds, as illustrated by Figure 4.10. It appoints one fixed point set and one moving set, drawing up a transformation matrix to align the moving point with the fixed one. To do so, the closest points from the moving set towards the fixed set are calculated and transformed iteratively to minimize the distance between the corresponding points. For this procedure to succeed, the two surfaces to be combined have to be close to one another; otherwise the solution will not converge. And when several point sets have to be combined, first two sets are stitched, and from then the combined set achieved is chosen to be the static point set for the next step to be combined with a new set of 'moving' points. 


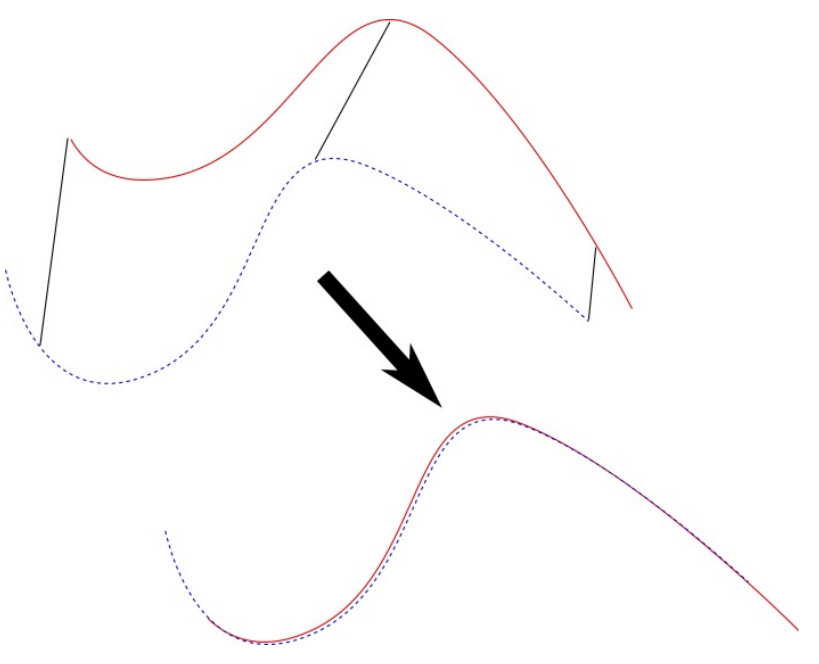

Figure 4.10: Schematic illustration of the iterative closest point algorithm.

In Paper C, several parameters are derived to describe particle shape on the global and local level. The micro level is not considered in this research because on this scale, shape can be adequately calculated using existing roughness parameters like $R_{\mathrm{a}}$ and $R_{\mathrm{q}}$. A brief description of the remaining parameters will be given here.

\subsubsection{Particle shape definitions}

These definitions are based on work reported in Paper C. The backgrounds and mathematical basis of the definitions can be found there.

\section{Global regularity $\left(r_{\mathrm{g}}\right)$}

The variation in the distance between the centroid of the particle and the surface is a measure for the shape of the particle. For a spherical particle, this variation will be equal to zero and the particle is thus perfectly regular. As the shape deviates from a sphere, the variations will increase and the particle will no longer be regular. The global regularity parameter is defined as the absolute average deviation of the distance between the centroid of the particle and its outline. 


\section{Local sharpness $\left(s_{1}\right)$}

Another particle shape characteristic is the outward normal direction of the triangles along the surface. By calculating the angles between these normal directions for surrounding triangles, information is gathered on a more local scale. The larger the angle, the more irregular the particle is.

\section{Threshold}

Because the methods proposed in this work are based on the discretization of the particles, there will always be some deviation from the actual particle shape. To prevent this discretization effect from largely affecting the various shape parameters, a threshold is proposed to make sure the small deviations due to the discretization are discarded. For simplicity, this is explained for the 2D case. For regularity, the difference between the distance from centroid to actual circular segment and from centroid to the discretized line segment is considered. In the case of sharpness the threshold is defined by the change in the direction of the outward normal between two consecutive points on a circle.

\section{Verification}

The shape parameters derived above are verified by checking them against several shapes. Both shape levels are validated; the global level by calculating the shape parameters for the range of platonic solids and the local level by applying a local sharpness to a spherical particle.

\section{Platonic solids}

As an example, the range of Platonic solids is used to evaluate the derived shape factors. These are all regular convex polyhedrons and range from a tetrahedron, cube (hexahedron), octahedron and dodecahedron to an icosahedron. In this order, the shapes get more regular and this should be confirmed by the shape parameters. A sphere is also included in the analysis, with varying grades of discretization, to confirm that the calculated sharpness indeed does approach the expected zero value. Referring to Figure 4.11 this is indeed true, as the shape and sharpness parameter values decrease with increasing regularity. 


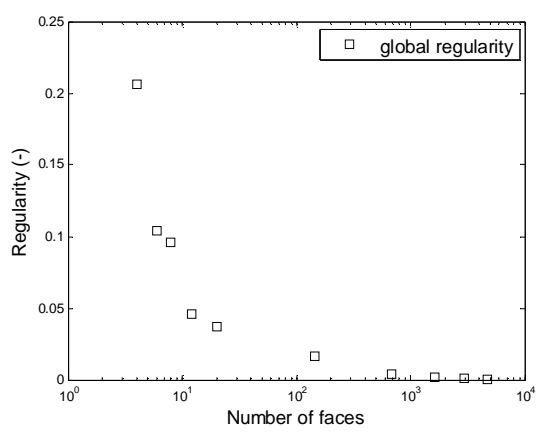

(a)

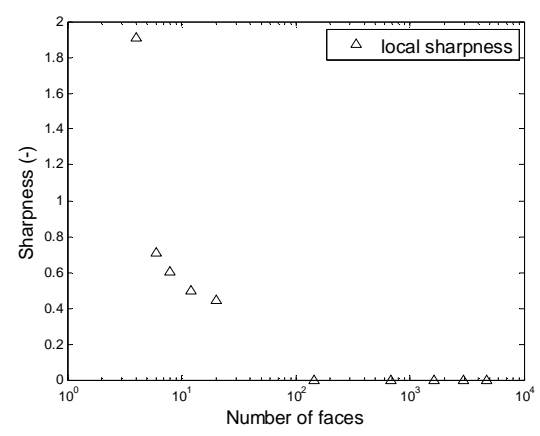

(b)

Figure 4.11: Regularity (a) and sharpness (b) parameter values against the number of faces on the solids tested.

\section{Shape variations}

Although platonic solids form a reasonable way of verification, the particle shape parameters should be able to recognize more subtle variations as well, e.g. a sphere evolving into an ellipsoid. To test whether such changes are observed properly, the shape parameters are calculated for ellipsoids with different major semi-axis length and constant minor semi-axis length. The results are shown in Figure 4.12, plotting the parameter value against the eccentricity of the ellipsoid and indicating that the global regularity recognizes the changes, while the local regularity and sharpness parameters, as expected, do not. This implies that a combination of the global regularity and the local sharpness is a good way of describing global particle shape. 


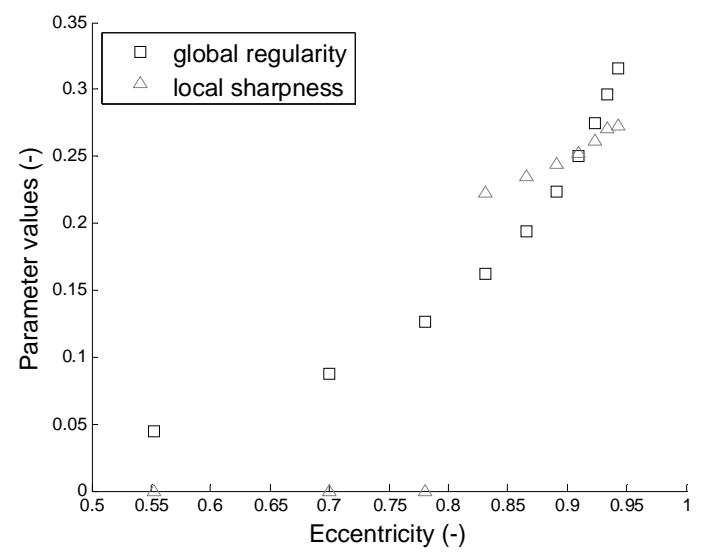

Figure 4.12: Effect of changing the aspect ratio of an ellipsoid on the values of the three shape parameters.

\section{Local sharpness}

To analyse the defined parameters on the local level, a small protrusion is added to a spherical particle, varying in both height and width. It turns out that the local sharpness parameter is well suited for identifying this protrusion. In Figure 4.13 some results are shown, indicating that the local sharpness parameter responds to changes in the bump height, whereas the regularity parameter is relatively insensitive to this. Similar trends are seen for the other configurations. Lower values of the bump height induce more of a change in the global shape rather than a local sharpness, which is therefore not recognized by the local sharpness parameter. Only when the bump is high and sharp enough will the sharpness parameter value be unequal to zero. The small changes in geometry at small bump heights are, however, quantified by the regularity parameters, since they do show a slight increase with increasing bump height. 


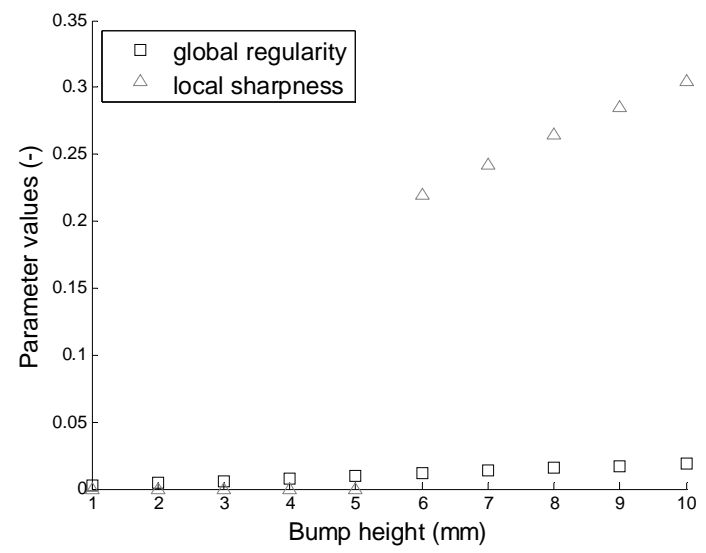

Figure 4.13: Effect of bump height on the calculated global and local shape parameters.

\subsection{Particle hardness}

It has been shown that there is a difference required between the hardness values of the particles and the surface for significant abrasion to arise [30, 31]. The relation between this hardness difference and the wear rates is asymptotic; first the wear rate increases with an increasing difference in hardness until the wear rate reaches a limit. According to [24], for hardness differences higher than around 1.2 the abrasive wear rate remains constant despite a further increase in the hardness difference. Sand mainly consists of silicon dioxide $\left(\mathrm{SiO}_{2}\right)$ and hence will approximately have a constant hardness value in the order of $10 \mathrm{GPa}$. This hardness value is generally much larger than the unhardened steel surfaces being worn, e.g. construction steel. The hardness difference will typically range between a value of 2 and 3 . Hence, the possible variation in the hardness of sand particles is considered not to influence the resulting wear rates. 


\section{Modelling abrasive wear}

\subsection{Introduction}

The experimental work reported in Chapters 3 and 4 covers some of the aspects on quantifying wear by abrasive particles. It helps in the basic understanding of the mechanisms of third-body abrasion, but before they can be applied to real applications more steps need to be taken. For one, the influence of the shape of the particle has to be verified. This is done with the help of a finite element model in Abaqus. With this model, first the scratching movement of a tip with predefined radius is simulated. The simulated results are compared with the experimental results from Paper B, in order to verify the model. The model is applied using different sizes and shapes for the tip.

\subsection{Numerical model}

The model is developed with Abaqus/Explicit, because of the plastic deformations and element removal involved. It consists of two geometries: a rigid tip with predefined radius and a flat deformable surface. The tip is fixed and the surface slid under the tip such that a groove is formed.

\subsubsection{The tip}

The abrasive medium initially is modelled based on the tip used in the single asperity scratch tests described in Paper B. An example of one of the first tips used is shown in Figure 5.1. To minimize the number of elements and thereby the computational time, the base of the tip is not modelled entirely. This can be done without introducing errors, as the base is only used for clamping and does not influence the scratching. 


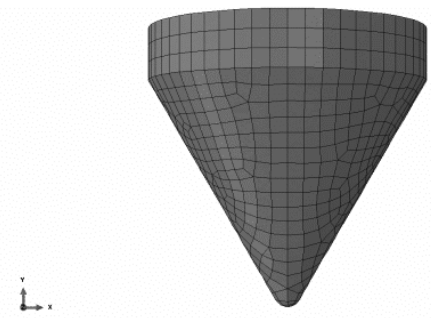

Figure 5.1: Representation of the tip used in the numerical simulations.

The tip material is quartz and because the tip is much harder than the steel surface and practically does not wear during the scratching movement, it is considered rigid to increase the calculating speed. In Abaqus, rigid bodies require a reference point to be assigned. The possible boundary conditions, loads and displacements and material properties of the rigid body are applied to this reference point. The location for the reference point on the tip is at the tip apex. To decrease to computational time while maintaining the spherical geometry of the tip, the mesh is kept as coarse as possible. The total number of elements is 1200 , the element size around the apex is approximately $5 \mu \mathrm{m}$. A rigid body does not have material properties, but in Abaqus/Explicit rigid bodies do need to have some kind of mass. The average mass of the tips used in the single asperity scratch tests is $0.018 \mathrm{~g}$ and this value is used in the numerical model too. The tip is fully constrained to prevent it from moving during the simulation.

Table 5-1: Mechanical properties of the material tested.

\begin{tabular}{|l|c|}
\hline \multicolumn{1}{|c|}{ Material } & Steel (DIN St-52) \\
\hline Hardness $(\mathrm{GPa})$ & 2 \\
\hline Young's Modulus $(\mathrm{GPa})$ & 210 \\
\hline Density $\left(\mathrm{kg} / \mathrm{mm}^{3}\right)$ & 7800 \\
\hline Poisson's ratio $(-)$ & 0.30 \\
\hline
\end{tabular}

\subsubsection{The specimen}

For the surface to be abraded, an adaptation is used of the St.52 steel specimens from the single asperity scratch tests described in Paper B. The specimen used in Abaqus is shown in Figure 5.2, the important material properties are listed in Table 5-1. It is not a representation of the complete specimen like used in the experiments, but only the region that is supposed to be influenced by the scratching of the tip. By applying boundary conditions to the sides and bottom, 
the rest of the specimen is still simulated, but elements do not need to be appointed. This is done to decrease the total number of elements and thus the computational time.

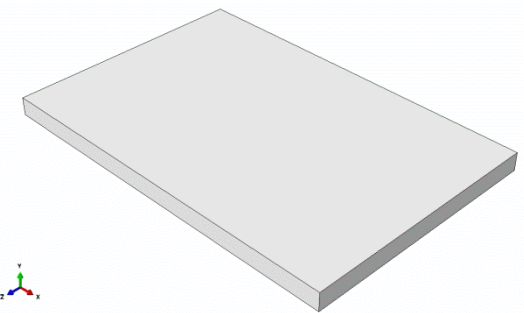

(a)

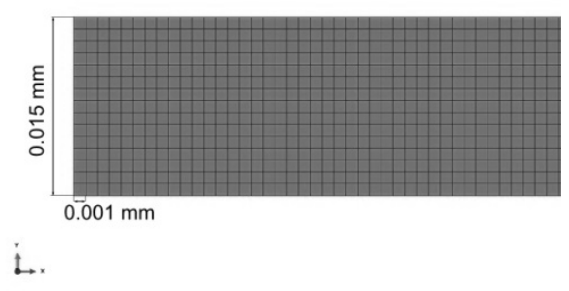

(b)

Figure 5.2: Representation of the specimen used in the numerical simulations (a) with a cross section to show the element size in (b).

The material model for the specimen is not straightforward, because it is required to include wear in the form of plasticity and element removal. The plastic material behaviour is modelled by extending the linearly elastic part of the stress-strain curve with a plastic part beyond the yield point. In Abaqus this is done by defining a table with values of the yield stress depending on the plastic strain. Because the material is strain-rate dependent, this is included as well by defining such tables for different values of the strain rate. Hence, the curves shown in Figure 5.3 are found. These curves are adapted from [32], where similar steel materials as those from the single asperity scratching tests are used. Not all curves are shown for clarity, but the figure gives a good indication of the plastic flow behaviour.

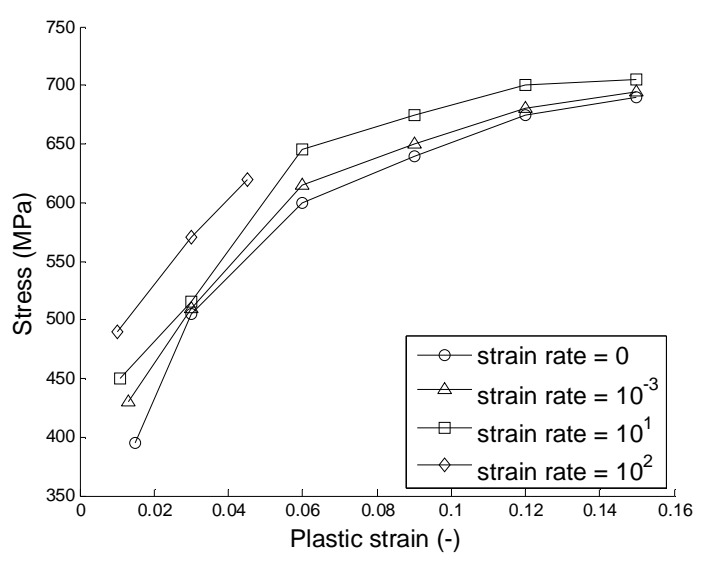

Figure 5.3: Plastic material behaviour. 
Damage under compressive stress conditions is defined with the Johnson-Cook failure model [33]. This model calculates the fracture strain based on the pressure, strain rate and temperature. Damage is defined as:

$$
D=\sum \frac{\Delta \varepsilon}{\varepsilon^{f}}
$$

with $D$ the damage parameter (-), $\Delta \varepsilon$ the increment of equivalent plastic strain during an integration cycle (-) and $\varepsilon^{f}$ the equivalent fracture strain (-) after [33]. Fracture will occur when the damage parameter $D$ is equal to 1 . The fracture strain at room temperature is defined as:

$$
\varepsilon^{f}=\left[J_{1}+J_{2} \cdot e^{J_{3} \cdot \sigma^{*}}\right]\left[1+J_{4} \cdot \ln \dot{\varepsilon}^{*}\right]
$$

with constant values for the pressure-stress ratio $\sigma^{*}(-)$, the dimensionless strain rate $\dot{\varepsilon}^{*}$ and $\sigma^{*}<=1.5$. These parameters are defined as:

$$
\begin{gathered}
\sigma^{*}=\frac{\sigma_{\mathrm{m}}}{\bar{\sigma}} \\
\dot{\varepsilon}^{*}=\frac{\dot{\varepsilon}}{\dot{\varepsilon}_{0}} \text {, with } \dot{\varepsilon}_{0}=1 \mathrm{~s}^{-1}
\end{gathered}
$$

with $\sigma_{\mathrm{m}}$ the average normal stress $\left(\mathrm{N} / \mathrm{m}^{2}\right)$ and $\bar{\sigma}$ the equivalent von Mises stress $\left(\mathrm{N} / \mathrm{m}^{2}\right)$ and $\dot{\varepsilon}$ the actual strain rate (-). The material parameters $J_{1}-J_{4}(-)$ are obtained empirically: the values for steel are listed in Table 5-2.

Table 5-2: Parameter values for the Johnson-Cook model.

\begin{tabular}{|c|c|}
\hline Parameter \# & Parameter value, steel \\
\hline$J_{1}$ & 0.05 \\
\hline$J_{2}$ & 3.44 \\
\hline$J_{3}$ & -2.12 \\
\hline$J_{4}$ & 0.002 \\
\hline
\end{tabular}

Elements are removed when the strain in an element exceeds the fracture strain defined in Equation 5.2, leading to volume loss and thus to wear of the scratched material. 
Damage may also be caused by shear stresses acting in the deforming material. Local shear bands can form due to large material deformations. These are zones of large shear strains causing damage to the material and ultimately leading to failure. In Abaqus, the onset of damage caused by this shear mechanism can be implemented with a shear criterion. With this criterion, the equivalent plastic strain at the initiation of damage can be calculated as a function of the shear stress ratio and the strain rate [34]. Damage will take place when the incremental increase in the equivalent plastic strain exceeds this limit. Consequently, the element over which this criterion is met will be removed.

\subsubsection{Simulations}

Because the simulations are run with Abaqus/Explicit, there is a limit on the time step to prevent the simulation from becoming unstable. The geometrical features of the model are typically quite detailed; the radius of the tip and the indentation depth are in the order of microns. In order to appropriately describe these features, the element size needs to be small too or even smaller. This means that the element is typically small.

The critical time increment $\Delta t_{\text {cr }}$ above which the simulation becomes unstable is related to the element size according to:

$$
\Delta t_{\mathrm{cr}}=\frac{l}{c}
$$

with $l$ the smallest element size $(\mathrm{m})$ and $c$ the wave speed along an element $(\mathrm{m} / \mathrm{s})$ :

$$
\mathrm{c}=\sqrt{\frac{E}{\rho}}
$$

with $E$ Young's modulus (MPa) and $\rho$ the material density $\left(\mathrm{kg} / \mathrm{m}^{3}\right)$. According to Equation 5.4, small values for the element length induce small time steps. In combination with the typically low sliding speeds in the order of $1 \mathrm{~mm} / \mathrm{s}$ this means that the calculation times become very long, in the order of weeks even when using multiple processors. Hence, an attempt is made to decrease the calculation time by appropriate measures. 
First, the simulated calculating time can be decreased by increasing the sliding speed. When the material is not strain rate dependent or when the strain rate dependency is changed in order to account for material behaviour at lower speeds, this can be done. Because in this situation the material is strain rate dependent, see Figure 5.3, the strain rate dependency is artificially changed in order to account for increasing the sliding speed from $1 \mathrm{~mm} / \mathrm{s}$ to $9000 \mathrm{~mm} / \mathrm{s}$. Doing this did not significantly change the results and hence, the technique of artificially increasing the sliding speed is applied.

Second, mass scaling can be performed to increase the critical time step. Though it may seem counterintuitive, it turns out that it is possible to change the wave speed to increase the time step [35]. This is done by artificially increasing the material density. As long as the kinetic energy in the material remains small compared to the internal energy, this is appropriate. The density was increased from $7800 \mathrm{~kg} / \mathrm{m}^{3}$ to $78000 \mathrm{~kg} / \mathrm{m}^{3}$ and according to Figure 5.4 , where the ratio of the internal energy and the kinetic energy is plotted against the simulation time, the internal energy is around 20 times larger than the kinetic energy. Hence, the proposed increase of the density does not influence the results. In conclusion, by artificially changing the strain rate sensitivity and the material density, the time step can be increased and thus the computational time decreased from around one day to around three hours.

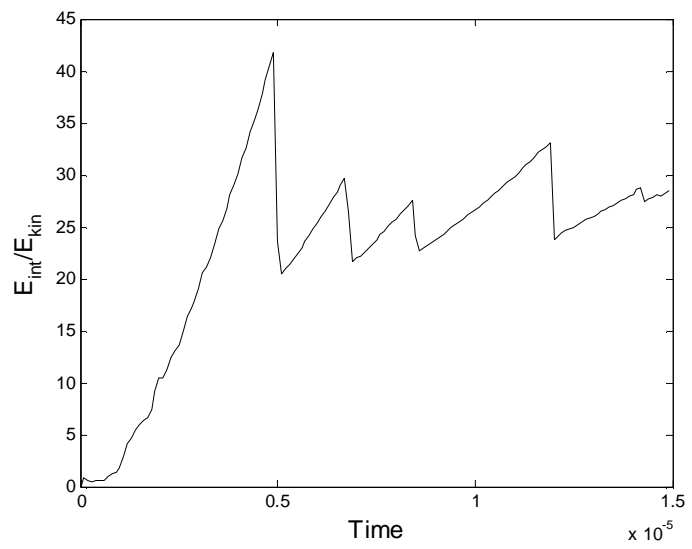

Figure 5.4: Energy ratio.

The scratching movement is simulated similarly to the single asperity scratch tests described in Section 4.2: the tip is fixed and the specimen is translated through under the tip, the tip and the specimen overlapping a little to make sure 
the tip scratches the specimen. There are some differences though, because in Abaqus/Explicit the simulations work best when it is displacement controlled rather than load controlled. This is because in load controlled simulations the stiffness matrix becomes singular when bodies disconnect [36], and this is not possible with displacement controlled simulations.

\subsection{Single asperity wear types}

The result of a single asperity scratch test is a groove formed on the specimen by the sliding movement of the tip across the surface, an example of which is shown in Figure 5.5.

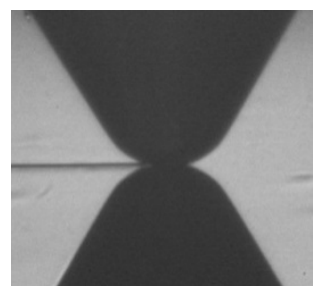

(a)

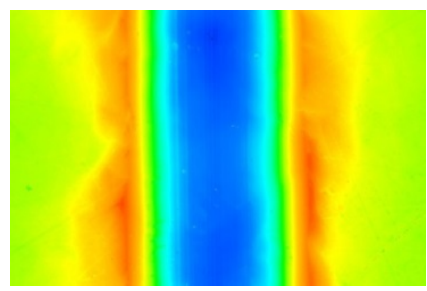

(b)

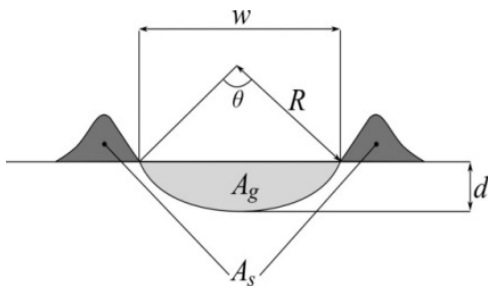

(c)

Figure 5.5: Example of a groove resulting from a single asperity scratch test, (a) during the experiment, (b) result of a confocal microscope height profile measurement (blue is low, red is high) (c) Schematic illustration of the cross section of a wear scar.

It has been shown [37] that there are three primary wear types related to abrasion that may occur in the contact between a scratching tip and a scratched surface: ploughing, wedging and cutting. The predominant wear type depends on conditions such as the applied load or the indentation depth. They are quantified by the degree of penetration, and the friction or the shear strength of the contacting interface between the two materials.

When a groove is formed while no material removal takes place, as shown in Figure 5.6, this is called ploughing. Ploughing causes the material to be pushed downwards and into the shoulders and it takes place at low loads and thus at low values for the degree of penetration. 


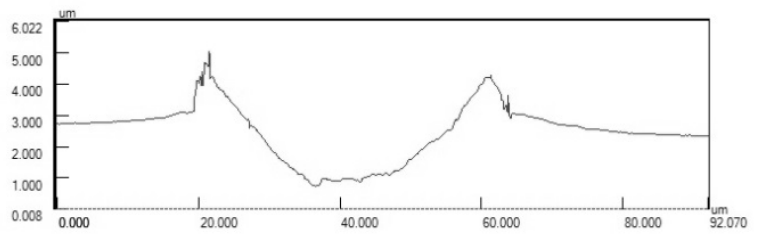

Figure 5.6: Example of an experimental groove, $R=100 \mu \mathrm{m}, d=0.002 \mu \mathrm{m}$.

In some cases, (almost) all material from the groove is removed completely in the form of a chip, and no or hardly any shoulders develop along the sides of the groove. This wear type is cutting: it is typically only observed at extreme conditions, such as high loads and very sharp particles.

The non-steady state behaviour that involves a groove to be formed and the displaced material from the groove to be collected in a 'bow' in front of the moving tip is referred to as wedging. As the groove evolves, the bow will grow and ultimately break off (i.e. wear will occur) after which the process of bow initiation and growth starts again.

The degree of wear parameter is generally used to analyse a scratch. The degree of wear is the fraction of the material from the groove that is actually removed from the surface.

Referring to the idealized schematic cross section of a wear scar shown in Figure 5.5 (c), the degree of wear $\delta$ is defined as:

$$
\delta=\frac{A_{g}-A_{s}}{A_{g}}
$$

with $A_{g}$ the groove area and $A_{s}$ the shoulder area. A value of $\delta$ close to 0 means ploughing, whereas a value of $\delta$ close to 1 is indicative of cutting and severe wear. It has been shown that the wear is a function of the degree of penetration $D_{p}$ of the scratching tip into the scratched material [38], which is defined as:

$$
D_{p}=\frac{2 d}{w}
$$

In Figure 5.7, an adaption of one of the curves presented by [38] is shown, indicating that the degree of wear increases with increasing degree of penetration following an S-shaped curve. The ploughing, wedging and cutting wear types are separated by the dotted lines. 


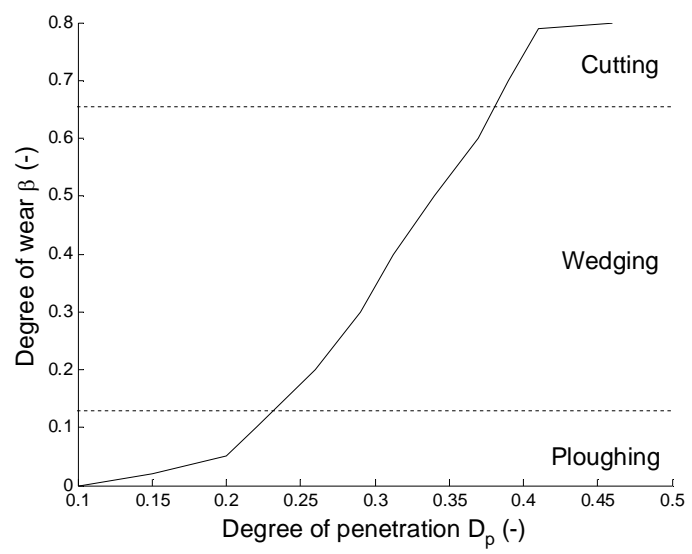

Figure 5.7: Degree of wear versus degree of penetration adapted from Hokkirigawa and Li [18].

The numerical model is employed to reproduce Hokkirigawa's experimental curve of Figure 5.7. The model is verified with the single asperity scratch tests described in Paper B. Note that the experimental results mostly showed the ploughing wear type, cutting was only observed at extreme loads and preceded failure of the quartz tips. The numerical model, however, should be capable of simulating all three wear types.

\subsubsection{Model verification}

In this section the numerical results of simulating the three wear types are treated.

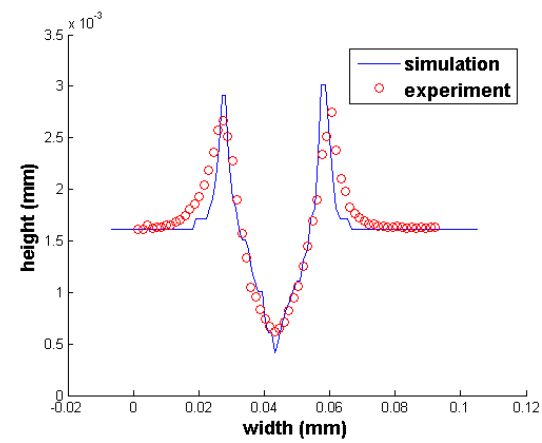

(a)

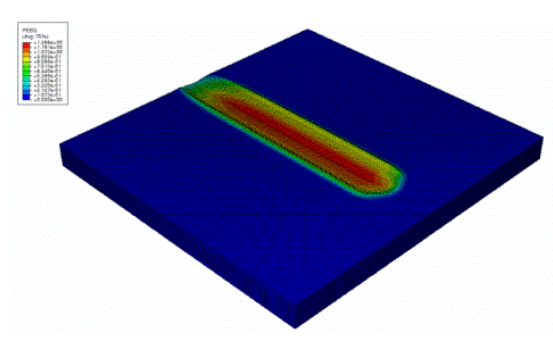

(b)

Figure 5.8: Ploughing results, $R=50 \mu \mathrm{m}, \mathrm{d}=\mathbf{0 . 0 0 1} \mathrm{mm}$, (a) cross section and comparison with experiment and (b) overview of the simulated groove. 
Numerical results for the ploughing action are shown in Figures 5.8. The resemblances between the cross section of an experimental and a numerical groove in Figure 5.8 (a) in particular indicate that the ploughing action can be simulated adequately.

Wedge formation requires material removal to take place, as is shown in Figure 5.9. The non-steady state repetitive behaviour of initiation and bow growth typical for wedging is visible in Figure 5.9 too. The wedging action thus can be simulated to a reasonable extent: for the correct morphology of the scratch to be reproduced, the material behaviour at plasticity and the nature of the damage needs to be studied more extensively.

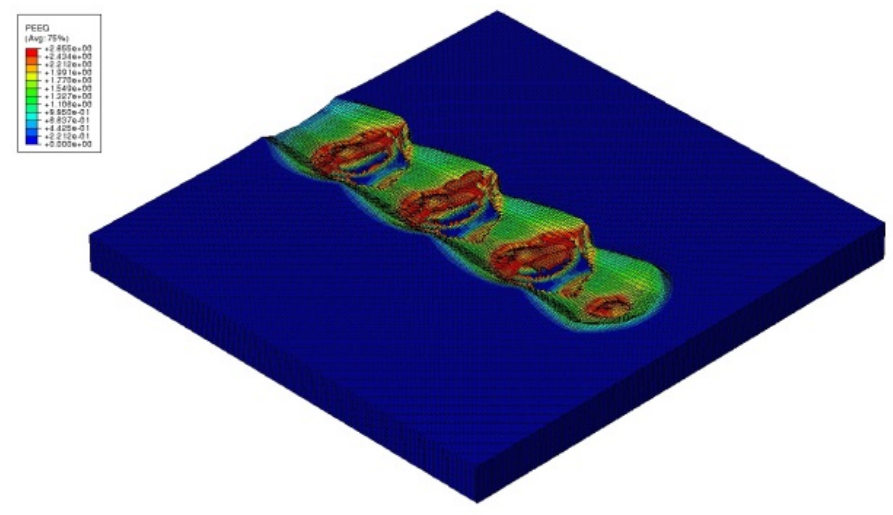

Figure 5.9: Overview of a wedging groove, $R=50 \mu \mathrm{m}, \mathrm{h}=0.002 \mathrm{~mm}$.

For values of the degree of wear parameter larger than around 0.7 , cutting takes place. Challen and Oxley [39] showed that reducing the interfacial shear strength between the indenter and the surface will result in an earlier onset of cutting. In the simulations, a transition from the wedging to the cutting regime is obtained by reducing the modelled coefficient of friction in the model from 0.1 to 0.01 . The results are shown in Figure 5.10, indicating that after a start-up phase a cutting groove without shoulder is formed. Hence, the cutting wear type can be simulated too and the applied technique for element removal used to model the abrasive wear mechanism. 


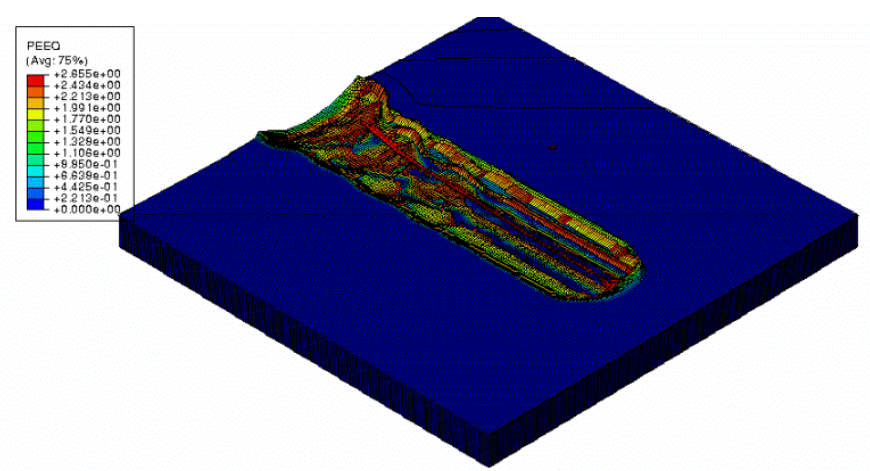

Figure 5.10: Example of a groove created by cutting.

\subsection{Application of the model to conical tips}

\subsubsection{Shape variations}

The next step is to apply the model to various tip shapes and verify the abrasive wear can also be predicted based on the shape of the abrasive medium. The tip shapes used in the simulations are shown in Figure 5.11 with $\theta$ the half-cone angle. In the simulations the indentation depth is equal to $5 \mu \mathrm{m}$ and the coefficient of friction is 0.01 to assure cutting takes place. The conical tips have a small radius at the tip of $2 \mu \mathrm{m}$ to prevent singularities in the simulations. By combining the simulation results with the global roundness parameter derived in Paper $\mathrm{C}$, the relation between the shape of the abrasive and the wear can be studied. 


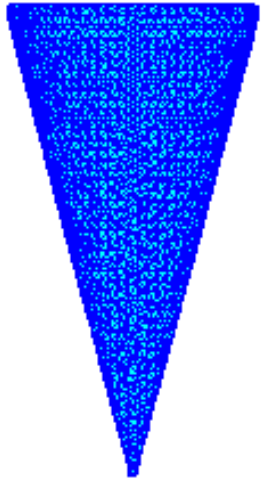

(a)

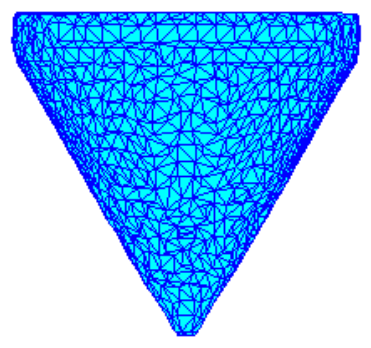

(b)

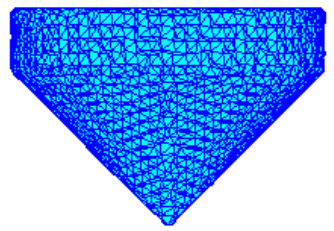

(c)

Figure 5.11: Representation of the conical tips used in the numerical simulations, (a) $\theta=$ $15^{\circ}$, (b) $\theta=30^{\circ}$, (c) $\theta=45^{\circ}$.

The simulation results are shown in Figure 5.12. It appears that the tip with larger cone angle from Figure 5.12 (c) has lower shoulders and causes more wear. The roundness and degree of wear values listed in Table 5-3 confirm this; the tips with lower roundness values (a sphere has roundness value 0 ) generate less wear.

Table 5-3: Shape values and degree of wear values for the different conical tips.

\begin{tabular}{|c|c|c|}
\hline Half cone angle $\left(^{\circ}\right)$ & Global roundness $(-)$ & degree of wear $(-)$ \\
\hline 15 & 0.2393 & 0.28 \\
\hline 30 & 0.1431 & 0.09 \\
\hline 45 & 0.1499 & 0.1 \\
\hline
\end{tabular}



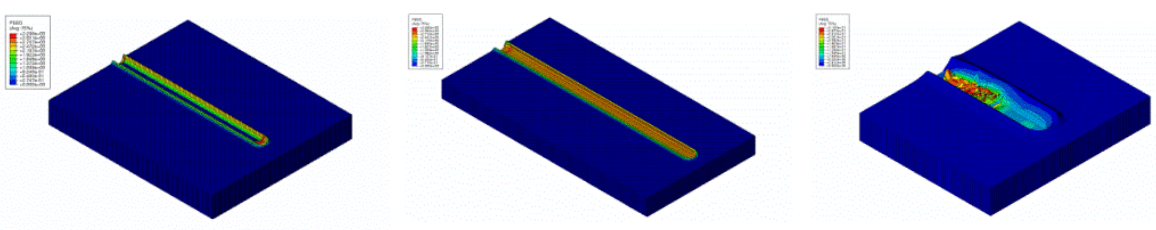

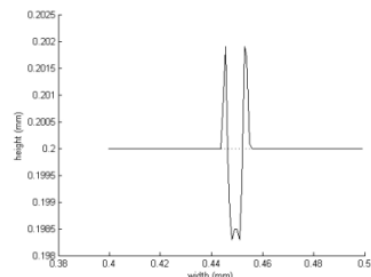

(a)

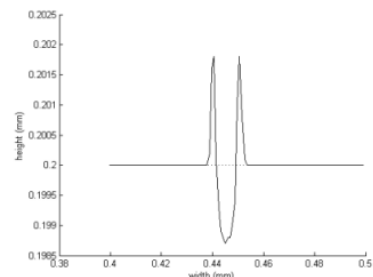

(b)

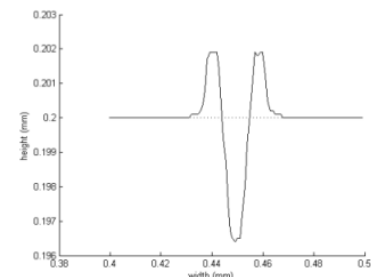

(c)

Figure 5.12: Resulting grooves for the three conical tips, (a) $\theta=15^{\circ}$, (b) $\theta=30^{\circ}$, (c) $\theta=45^{\circ}$.

It is thought that the roundness value of the tip with cone semi-angle of $45^{\circ}$ is higher than the roundness value of the tip with cone angle of $30^{\circ}$ because the higher cone angle causes a larger transition between the faces. This causes the degree of wear value of the $45^{\circ}$ tip to be slightly higher than the degree of wear value of the $30^{\circ}$ tip. Figure 5.13 shows the degree of wear as a function of the calculated roundness of the tips.

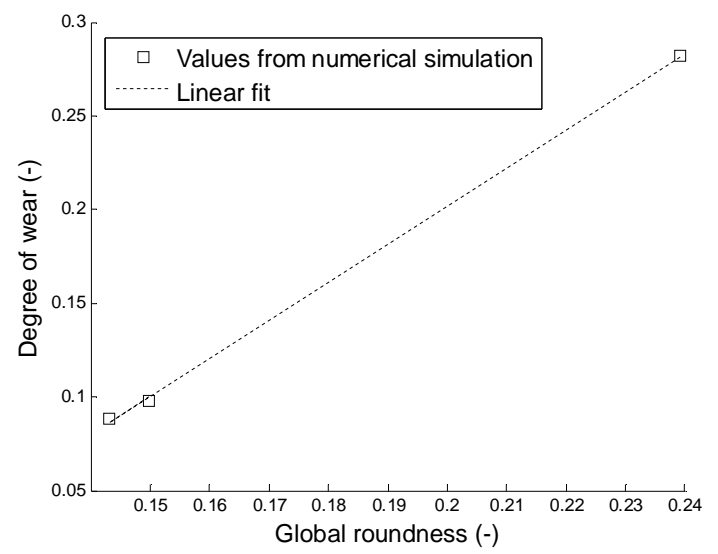

Figure 5.13: Simulation results for different tip shapes, degree of wear plotted against the global roundness values. 


\subsubsection{Degree of wear}

When the degree of wear is calculated based on the numerical results and plotted against the accompanying indentation depths, Figure 5.14 is obtained. The results should resemble the S-shaped curve from Hokkirigawa and Li [38]. According to Figure 5.14, the initial results indeed indicate the S-shaped curve can be approximated and regions for the wear types ploughing, wedging and cutting distinguished.

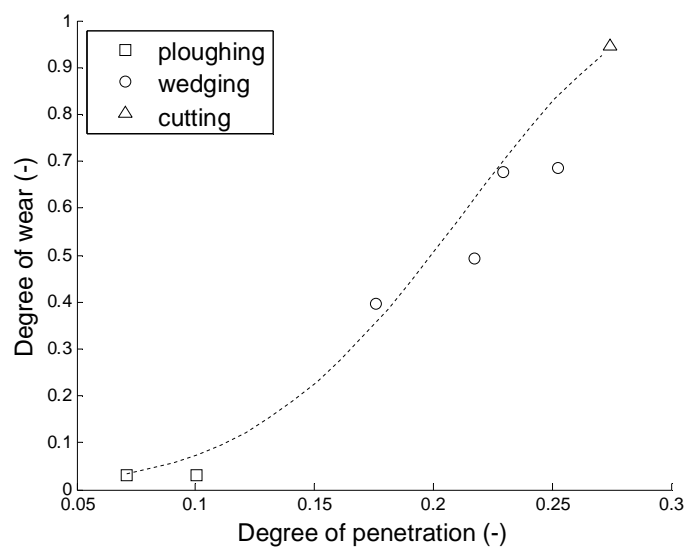

Figure 5.14: Simulation results, degree of wear plotted against the indentation depth. 


\section{Practical application of the wear model}

\subsection{Introduction}

To optimize the maintenance of machines, often a strategy can be based on historical data or on basic understanding of the failure modes of the critical components. When the usage of the machine can be predicted before it enters service this is fairly straightforward; maintenance intervals can be determined beforehand and parts can be repaired or replaced before they fail. On the other hand, when it is uncertain how a machine is going to be used, it is more difficult to determine the appropriate maintenance strategy. In such situations, more advanced techniques have to be applied. These are often based on the actual usage of the machine and the expected remaining lifetime.

This section will focus on the application of the developed wear model in practice. First, maintenance will be discussed in more general terms. Then, the application of the wear models to the maintenance strategies is treated by defining a case study. Also, the main usage and environmental conditions relevant for the wear process are discussed.

\subsection{Maintenance}

To make sure machines can run as long as possible at minimal costs, maintenance has to be performed. It is often more efficient to repair or replace damaged components before the entire machine fails. Maintenance can be defined as the combination of all technical, administrative and managerial actions during the life cycle of an item that serve the purpose to retain it in, or restore it to, a state in which it can perform the required function [40]. This means the required function has to be defined as well as the amount of degradation before the function is no longer fulfilled properly. In practice, performing maintenance means that e.g. machines need to be cleaned regularly, lubricating oils refreshed and damaged parts repaired or replaced. By doing this, the amount of wear will be minimized, extending the lifetime and ensuring the performance of the machine. Two basic types of maintenance can be defined; 
preventive and corrective maintenance, as will be shortly described below. Also, the concept of reliability centred maintenance (RCM) is introduced shortly as a method to select the appropriate maintenance strategy.

\subsubsection{Corrective maintenance}

When maintenance is performed after failure of the component, this is termed corrective or breakdown maintenance. This type of maintenance is generally performed when damage to a machine component is not harmful to the entire machine and a certain amount of downtime is preferred above implementing one of the other (more expensive) maintenance strategies.

\subsubsection{Preventive maintenance}

When machines are supposed to keep working without unexpected stops and when damaged components are repaired or replaced before they actually fail, it is called preventive maintenance. This requires some kind of knowledge on the condition of the component and its evolution in time. When the damage evolution can be predicted beforehand, preventive maintenance is generally performed on a (time) scheduled basis. When this is not possible, i.e. the amount of wear cannot be estimated, so-called condition-based maintenance can in some cases be performed.

\section{Condition-Based Maintenance (CBM)}

When the condition of machine components is tracked continuously, it is possible to perform maintenance just before the components fail. Although this is an efficient way of maintaining a machine, technically it can prove quite difficult to implement. For instance, it is difficult to establish the relations between the condition of the machine and its system data like the loads, velocities, temperatures or even vibrations. On the other hand, when the external operating conditions are not known beforehand, as is the case for the applications discussed in this thesis, there practically is no other solution to maintenance other than waiting for failures to occur, i.e. fall back to corrective maintenance. The main goal of this thesis is to define relations between the conditions and usage of a machine and the abrasive wear that ultimately causes the machine to fail. The important conditions and usage parameters will be monitored and used as input for the model to calculate the (abrasive) wear rate on the critical components of a machine. 


\subsubsection{Reliability centred maintenance}

The failure behaviour of the machine under consideration has a great influence on the maintenance strategy to be performed. By performing reliability centred maintenance, attention is paid to this failure behaviour, often by drawing up a Failure Mode Effects and Criticality Analysis (FMECA). Such an analysis studies the possible failure modes of the machine, their probability of occurrence and their effect on the performance of the machine. It helps in identifying the main failure modes on which the focus must be to improve the maintenance strategy.

\subsection{Maintenance application}

\subsubsection{Case study}

One of the military vehicles suffering from excessive wear caused by the abrasive action of sand particles is the Combat Vehicle 90 (termed CV90). This infantry vehicle, depicted in Figure 6.1 is driven by tracks and predominantly when driving in sandy environments wear will take place in the contact between the track stop and the sprocket and guide wheels. Because the wheels are made of a softer material than the tracks, most wear will take place on the wheels and in this case study, only abrasion that occurs on the wheels is taken into account. Based on inspections of the worn sprocket wheels, the dominant mechanism of wear is considered to be that of abrasion and surface fatigue is neglected.

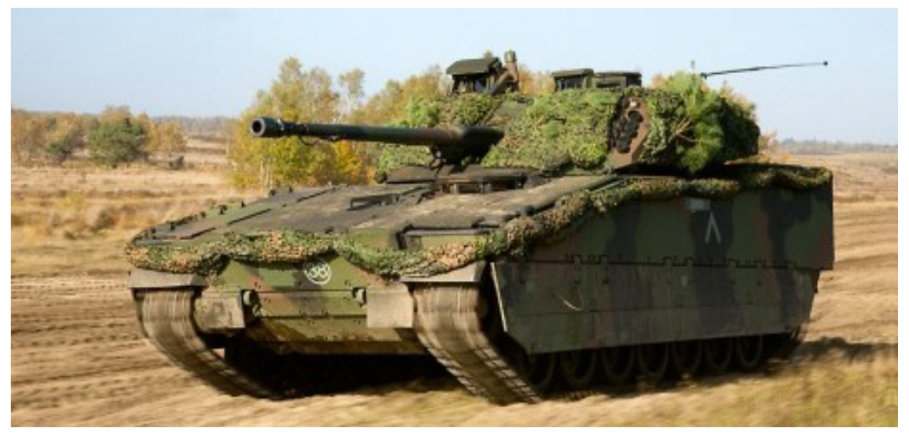

Figure 6.1: The CV90 infantry vehicle. Source: Dutch Ministry of Defence. 
The CV90 vehicle operates in various situations and locations, encountering different environmental conditions and sand varieties. Because the sand variety influences abrasion directly, i.e. according to the particle properties size and shape mentioned in Section 4, these properties are chosen as the environmental parameters for the maintenance setup. Other environmental conditions, like the humidity and wind speeds, are not considered in this thesis, as they have an indirect influence and the particle properties are considered to be more important. The maintenance concept is verified with the sand varieties that were studied in Paper A. These sand varieties can typically be encountered by the CV90 vehicles and both their important particle properties and their specific wear rates are known.

Along the outline of the sprocket wheel, a number of tactically placed blind holes are positioned, as indicated schematically in Figure 6.2. These so-called wear indicators are located a certain distance from the contact surface of the teeth. As the wheel starts to wear the distance between the surface and the hole will decrease until the surface contour reaches the holes. The play between the track and the sprocket will increase and eventually the track might run off the wheels, stopping the machine. Therefore, maintenance has to be performed as soon as the wheel surface reaches the indicators. This gives a maximum wear volume that is allowed to occur on the teeth before maintenance has to be performed. The maximum wear volume is the distance from the surface to the wear indicators for an unused sprocket multiplied by the width of the tooth and the contact length.

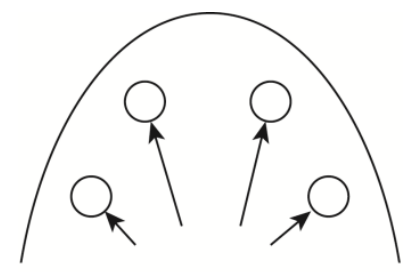

wear indicator

Figure 6.2: Wear indicators on the sprocket teeth. 
The actual amount of wear can be calculated by combining the Archard's law from Equation 3.2 with the empirical equations for the specific wear rate derived in Paper A:

$$
\begin{aligned}
& \frac{k}{k_{\mathrm{ref}}}=\left(\frac{\text { size }_{\mathrm{i}}}{\text { size }_{\mathrm{ref}}}\right)^{\alpha_{1}} \cdot\left(\frac{\text { feedrate }_{\mathrm{i}}}{\text { feedrate }_{\mathrm{ref}}}\right)^{\alpha_{2}} \cdot\left(\frac{\text { sharpness }_{\mathrm{i}}}{\text { sharpness }_{\mathrm{ref}}}\right)^{\alpha_{3}} \\
& \text { with }\left\{\begin{array}{l}
\text { size }_{\mathrm{i}}=\text { size }_{\mathrm{i}} \quad \text { if } \text { size }_{\mathrm{i}}<100 \mu \mathrm{m} \\
\text { size }_{\mathrm{i}}=\text { size }_{\mathrm{ref}} \text { if } \text { size }_{\mathrm{i}}>100 \mu \mathrm{m}
\end{array}\right.
\end{aligned}
$$

with size $_{\mathrm{i}}(\mu \mathrm{m})$, feedrate $_{\mathrm{i}}(-)$, and sharpness $\mathrm{i}_{\mathrm{i}}(-)$ the particle property values for the different sand varieties, size $e_{\text {ref }}(\mu \mathrm{m})$, feedrate $_{\text {ref }}(-)$, and sharpness $s_{\text {ref }}(-)$ the particular values for silver sand taken as reference, $k_{\text {ref }}\left(\mathrm{mm}^{3} / \mathrm{N} \cdot \mathrm{m}\right), \alpha_{1}, \alpha_{2}$, and $\alpha_{3}(-)$ model parameters and $i$ the index for the different sand varieties.

The calculated wear volume can now be compared with the maximum allowed total wear volume. As soon as the calculated wear volume exceeds the maximum allowed wear volume, maintenance has to be performed. Thus, this method allows the prediction of the service life of the wheel as a function of certain operating conditions.

\section{Usage profiles}

The Royal Netherlands Army has derived usage profiles [41] to analyse the performance of a military vehicle in the design stage and specify the requirements of the military vehicle during procurement. These profiles can also be used to analyse the case study described above. For the CV90 two scenarios exist, one for a training mission and one for a military operation.

The usage profile is shown in Table 6-1. The profile is based on a certain distance travelled in several terrains (asphalt, unpaved and heavy soil and loose sand) with varying unevenness (light, medium and heavy). The numbers in Table 6-1 represent the fractions of the total distance driven under those conditions. 
Table 6-1: Usage profile for training missions.

\begin{tabular}{|c|c|c|c|c|}
\hline \multirow[b]{2}{*}{ Unevenness } & \multicolumn{3}{|c|}{ Surface type } & \\
\hline & Asphalt & Unpaved & Heavy soil and loose sand & \\
\hline Light & $2 \%$ & $6 \%$ & $12 \%$ & $20 \%$ \\
\hline Medium & $5 \%$ & $15 \%$ & $30 \%$ & $50 \%$ \\
\hline Heavy & $3 \%$ & $9 \%$ & $18 \%$ & $30 \%$ \\
\hline & $10 \%$ & $30 \%$ & $60 \%$ & \\
\hline
\end{tabular}

These varying conditions will require the machine power and driving torque to vary. This leads to a variation of the load on the sprocket wheel, which has an influence on the amount of wear arising on the wheel. Moreover, the amount of sand, quantified as the particle feed rate, is influenced by the surface type; fewer particles are encountered on asphalt than on unpaved terrain. Both these effects are implemented with the help of load factors. Taking the most demanding situation of heavy soil and loose sand combined with the heavy terrain conditions as a reference, the severity of the other situations is scaled.

Table 6-2: Specific wear rates, corrected for the terrain.

\begin{tabular}{|c|c|c|c|}
\hline \multirow{2}{*}{ Sand variety } & \multicolumn{3}{|c|}{ Terrain } \\
\cline { 2 - 4 } & Paved & Unpaved & Heavy soil \\
\cline { 2 - 4 } & $\left(\cdot 10^{-6} \mathrm{~mm}^{3} / \mathrm{N} \cdot \mathrm{m}\right)$ & $\left(\cdot 10^{-4} \mathrm{~mm}^{3} / \mathrm{N} \cdot \mathrm{m}\right)$ & $\left(\cdot 10^{-3} \mathrm{~mm}^{3} / \mathrm{N} \cdot \mathrm{m}\right)$ \\
\hline Ref & 8.1 & 2.5 & 2.9 \\
\hline 1 & 0.5 & 0.2 & 0.2 \\
\hline 2 & 0.8 & 0.3 & 0.3 \\
\hline 3 & 1.4 & 0.5 & 0.5 \\
\hline 4 & 1.4 & 0.5 & 0.5 \\
\hline 5 & 0.5 & 0.2 & 0.2 \\
\hline
\end{tabular}

A load analysis, using Hertz theory, is used to estimate the load acting on a gear tooth, depending on the driving torque as well as the particle feed rate in the contact. Combining this with Equation 6.1 for the specific wear rates (shown in Table 6-2) and the maximum allowed wear volume $Q_{\max }$ gives the maximum allowed sliding distance $s_{\max }$. This sliding distance can be translated into the maximum allowed driving distance $S_{\max }$ and then compared with the actual driving distance to check whether maintenance needs to be performed. A schematic overview of the process is shown in Figure 6.3. The derivation and background of the different steps in this process can be found in Paper E. 


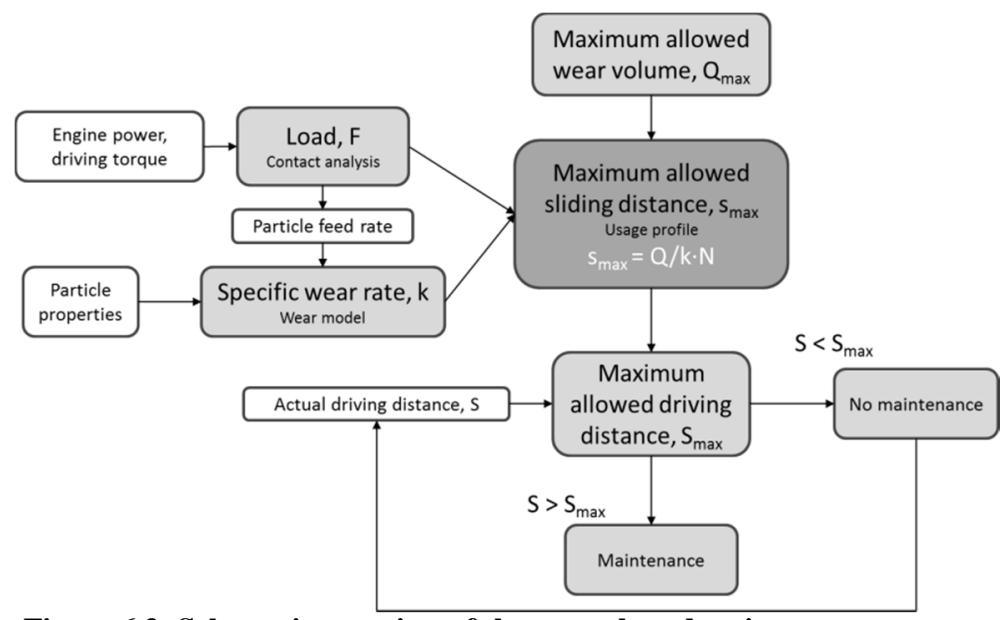

Figure 6.3: Schematic overview of the usage-based maintenance concept.

\subsubsection{Failure behaviour}

The collection of data for the whole fleet of the CV90 vehicles can be used to analyse the failure behaviour of the tracks. The vehicles were taken into operation in the period between 2008 and 2012, meaning that some vehicles have now been operating for five years, while others have only been in operation for around one year. The vehicles are divided over four battalions. Additionally, the driver training facility also has a small number of vehicles.

The CV90 is monitored with a Computerized Maintenance Management System (CMMS). From the CMMS system logs the date of e.g. the replacement of the sprocket wheels can be obtained. Combining this information with the estimated date for the start of operation gives the Mean Time Between Failures (MTBF) of the sprocket wheel, which is shown in Table 6-3. The failure data for the training is not available and thus not included. To couple the failure behaviour to the usage the average distance driven per year is calculated, which is estimated by dividing the present distance driven for each vehicle by the number of years the vehicle has been in operational use. The results are shown in the two final columns of Table 6-3, giving the usage and the MTBF in terms of distance. These results show that not only does the usage of the vehicles vary across the battalions, but also the failure behaviour, both in terms of calendar time and kilometres. 
Table 6-3: Failure behaviour of sprocket wheels at various battalions.

\begin{tabular}{|c|c|c|c|}
\hline \multirow{2}{*}{ Battalion } & MTBF & Usage & MTBF \\
\cline { 2 - 4 } & days & km/year & $\mathrm{km}$ \\
\hline 1 & 262 & 945 & 679 \\
\hline 2 & 457 & 963 & 1206 \\
\hline 3 & 1036 & 678 & 1923 \\
\hline 4 & 760 & 859 & 1788 \\
\hline Driver training & n.a. & 1396 & n.a. \\
\hline
\end{tabular}

\subsubsection{Sprocket service life}

The method described above is used to calculate the maximum allowed driving distances for the usage profiles from Section 6.3.2 in combination with the six sand varieties tested in Paper A. The results are shown in Figure 6.4, indicating that the silver sand that was used as a reference has significantly higher wear compared to the other (realistic) sand varieties. This is because silversand is more aggressive than the other sand varieties, it is sharper.

Now, the calculated values for the sprocket service life are compared to the numbers observed in practice, which were mentioned in Section 6.3.2. Comparing the data from Table 6-3 with Figure 6.4 and stating that the sand encountered in practice is assumed to be similar to variety 3 , the service life in practice is typically lower than the calculated value. There are several possible explanations for this.

First, the predefined usage profile is based on a regular training profile, while the first year of usage comprises the training of the driver and crew. The conditions for this first year of usage are typically heavier than the predefined usage profile shown in Table 6-1. By modifying the usage profile to account for the heavier circumstances it is verified whether this explains the differences between the calculated and real service lives. The modified usage profile is shown in Table 6-4, the resulting sprocket service life for the different sand varieties are depicted in Figure 6.4. According to Figure 6.4 the modified scenario causes the allowed driving distances to be halved. This means that the more severe conditions indeed decrease the sprocket service life. 
Table 6-4: Modified usage profile for training missions under heavier circumstances.

\begin{tabular}{|l|c|c|c|c|}
\hline \multirow{2}{*}{ Unevenness } & \multicolumn{2}{|l|}{ Surface type } & \multirow{2}{*}{} \\
\cline { 2 - 5 } & Asphalt & Unpaved & Heavy soil and loose sand & \\
\hline Light & $1 \%$ & $1 \%$ & $18 \%$ & $20 \%$ \\
\hline Medium & $1 \%$ & $1 \%$ & $18 \%$ & $20 \%$ \\
\hline Heavy & $3 \%$ & $3 \%$ & $54 \%$ & $60 \%$ \\
\cline { 2 - 5 } & $5 \%$ & $5 \%$ & $90 \%$ & \multicolumn{2}{|l}{} \\
\cline { 2 - 5 }
\end{tabular}

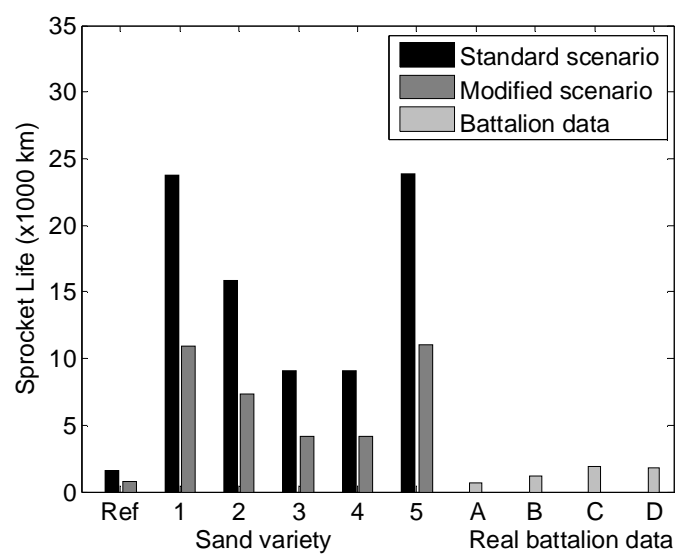

Figure 6.4: Results of the standard and modified usage profile, sprocket wheel service life.

Secondly, it appears the reference sand shows better correlation than the sand variety that was assumed to be representative for the real situation. Also, the variation in the results in Figure 6.4 indicates that the abrasive properties of the sand variety are a main factor in establishing the sprocket service life. Hence, it is important to properly implement the particle properties in the maintenance strategy. The behaviour of the sand particles in the contact are also important, because possibly the sand particles crush in the contact zone, increasing their sharpness.

Thirdly, it is clear that a considerable difference between the predicted and actual value could be introduced by the assumptions that have been made during the model setup. For instance, the load factors, the contact area and the amount of sand in the contact cause uncertainties in the prediction of the sprocket service life, and this prohibits the accurate prediction of a service life in an absolute sense. 
The main advantage of using the proposed concept is that it makes it possible to study the performance of a system under various conditions for the usage of the system and different geographical locations. By monitoring the usage of the system and analysing the properties of the local sand, the amount of abrasive wear and sprocket wheel service life can be predicted and the maintenance strategy optimized. 


\section{Conclusions and recommendations}

\subsection{Conclusions}

- The influence of the main abrasive particle properties on abrasive wear was studied. Experimentally, dry sand-rubber wheel tests were performed on the global scale and single asperity scratch tests were performed on the local scale.

- Dry sand-rubber wheel tests were performed with six different sand varieties to study the effect of sand particle properties on abrasion.

- Based on the results from dry sand rubber wheel tests, a general empirical relation has been derived describing the effects of particle size, shape and feed rate on the abrasive wear rate.

- Single asperity scratch tests were performed using quartz tips with predefined radius to study the particle size effect. The material combination of quartz with standard construction steel primarily leads to the wear types ploughing and wedging, cutting was only observed at relatively high loading conditions.

- Decreasing the particle size leads to increasing amounts of wear. This is because tips with smaller radius cause a larger groove volume at the same loading conditions compared to larger tips.

- A set of parameters was proposed to quantify the shape of a particle.

- It has been shown that shape should be described on different length-scales; shape on the global scale, sharpness on the local scale and roughness on the micro scale.

- A combination of parameters is required to describe the overall particle shape in relation to abrasion; (i) the regularity to define the global shape and (ii) the sharpness to identify local irregularities. 
- A numerical finite element model was developed in Abaqus/Explicit to simulate scratches. The numerical model is verified for the ploughing part of a tip with predefined shape sliding through the top layer of a flat surface.

○ The simulations allow the study of all three wear types related to abrasion: ploughing, wedging and cutting.

- The actual wear type that arises is determined by the indentation depth and the interfacial shear strength, quantified by the coefficient of friction.

- The experimental and numerical results were applied to develop a usage severity based maintenance concept for systems operating in a sandy environment.

- The maintenance policy is based on the relations between the degradation rate (abrasion) and the parameters that cause the wear, like the applied loads, sliding distances and the important abrasive particle properties.

- The maintenance concept has been applied to the specific case study of the CV90 military vehicle, predicting the abrasive wear on the sprocket wheels. The method allows determining the maintenance interval lengths for given usage profiles and sand varieties. 


\subsection{Recommendations}

- In this work the particle size effect has been studied separately using the single scratch test results. However, in real contact situations many other parameters play a role, as was observed in the dry sand rubber wheel tests. The following aspects should be studied further to accurately predict wear rates in a real situation:

$\circ$ The relation between the proposed shape parameters and wear rate must be established.

- The single scratch model must be extended to a situation for repetitive sliding and (partial) overlap between successive scratches.

- The scratching effect of one single particle must be extended to the combined scratching effect of a large number of particles. This could be done using a statistical approach to assess the fraction of the particles carrying the load, and the fraction of the particles that are rolling rather than being embedded.

- The contact behaviour of the particles should be studied in more detail. This includes the particle orientation in the contact, e.g. are particles rolling or sliding, low cycle surface fatigue and degradation and fracture of the particles due to crushing.

- Improving the numerical model and applying it in a virtual wear test program will further increase insight into abrasive wear behaviour.

$\circ$ Modifying the numerical model used for the finite element simulations would improve the modelling capabilities of the wear types wedging and cutting:

- The model currently contains a 'standard' material model for the surface to be worn, including plasticity and material removal. If the material model was expanded with better descriptions for plastic behaviour and damage under the complicated conditions of contact and sliding, this will enhance the results and allow a more accurate simulation of the Hokkirigawa and Kato diagram.

- When the role of friction would be studied more extensively and implemented into the model, better simulations of both the wedging and cutting would be obtained. 
- The presently used model is only the starting point for a numerical study of abrasive wear. The basic mechanisms are shown to be covered by the model, so it can now be applied to simulate the scratching with a wide range of indenter shapes and sizes, indentation depths and scratching patterns (single scratch / multiple scratches). The model provides much more freedom and can be performed at much lower costs and duration than an equivalent experimental program.

- The maintenance setup was mainly verified using predefined usage profiles for the CV90 military vehicle. When more knowledge would be acquired about the actual usage of the machine the model can be modified and the efficiency of the new maintenance setup improved.

- The particle properties are a dominant influence on abrasion and it is a must to measure them properly in order to obtain appropriate results.

- For this maintenance concept to be successful, it is essential that the usage of the system, in terms of surface type, driving speed, distance, etc. is registered accurately. Application of the concept to a case study where this type of information is available would demonstrate the added value of this maintenance policy. 


\section{References}

[1] I.M. Hutchings, Tribology: Friction and Wear of Engineering Materials, Edward Arnold, London, 1992.

[2] D.V. De Pellegrin, A.A. Torrance, and E. Haran, Wear mechanisms and scale effects in two-body abrasion. Wear, 266(1-2): p. 13-20, 2009.

[3] H. Sin, N. Saka, and N.P. Suh, Abrasive Wear Mechanisms and the Grit Size Effect.

Wear, 55(1): p. 163-190, 1979.

[4] A. Misra, and I. Finnie, On the size effect in abrasive and erosive wear. Wear, 65(3): p. 359-373, 1981.

[5] D.V. De Pellegrin and G.W. Stachowiak, Simulation of three-dimensional abrasive particles. Wear, 258(1-4): p. 208-216, 2005.

[6] R. Gåhlin, and S. Jacobson, The particle size effect in abrasion studied by controlled abrasive surfaces. Wear, 224(1): p. 118-125, 1999.

[7] D.V. De Pellegrin and G.W. Stachowiak, Assessing the role of particle shape and scale in abrasion using `sharpness analysis': Part I. Technique development. Wear, 253(9-10): p. 1016-1025, 2002.

[8] Y. Xie, and B. Bhushan, Fundamental wear studies with magnetic particles and head cleaning agents used in magnetic tapes. Wear, 202(1): p. 3-16, 1996.

[9] A.W.J de Gee and G.W. Rowe (ed.), Glossary of terms and definitions in the field of friction, wear and lubrication-Tribology, Technical report, IRG-OECD, 1969.

[10] G. Salomon, Application of Systems Thinking to Tribology. ASLE Transactions, 17(4): p. 295-299, 1974.

[11] DIN, Verschleiß; Begriffe, Systemanalyse von Verschleißvorgängen, Gliederung des Verschleißgebietes, in 50320. Beuth Verlag, Berlin, 1986.

[12] J.F. Archard, Contact and Rubbing of Flat Surfaces. Journal of Applied Physics,

24(8): p. 981-988, 1953.

[13] D. Landheer and A.W.J. De Gee, tribologie deel A: inleiding dynamische contactverschijnselen. 1997.

[14] M.A. Masen, Abrasive tool wear in metal forming processes, PhD Thesis.

University of Twente: Enschede, 2004.

[15] T. Al-Rousan, et al., Evaluation of image analysis techniques for quantifying aggregate shape characteristics. Construction and Building Materials, 21(5): p. 978-990. 2007. 
[16] J.-P. Latham et al., Three-dimensional particle shape acquisition and use of shape library for DEM and FEM/DEM simulation. Minerals Engineering, 21(11): p. 797-805, 2008.

[17] S.M. Nahvi, P.H. Shipway and D.G. McCartney, Particle motion and modes of wear in the dry sand-rubber wheel abrasion test. Wear, 267(11): p. 2083-2091, 2009.

[18] M. Sasso et al., Superimposed fringe projection for three-dimensional shape acquisition by image analysis. Appl. Opt., 48(13): p. 2410-2420, 2009.

[19] G.B. Stachowiak, and G.W. Stachowiak, The effects of particle characteristics on three-body abrasive wear. Wear, 249(3-4): p. 201-207, 2001.

[20] A.N.J. Stevenson and I.M. Hutchings, Development of the dry sand/rubber wheel abrasion test. Wear, 195(1-2): p. 232-240, 1996.

[21] G. Herdan, Small particle statistics: an account of statistical methods for the investigation of finely divided materials. With a guide to the experimental design of particle size determinations.

Academic Press, 1960.

[22] Standard test method for measuring abrasion using the dry Sand/Rubber wheel apparatus: [Standard] ASTM G 65-04.West Conshohocken, PA: ASTM, 2004.

[23] J. Williams, Engineering Tribology. Cambridge University Press, Cambridge, 2005.

[24] K.H.Z. Gahr, Microstructure and Wear of Materials. Elsevier Science, 1987.

[25] W.C. Krumbein, Measurement and geological significance of shape and roundness of sedimentary particles. Journal of Sedimentary Research, 11(2): p. 64-72, 1941.

[26] A.A. Torrance, Modelling abrasive wear. Wear, 258(1-4): p. 281-293, 2005.

[27] M.G. Hamblin, and G.W. Stachowiak, A multi-scale measure of particle abrasivity. Wear, 185(1-2): p. 225-233. 1995.

[28] D.V. De Pellegrin and G.W. Stachowiak, A new technique for measuring particle angularity using cone fit analysis. Wear, 247(1): p. 109-119, 2001.

[29] P.J. Besl, A Method for Registration of 3-D Shapes. IEEE Transactions on Pattern Analysis and Machine Intelligence, 14: p. 239-256, 1992.

[30] R.C.D. Richardson, The wear of metals by relatively soft abrasives. Wear, 11(4): p. 245-275, 1968.

[31] A.A. Torrance, An explanation of the hardness differential needed for abrasion. Wear, 68(2): p. 263-266, 1981. 
[32] G.H. Majzoobi et al., Determination of materials parameters under dynamic loading. Part I: Experiments and simulations. Computational Materials Science, 49(2): p. 192-200, 2010.

[33] G.R. Johnson and W.H. Cook, Fracture characteristics of three metals subjected to various strains, strain rates, temperatures and pressures. Engineering Fracture Mechanics, 21(1): p. 31-48, 1985.

[34] Abaqus, Analysis User's Manual, 2011.

[35] L. Olovsson, K. Simonsson and M. Unosson, Selective mass scaling for explicit finite element analyses. International Journal for Numerical Methods in Engineering, 63(10): p. 1436-1445, 2005.

[36] R. De Borst et al., Nonlinear Finite Element Analysis of Solids and Structures. Wiley, 2012.

[37] K. Hokkirigawa and K. Kato, An experimental and theoretical investigation of ploughing, cutting and wedge formation during abrasive wear. Tribology International, 21(1): p. 51-57, 1988.

[38] K. Hokkirigawa, K. Kato, and Z.Z. Li, The Effect of Hardness on the Transition of the Abrasive Wear Mechanism of Steels. Wear, 123(2): p. 241$251,1988$.

[39] J.M. Challen and P.L.B. Oxley, An explanation of the different regimes of friction and wear using asperity deformation models. Wear, 53(2): p. 229-243, 1979.

[40] CEN EN 13306, Maintenance terminology, European standard, Brussels, 1979.

[41] Dutch Ministry of Defence, Operationele scenario CV9035NL. Appendix 8 of Systeemplan Infantry Fighting Vehicle, 2004. 


\section{Acknowledgements}

Here is a big thank-you to everybody that helped me or was of assistance during the four years and a bit of my $\mathrm{PhD}$ research.

I would like to thank my supervisors. Marc, it has been a pleasure working together, you have inspired me and kept me enthusiastic throughout my research. And Tiedo, my discussions with you kept me sharp and helped me focus on the important things. The same counts for Emile, I appreciate that you helped me get through. And Dik, even though you were mostly involved during my first year, thank you for your assistance wherever you could.

Part of my research was spent at the Dutch Defence Academy in Den Helder, the tribology group at TNO in Eindhoven and the University of Southampton in the UK. Though I was mostly just a visitor, I always felt welcome and appreciated. Thank you for that. I would like to thank Henk Slot and Edwin Stam from TNO for helping me run my experiments. At the Dutch Defence Academy, I thank Axel Homborg, Flip Wubben, Thade Kuiters and Wieger Tiddens for discussing my work. Georges, thanks for having me in Southampton and assisting me in setting up my model.

Most of the time I worked at the tribology group at the University of Twente. To my colleagues there: Milad, Matthijs, Michel, Adriana, Febin, Noor, Ioan, Mahdiar, Rob, Dedy, Julien, Sheng, Jincan, Jianchang, Agnieszka, Aydar, Ellen, Marina, Yibo, Dariush, Adeel, Dinesh, Xiao, Radu, Belinda, Erik, Matthijn, Walter, Piet, Lydia and Mark, and also Debbie, Martin, Willie and Robin, thanks to all of you I never really felt like not going to work. I'm going to miss you, as well as the labs and all of its equipment, which maybe weren't always used for their main purposes, but the ice-cream tasted great.

To Wessel, Mirthe, Jan Robert, Joep and Natalia, thanks for keeping me cheerful outside work. Thanks to my parents for always being there for me. And thank you, my dearest Evelien. 



\section{Part II}

\section{Paper A:}

Investigating the influence of sand particle properties on abrasive wear behaviour,

M. Woldman, E. Van Der Heide, D.J. Schipper, T. Tinga and M.A. Masen, Wear, 2012, Volume 294-295, Pages 419-426.

\section{Paper B:}

The influence of abrasive body dimensions on single asperity wear, $M$. Woldman, E. Van Der Heide, T. Tinga and M.A. Masen, Wear, 2013, Volume 301, Issues 1-2, Pages 76-81.

\section{Paper C:}

Classification of Particle Shapes in 3D, M. Woldman, E. Van Der Heide, T. Tinga and M.A. Masen, submitted to Applied Mathematical Modelling (5-2013).

\section{Paper D:}

Modelling of third body abrasive wear, M.Woldman, E. van der Heide, T. Tinga, G. Limbert and M.A. Masen, Tribology Transactions (2014).

\section{Paper E:}

Implementation of an abrasive wear model in a predictive maintenance concept for systems operated in sandy conditions, M. Woldman, T. Tinga, E. Van Der Heide and M.A. Masen, submitted to Engineering Failure Analysis (1-2014). 



\section{Paper A}

Investigating the influence of sand particle properties on abrasive wear behaviour, M. Woldman,

E. Van Der Heide, D.J. Schipper, T. Tinga and M.A. Masen, Wear, 2012, Volume 294-295, Pages 419-426. 
A-2 


\title{
Investigating the Influence of Sand Particle Properties on Abrasive Wear Behaviour
}

\author{
M. Woldman - E. Van Der Heide - D.J. Schipper - T. Tinga $\cdot$ M.A. \\ Masen
}

\begin{abstract}
Abrasion by sand particles is an important factor causing excessive wear in machines operating in sandy environments. To prevent such machines from failing, knowledge about the abrasive wear process is required. This work focuses on the relation between abrasive particle properties and the wear they cause.
\end{abstract}

Sand was taken from several locations around the world, with variations in particle size and shape. The wear of DIN St-52 steel samples caused by the particles was investigated by performing dry sand-rubber wheel tests with the varieties of sand. The sand particles were sieved to determine their size range. The particle shape was characterized by making images with a confocal microscope and calculating shape factors. The experimental results show significant differences in wear caused by the sand varieties tested. Traditionally used characterisation parameters like size and shape factor, however, cannot explain these differences. There appears to be a relation between the amount of wear and a combination of the particle properties tested.

Keywords Abrasive wear $\cdot$ Wear rate $\cdot$ Sand particle characterisation

\section{Highlights}

- Dry sand-rubber wheel tests were employed on six different sand varieties to study the influence of the particle properties, size and shape, on three-body abrasive wear.

- The particle size and shape were characterized performing sieve analyses combined with confocal microscopy and calculating shape factors respectively.

- It was confirmed that, next to particle size and shape, the particle feed rate influences the abrasive wear.

- By combining the particle size, shape and feed rate, a relation between the properties and the wear they cause can be defined.

\section{Introduction}

Machinery that is operating in sandy environments is vulnerable to sand particles entering and becoming entrapped between components, causing abrasive wear. Sand particles are relatively hard compared to metals and because 
of the small particles it is difficult to prevent them from entering machines by, for example, filtering. Furthermore, the use of filters may adversely affect the performance of the system. Altogether, this makes abrasive wear caused by sand particles a serious problem.

In the literature, several models have been described [1-4] to calculate two-body abrasive wear, which arises because of the sliding movement of a hard and rough surface, or embedded particles over a softer surface. However, when abrasion is caused by particles that are able to move freely between the surfaces in sliding contact, these models do not suffice. Some effort has been made to model this three-body abrasive wear [3, 5, 6]. Torrance [3] used wedge wear tests to relate the abrasive wear resistance to strain to failure. Fang et al. [5] applied Monte Carlo simulations for generating a layer of spherical abrasive particles and combined the Manson-Coffin equation for low-cycle fatigue [7] with Miner's rule of linear cumulative damage [8] to calculate the wear loss of the generated particle layers. Finally, Xie and Bhushan [6] derived a wear index for polishing based on the particle size, the hardness of both the polishing pad and the polished surface and the contact pressure, to calculate the wear rate during polishing. However, improvements are needed for three-body abrasion to be approximated to a reasonable extent, e.g. by incorporating the particle shape and motion into the model.

One important aspect of modelling three-body abrasive wear is the characterisation of the abrasive particles, i.e. the third bodies. Particle properties such as size and geometry influence the wear process and thus need to be included in the model. Despite previous work on the characterisation of the abrasive medium [e.g. 6-26], the relations between the most important sand particle properties and abrasion are yet to be defined.

The so-called 'particle size effect' on abrasion has been well recognized and studied [9-14]: the wear rate increases with increasing abrasive medium size, up to around $100 \mu \mathrm{m}$ [12]. This means that the particle size must be known to be able to define the influence of specific sand varieties on abrasion.

The characterisation of particle shape remains one of the main considerations in modelling abrasive wear. Intuitively, one may suppose that sharper particles cause more wear than blunter particles do. However, it is difficult to describe an exact relation between particle shape and wear rate, primarily because a property such as particle shape is hard to define unambiguously.

Particle shape can be qualified on two levels: global shape itself to describe the macro scale and a smaller scale characterized by e.g. sharpness, angularity or roundness. Global particle shape is usually defined in terms of similarity to standard shapes such as spheres, hyperboloids, cones and wedges [3, 14, 25]. Some more sophisticated models use polyhedrals to simulate the particles 
in 3D [14]. De Pellegrin [26] proved that in two-body abrasion, it is also possible to characterize shape locally with so-called sharpness parameters. These parameters for instance are based on Fourier analysis, fractal behaviour or changes along the particles' outline [25].

Although image capturing and processing techniques are used to analyse 3D shapes in e.g. the automotive [15] and geoscience [16] research fields, it seems that the tribological field is still mainly using $2 \mathrm{D}$ analysis, e.g. employing laser based measurement systems in condition monitoring and oil analyses. An exception is De Pellegrin [14], who applies image processing techniques to define artificial particle shapes, for future use in simulations of three-body abrasive wear.

The work reported in this paper focuses on the relation between sand particle properties and abrasive wear, performing dry sand-rubber wheel tests to quantify the abrasive wear. Where these tests are normally used to characterize wear rates of different materials, in this work they are utilized to quantify the effects of different sand types. Next, methods to study the particle properties that influence the abrasive wear are defined and applied to relate these properties to the abrasive wear rate. The resulting structured analysis of the relation between particle property and wear rate is not yet available in the literature and can be used in a model for three-body abrasion and applied in the usage based maintenance framework by Tinga [27].

\title{
2 Dry sand-rubber wheel tests
}

\begin{abstract}
Abrasive wear is commonly studied by performing dry sand-rubber wheel tests [17-19]. During these experiments, sand particles are fed into the contact between a rotating rubber wheel and a steel sample; see Fig. 1 for a schematic overview of the test setup. Conventionally, the dry sand-rubber wheel test is applied to investigate the resistance of materials to three-body abrasive wear, using a standardized abrasive such as silversand or Ottawa sand. In this research, the goal is to study the influence of the sand particle properties on wear. Therefore, the particle properties are varied by using different sand varieties and performing tests on identical steel DIN St-52 samples. Sands are selected from several global locations - beaches and deserts - and characterized by measuring their size and shape as discussed in Sec. 3 .
\end{abstract}




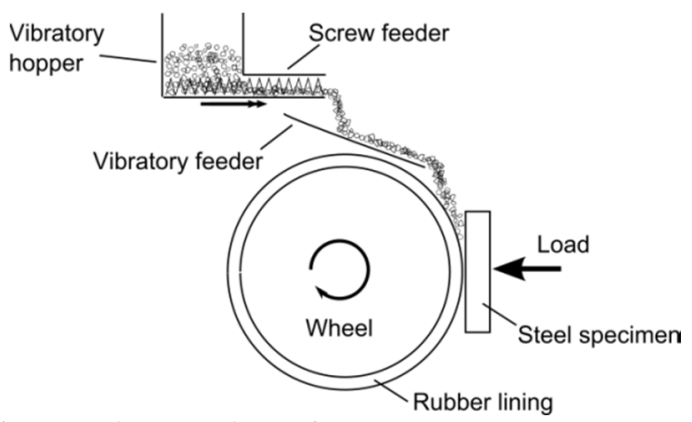

Fig. 1 Schematic overview of the dry sand-rubber wheel test.

Dry sand-rubber wheel tests are run for periods of 5,10 and $15 \mathrm{~min}$ at a normal load of $100 \mathrm{~N}$ and a sand feed rate of $15 \mathrm{~g} / \mathrm{min}$. The specific wear rate $k\left(\mathrm{~mm}^{3} / \mathrm{N} \cdot \mathrm{m}\right)$ of the steel samples is calculated according to the Archard wear equation [28]:

$$
k=\frac{Q}{N \cdot s}
$$

With $N$ the normal load (N), $Q$ the volume loss $\left(\mathrm{mm}^{3}\right)$ of the test specimen based on its weight loss and $s$ the sliding distance $(\mathrm{m})$. Wear tests are repeated four times to check reproducibility and the obtained specific wear rates are averaged to define a representative value for the particular sand variety.

\section{Controlling the sand feed rate: design of a new feeder system}

In conventional dry sand-rubber wheel tests, employed to characterize the wear of various steel samples and using only one abrasive medium, the abrasive flow rate is found to have a limited influence on the test results [29]. Therefore, generally, a hopper and a gravity-controlled flow ensure a sufficiently constant feed rate. For the wide range of sands used in the present work, such a simple set-up does not work because of sand clogging the system. Moreover, because in this work the abrasive medium is studied rather than the steel sample, the particle flow has to be accurately controlled. Hence, a new sand feeding system was developed to ensure a stable flow of sand into the contact. The feeding system combines a screw feeder and a vibratory feeder; the screw feeder prevents the sand from clogging whilst the vibratory feeder steadies the flow into the contact.

The new feeder system was tested for all sand varieties used, by periodically weighing the total amount of sand that has fallen from the vibratory feeder during a period of $15 \mathrm{~min}$, which is the maximum duration of the dry sandrubber wheel tests performed. The feed rate deviates less than $0.5 \mathrm{~g} / \mathrm{min}$ or $3.3 \%$, which is considered acceptable. 


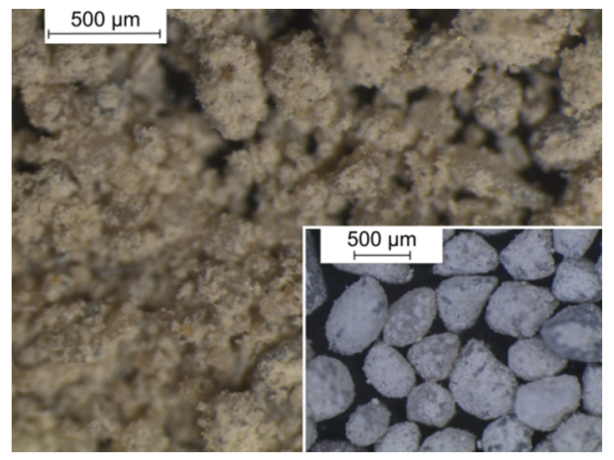

Afghanistan

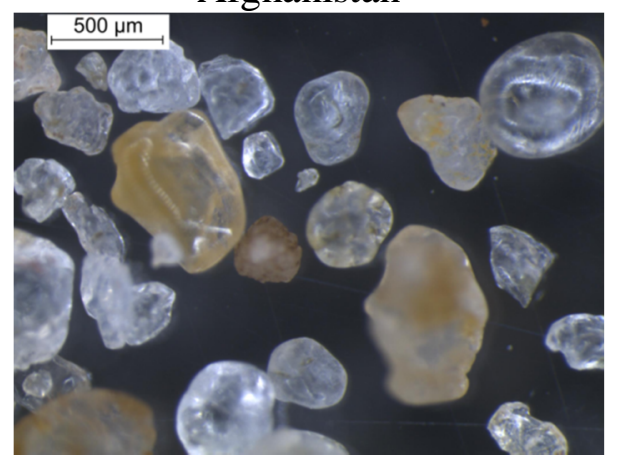

Gambia II

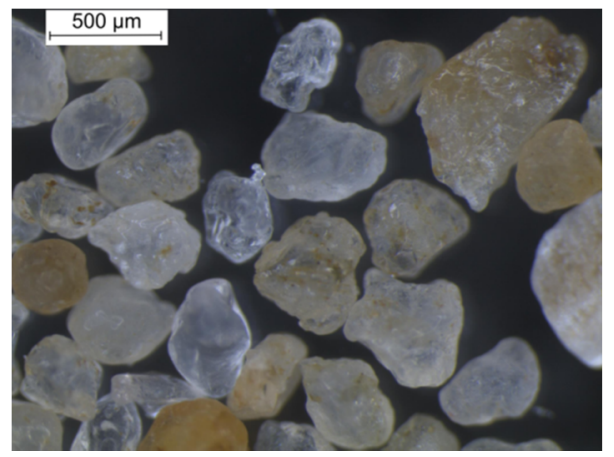

Netherlands II

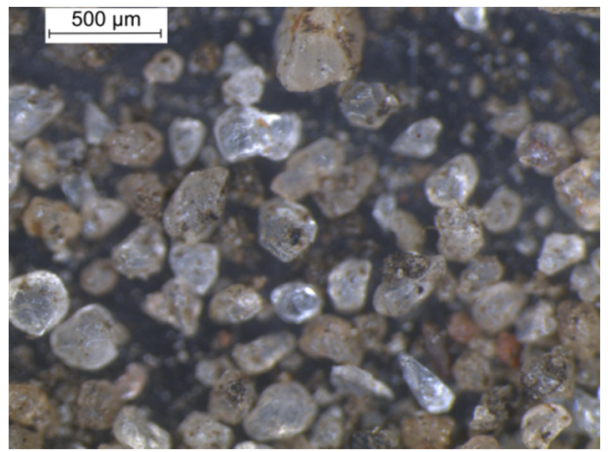

Gambia I

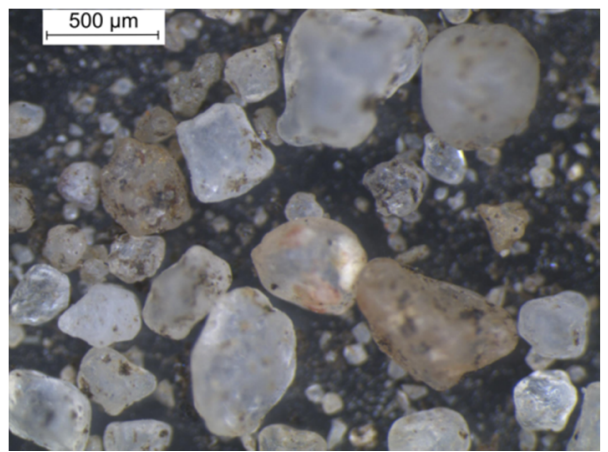

Netherlands I

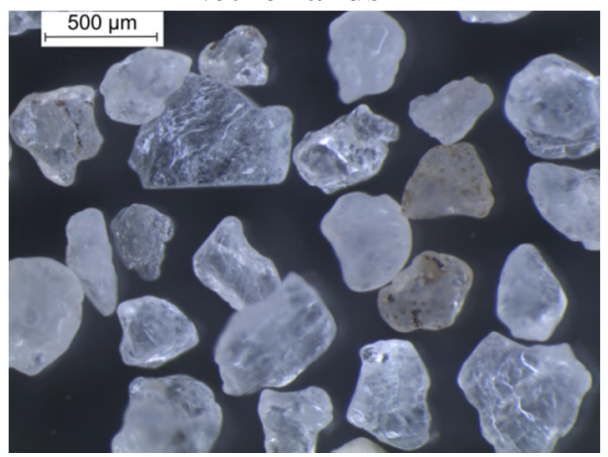

Silversand

Fig. 2 Stereo microscope pictures of the sand varieties tested. The Afghan sand particles in the top-left image are so small it is hard to separate them; in the inset the larger particles are shown, to give an idea about their shape. 


\section{$3 \quad$ Measuring Sand Particle Properties}

According to e.g. Stachowiak [20] and Williams [21], important particle properties that influence abrasion are the size, the shape and the hardness. Initial hardness measurements on the sand varieties used in the present work, performed by nano-indentation, however, show insignificantly small differences. Moreover, Zum Gahr [22] showed that when the hardness differential between the abrasive and the surface exceeds a value of around 1.2, the abrasive wear rate does not change with further increasing hardness of the abrading particles, all other things being equal. Sand mainly consists of silicon dioxide $\left(\mathrm{SiO}_{2}\right)$, with a hardness of approximately $1000 \mathrm{HV}$. This means that the hardness differential between the sand particles and the steel surface $(140 \mathrm{HV})$ is in the order of 7 to 8 and thus well higher than the threshold value of 1.2. This implies that, in this research, the particle hardness does not influence abrasive wear. Hence, particle size and shape are studied and the particle hardness is not further considered.

Sand was obtained from five locations around the world; silversand was added to the set as this is used as the 'standard' sand for dry sand-rubber wheel tests:

- Afghanistan

- Gambia I

- Gambia II (beach)

- Netherlands I

- Netherlands II (beach)

- Silversand

Fig. 2 shows pictures of random selections of the sand varieties tested, taken with a stereomicroscope. Because most of the Afghan sand particles are so small it is hard to separate them; for this sand variety some bigger particles are shown in the inset, to give an idea about their shape.

\subsection{Particle Size}

\section{Measuring particle size}

A mechanical shaker is used to perform sieve analyses on the selected sand varieties. It is common to create cumulative plots on the weight fraction against the particle size and use the Median to represent the size of the particular sand variety [23]. However, when the variation in the particle size is large, the Median value is not a representative measure for the particle size. Moreover, some sand varieties contained a considerable amount of particles that passed through the sieve with the smallest gap size used $(45 \mu \mathrm{m})$. This means that sieve analysis cannot be used to obtain the size distributions with sufficient detail. To 
overcome this, the particles passing through the finest sieve are analysed using a confocal microscope. Based on pictures similar to those shown in Fig. 2, the separate particles can be identified and characterized by their maximum diameters. These diameters represent the sizes of the specific particles. Similar to the sieve analysis, the particles are divided over different size categories up to $45 \mu \mathrm{m}$. Instead of weight fractions however, this division is based on the number of particles per category with respect to the total number of particles in a picture. Combining the visual results with the sieve analyses gives an improved overview of the particle size distribution within a sand variety.

\section{The representative particle size}

The so-called particle size effect means that the resulting wear rate increases approximately linearly with the particle size for particles up to around $100 \mu \mathrm{m}$ [14], whilst for larger particles there is no influence of size on the wear rate. This results in a non-direct relation between the mass flow of particles, their sizes and the resulting wear in a dry sand-rubber wheel test. To calculate the average size of the particles, the number of particles for each size going through the contact is required to obtain the proper weighting. Geometrically, the number of particles in the contact is approximately proportional to the inverse-square of particle diameter. Hence, the relative numbers of particles for each size can be obtained from the mass flow.

Therefore, the measured weight fractions are converted into 'number of particle' fractions, the number of particle fractions representing the proportion of particles of a specific size category over the total amount of sand. For this, the weight fractions are recalculated into particle fractions using the characteristics of the dry sand-rubber wheel test [19]:

$$
\begin{gathered}
n_{i}=f_{w, i} \frac{W x}{m_{p, i} v} \\
f_{n, i}=\frac{n_{i}}{\sum_{i} n_{i}}
\end{gathered}
$$

with $n_{i}$ the number of particles in the contact at a given moment, based on the weight fractions and $f_{n, i}$ the particle fraction. Further, $f_{w, i}$ is the weight fraction, $W$ the particle feed rate $(0.25 \mathrm{~g} / \mathrm{s}), x$ the contact length i.e. the size of the contact between the rubber wheel and the steel sample $(0.01 \mathrm{~m}), m_{p, i}$ the mass of the largest particle belonging to the specific fraction (in grams, as obtained from the sieving process $), v$ the sliding speed $(0.1 \mathrm{~m} / \mathrm{s})$ and $i$ the index for the different size fractions. Multiplication of the particle fractions with the fractions' 
accompanying sizes $d_{i}$ and summation gives the representative values for the sand variety's particle size $d$ :

$$
d=\sum_{i} f_{n, i} d_{i}
$$

\subsection{Particle Shape}
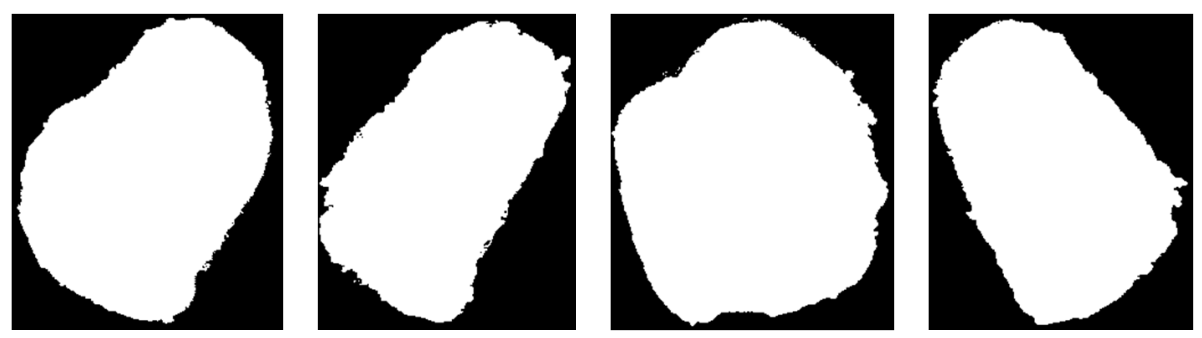

Fig. 3 Binarized sand particle scans, obtained with a confocal microscope.

In this research, two definitions for particle shape are applied, one for the global (shape) and one for the local (sharpness) level. Particles are scanned using a confocal microscope and projected in 2D, like the example shown in Fig. 3. Based on such projections and after applying a median filter to reduce the influence of noise on the length of the perimeter, a global shape parameter termed roundness factor $\kappa_{R}$ can be calculated:

$$
\kappa_{R}=\frac{P^{2}}{4 \pi A}
$$

with $A$ the area and $P$ the perimeter of the two-dimensional projection. Note that the circular $2 \mathrm{D}$ projection of a sphere results in a roundness factor value of 1 whilst more deviating shapes yield values larger than 1 .

Sand particles are measured automatically under a confocal microscope. A number of 25 measurements is required to measure a particle 360 degrees around. The average roundness value over such 25 measurements is then taken as the representative value for the particle. This procedure is performed for 5 sand particles in each variety, the average over these 5 measurements representing that particle varieties' roundness factor.

The local shape quantification for sharpness is based on visual inspection, classifying shape by comparing the measured particle's shape as shown in Fig. 2 with the so-called Krumbein chart in Fig. 4 [24, 25]. In this chart the shape, or sharpness, of particles is quantified from 1 (round shape) to 0.1 (deviating from 
round shape). To make the values from this shape factor equivalent the $\kappa_{R}$ values from Eq. 5, the reciprocal values from Fig. 4 are used. This means that the Krumbein shape factor values, denoted $\kappa_{K}$, are equal to 1 for smooth circular shapes and larger than 1 for deviating shapes. Since the visual inspection is a subjective method, the assessment of the sand varieties has been performed by two people and the average values are used for the further analysis. As was mentioned in the introduction, also objective methods to characterize the (local) sharpness have been proposed [25, 26], but currently no consensus exists on which method provides the best results. Therefore, in the present work the classical and widely accepted Krumbein method has been adopted, thereby taking the somewhat lower accuracy due to subjectivity for granted.

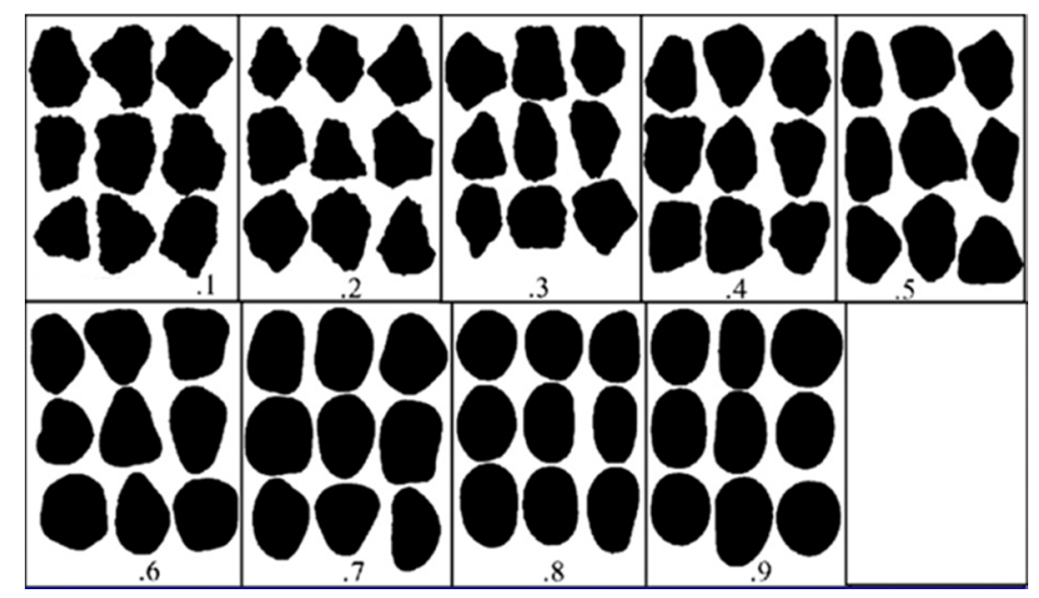

Fig. 4 Krumbein chart [after 25].

\section{$4 \quad$ Results}

\subsection{Dry sand-rubber wheel tests}

Fig. 5 shows the test specimens' mean volume loss plotted against the test duration for the different sand varieties tested. Since the normal load and the rotational speed of the rubber wheel are constant during the test, the volume loss after running in is expected to be proportional to the test duration. By fitting a line through the data for each sand variety and calculating the slope, the value for the wear rate is found. The wear rates for the sand varieties tested are displayed in both Fig. 5 and Table 1, showing distinct variations in wear rates and thus indicating that different sand varieties have a different influence on abrasive wear. Note that the fitted lines do not pass through zero to avoid taking 
into account the effects of running in (with non-representatively high wear rates). 
The error bars represent the standard deviation of the volume loss across 4 tests. The coefficient of determination values $\left(\mathrm{R}^{2}\right)$ in Table 1 indicate how well the volume loss is proportional to the test duration.

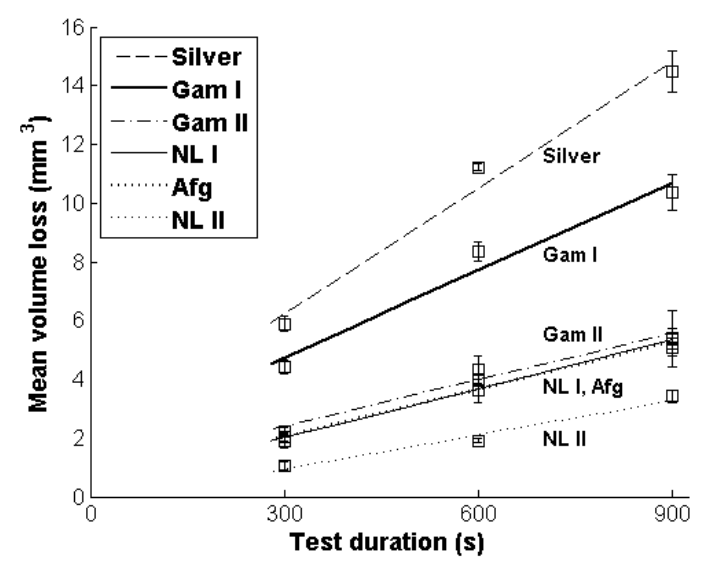

Fig. 5 Results dry sand- rubber wheel tests; mean volume loss versus test duration for the sand varieties tested.

\begin{tabular}{|l|c|c|c|c|c|}
\hline $\begin{array}{l}\text { Sand } \\
\text { variety }\end{array}$ & \multicolumn{2}{|l|}{ Wear rate } & $\begin{array}{l}\text { Particle } \\
\text { size }\end{array}$ & $\begin{array}{l}\text { Shape } \\
\text { factor } \\
\kappa_{R}\end{array}$ & $\begin{array}{l}\text { Shape } \\
\text { factor } \kappa_{K}\end{array}$ \\
\cline { 2 - 6 } & $\begin{array}{c}\left(\cdot 10^{-4}\right. \\
\left.\mathrm{mm}^{3} / \mathrm{Nm}\right)\end{array}$ & $\mathrm{R}^{2}$ & $(\mu \mathrm{m})$ & $(-)$ & $(-)$ \\
\hline Silversand & 15 & 0.97 & 230 & 1.65 & 5.0 \\
\hline Gambia I & 11 & 0.95 & 80 & 1.77 & 2.0 \\
\hline Gambia II & 5.7 & 0.87 & 226 & 1.60 & 2.5 \\
\hline $\begin{array}{l}\text { Netherlands } \\
\text { I }\end{array}$ & 5.7 & 0.97 & 90 & 1.54 & 2.5 \\
\hline Afghanistan & 5.6 & 0.96 & 78 & 1.85 & 1.7 \\
\hline $\begin{array}{l}\text { Netherlands } \\
\text { II }\end{array}$ & 3.8 & 0.96 & 515 & 1.63 & 1.4 \\
\hline
\end{tabular}

Table 1 Experimental and measurement results for sand varieties tested. 


\subsection{Particle size}

The cumulative weight fractions of the six sand varieties are shown in Fig. 6 (a). According to Fig. 6 (a) and Table 1, three sand varieties are observed to have a significant fraction of particles smaller than the finest sieve $(45 \mu \mathrm{m})$ used. These are the sand from Afghanistan and sands I from Gambia and the Netherlands. Samples from the fractions smaller than $45 \mu \mathrm{m}$ were observed under a confocal microscope, Fig. 6 (b) showing the results. Note that the distributions shown in Figs. 6 are used as input for Eqns. 2, 3 and 4 to calculate the size values given in Table 1.

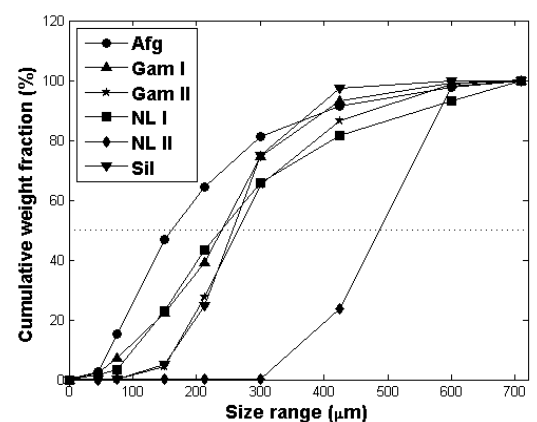

(a)

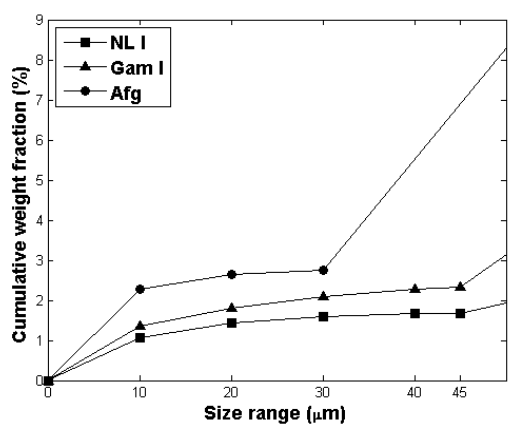

(b)

Fig. 6 Sieve analysis (a), and zoomed in on smaller particle size (b).

\subsection{Particle shape}

The final two columns in Table 1 show the shape factor values for the sand varieties tested, according to Eq. 5 and Fig. 4 respectively. The closer the shape factor value to one, the more spherical the particle. Moreover, significant differences are seen in corresponding shape factor values.

\section{$5 \quad$ Discussion}

\subsection{Particle size}

The mean specific wear rate is plotted against particle size in Fig. 7 (a). The particle size cannot be used to explain the observed wear rate difference generally, because half of the mean particle sizes are larger than 100 microns and thus in the size independent regime. Hence, even though Fig. 7 (a) shows differences in wear rate with different particle size, this does not mean that the particle size is solely responsible for this. 


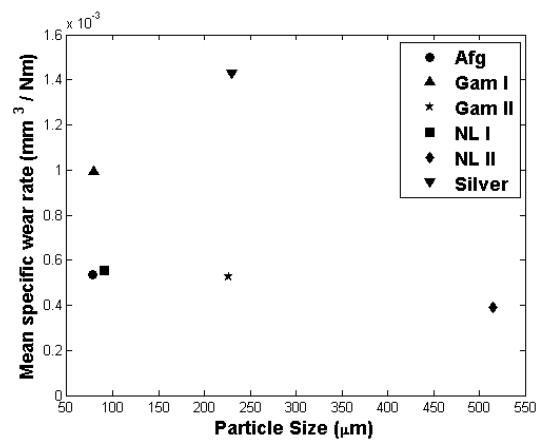

(a)

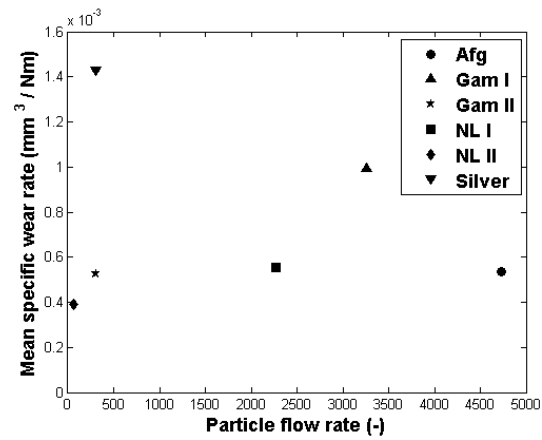

(b)

Fig. 7 Wear rate plotted against particle size (a), wear rate plotted against particle flow rate $(b)$.

The feed rate of sand into the contact is controlled as a constant mass flow of 15 grams per minute. This means that the number of particles that get in the contact and thus cause abrasive wear in a test depends on the particle size. Converting the mass flow rate to a particle flow rate using:

$$
\dot{p}=\sum_{i} f_{n, i} n_{i}
$$

with $\dot{p}$ the particle flow rate, $f_{n, i}$ the particle fraction from Eq. 3 and $n_{i}$ the number of particles in the contact at a moment, from Eq. 2. Plotting the results against the wear rate gives Fig. 7 (b). This figure could explain the low wear rate of sand II from the Netherlands: because of its bigger particle size compared to the other sand varieties, the total number of particles in the contact is low, causing a relatively low amount of wear.

In contrast, for the Afghan sand the number of abrasive particles encountered during the experiment is relatively high, thereby causing the wear rate to increase. According to Fig. 7 (b) and following the general trend of wear rate increasing with feed rate, the Afghan sand's wear rate is expected to be even higher. It is however thought that the Afghan particles causing the number of particles to be high are predominantly smaller than 100 microns, thereby suffering from the particle size effect. In other words, the Afghan particles may be that small that they cause less wear. The sheer number of particles would then raise the wear rate up to the reasonable level it appears to have.

Finally, another aspect that might play a role is the loading of the particles. Small particles may be loaded less severe when they are in between many large particles. Since in the present work real sand samples are used with a variety of particle sizes, the particle size effect on wear may not be fully revealed due to this load reduction effect for small particles. However, recent research (M. Rechberger, personal communication, November 2, 2011) showed that small 
particles might also stick to larger particles and thus do contribute to the wear process.

Thus, since the contribution of the different sizes to the wear process is still under debate, in the present work the size effect is studied using the average or representative particle size as defined in Eq. 4.

\subsection{Particle shape}

According to the results shown in Fig. 8, where the wear rate is plotted against the two shape definitions, particle shape, or at least the adopted quantifications, cannot solely be used to explain the differences in wear rates measured. Although there seems to be a coarse relation; wear rate increasing with decreasing particle roundness, some discrepancies are found. Note that the sharpness factor $\kappa_{K}$, the one based on visual inspection, shows more of a trend with the wear rate than shape factor $\kappa_{R}$ does. This implies that the local shape definitions have better correlation with the abrasive wear rate than global shape definitions do, which is not surprising, since local (sharp) protrusions are expected to penetrate more into the metal surfaces and thus are expected to cause more wear.

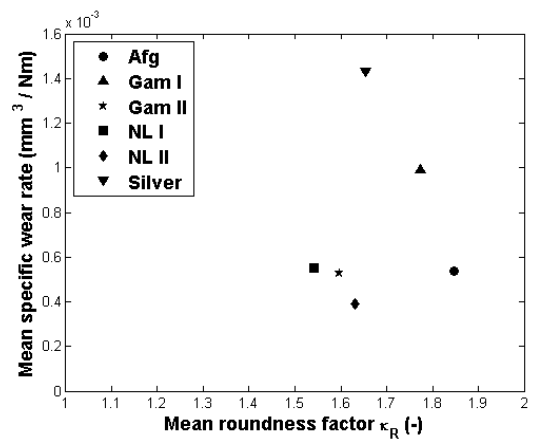

(a)

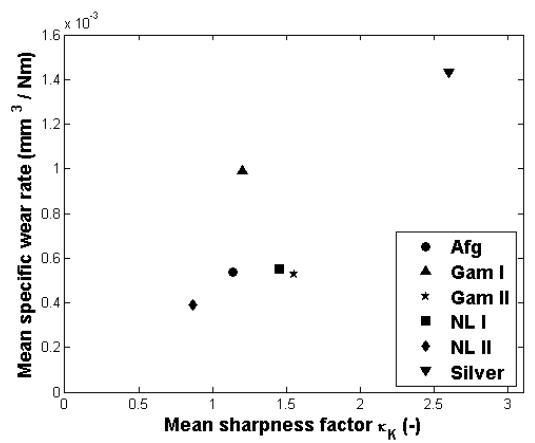

(b)

Fig. 8 Wear rate plotted against shape factor (a) and sharpness value (b).

It is expected that the observed differences in wear rate depend largely on the particle shape. It is clear that the available definitions for describing the particle shape do not suffice. This asks for an improved definition of the particle shape based on an accurate 2D definition or the actual 3D shape of the particle.

\subsection{Combining all factors}

As discussed in Secs. 5.1 and 5.2, it is not possible to relate abrasive wear to one of the verified particle properties alone. Either this means that a combination of 
the different properties explains abrasion or that there is another property influencing abrasive wear. The first option is the most plausible, hence it is tried to find a relation between abrasive wear and a combination of the particle properties size, feed rate and shape. Note that for shape, the shape factor $\kappa_{K}$, the one based on the Krumbein chart, is used rather than the shape factor $\kappa_{R}$. This is because, according to Fig. 8, the local sharpness values seem to describe abrasive wear more reliably than the global roundness factors do.

Since there is no physical explanation known for relating abrasion to the particle properties, the wear test results are fitted with the following equation:

$$
\begin{aligned}
& \frac{k}{k_{\text {ref }}}=\left(\frac{\text { size }_{i}}{\text { size }_{\text {ref }}}\right)^{a_{1}} \times\left(\frac{\text { feedrate }_{i}}{\text { feedrate }_{\text {ref }}}\right)^{a_{2}} \times\left(\frac{\text { sharpness }_{i}}{\text { sharpnes }_{\text {ref }}}\right)^{a_{3}} \\
& \text { with } \begin{cases}\text { size }_{i}=\text { size }_{i} & \text { if } \text { size }_{i}<100 \mu \mathrm{m} \\
\text { size }_{i}=\text { size }_{\text {ref }} & \text { if } \text { size }_{i}>100 \mu \mathrm{m}\end{cases}
\end{aligned}
$$

with size $_{i}$, feedrate ${ }_{i}$, and sharpness $s_{i}$ the particle property values for the different sand varieties as plotted in Figs. 7 and 8, size $_{\text {ref, }}$ feedrate ref $_{3}$, and sharpness sef $_{\text {ef }}$ the same values for silversand taken as reference, $k_{\text {ref }}\left(\mathrm{mm}^{3} / \mathrm{Nm}\right), a_{1}, a_{2}$, and $a_{3}$ fitting parameters and $i$ the index for the different sand varieties. Note that the size term in Eq. 7 is conditioned to make sure only the three leftmost sand varieties in Fig. 7 (a) are taken into account, because they are the only ones with significant fractions smaller than $100 \mu \mathrm{m}$ and thus are influenced by the particle size effect.

Using a subroutine and trying different combinations for the values of the fitting parameters, the optimal fit shown in Fig. 9 is found. With a coefficient of determination $R^{2}$ equal to 0.85 this fit is considered good enough to state that there is a relation between abrasive wear and a combination of the properties of the particles causing this wear.

The parameter values leading to the optimum fit are given in Table 2, showing positive values for all three particle property exponents. This means that, as expected, the abrasive wear rate increases with increasing particle size, feed rate and sharpness. Moreover, the different fit values indicate differences in the importance of the particle properties in relation with abrasion. According to Table 2, the feed rate has the smallest influence on abrasive wear, whilst the particle size the largest. It is thought this is because in the calculations presented, particle size only considers the (three) smallest size varieties. Doing this, a strong influence of particle size is seen, stronger than the influence of the particle feed rate. On a global level, the role of particle size would be less important. 


\begin{tabular}{|l|c|c|}
\cline { 2 - 3 } \multicolumn{1}{c|}{} & Fit parameter & Value \\
\cline { 2 - 3 } \multicolumn{1}{c|}{} & $k_{f i t}\left(\mathrm{~mm}^{3} / \mathrm{Nm}\right)$ & 0.00285 \\
\hline Size & $a_{1}(-)$ & 3 \\
\hline Feedrate & $a_{2}(-)$ & 1.5 \\
\hline Sharpness & $a_{3}(-)$ & 2.5 \\
\hline
\end{tabular}

Table 2 Parameter values used to fit Eq. 7

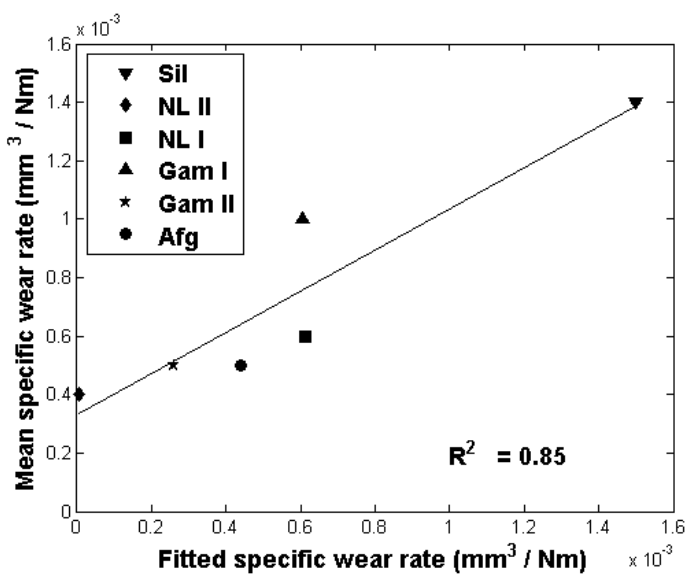

Fig. 9 Fit of wear rate against a combination of particle property values

\section{Conclusions}

The influence of sand particle properties on abrasive wear was studied. Using a dry sand-rubber wheel tester with a modified sand supply, it has been shown that different sand varieties have different specific wear rates to DIN St-52 samples. Particle size, feed rate and shape cannot explain these differences separately. However, when a combination of these particle properties is used, a relation can be derived between the properties of the sand and the abrasion that is caused. Still, further work is required to obtain this relation's physical background, for instance by using better definitions for particle shape.

\section{$7 \quad$ Acknowledgements}

The authors wish to thank the supporting staff of the Laboratory for Surface Technology and Tribology at the University of Twente. Furthermore, TNO Eindhoven and Henk Slot in particular are thanked for making their dry sand-rubber wheel abrasion tester available for this work and helping setting up the experiments. 
[1] M.A. Masen, M.B. de Rooij, D.J. Schipper, Micro-contact based modelling of abrasive wear, Wear 258 (1-4) (2005) 339-348.

[2] K.H. Zum Gahr, Modelling of two-body abrasive wear, Wear 124 (1) (1988) 87-103.

[3] A.A. Torrance, Modelling abrasive wear, Wear 258 (1-4) (2005) 281-293.

[4] Y. Xie, J.A. Williams, The prediction of friction and wear when a soft surface slides against a harder rough surface, Wear 196 (1-2) (1996) 21-34.

[5] L. Fang, W. Liu, D. Du, X. Zhang, Q. Xue, Predicting three-body abrasive wear using Monte Carlo methods, Wear 256 (7-8) (2004) 685-694.

[6] Y. Xie, B. Bhushan, Effects of particle size, polishing pad and contact pressure in free abrasive polishing, Wear 200 (1996) 281-295.

[7] S.S. Manson, Fatigue: a complex subject-some simple approximation, Exp. Mech. 5 (7) (1965) 193-226.

[8] M.A. Miner, Cumulative damage in fatigue, J. Appl. Mech. Trans. ASME 12 (1945) 159-164.

[9] I.M. Hutchings, Tribology: Friction and Wear of Engineering Materials, Edward Arnold, London, 1992.

[10] D.V. de Pellegrin, A.A. Torrance, E. Haran, Wear mechanisms and scale effects in two body abrasion, Wear 266 (1-2) (2009) 13-20.

[11] H. Sin, N. Saka, N.P. Suh, Abrasive wear mechanisms and the grit size effect, Wear 55 (1) (1979) 163-190.

[12] A. Misra, I. Finnie, On the size effect in abrasive and erosive wear, Wear 65 (1980) $359-373$.

[13] R. Gåhlin, S. Jacobson, The particle size effect in abrasion studied by controlled abrasive surfaces, Wear 258 (1-4) (1999) 118-125.

[14] D.V. de Pellegrin, G. Stachowiak, Simulation of three-dimensional abrasive particles, Wear 258 (1-4) (2005) 208-216.

[15] M. Sasso, G. Chiappini, G. Palmieri, D Amodio, Superimposed fringe projection for three-dimensional shape acquisition by image analysis, Appl. Optics 48 (13) (2009) 2410-2420.

[16] J.-P. Latham, A. Munjiza, X. Garcia, J. Xiang, R. Guises, Threedimensional particle shape acquisition and use of shape library for DEM and FEM/DEM simulation, Miner. Eng 21 (11) (2008) 797-805.

[17] Standard test method for measuring abrasion using the dry sand/rubber wheel apparatus, ASTM Standards, G 65-04 (2004).

[18] S.M. Nahvi, P.H. Shipway, D.G. McCartney, Particle motion and modes of wear in the dry sand-rubber wheel abrasion test, Wear 267 (11) (2009) 20832091.

[19] A.N.J. Stevenson, I.M. Hutchings, Development of the dry sand/ rubber wheel abrasion test, Wear 195 (1996) 232-240. 
[20] G.B. Stachowiak, G.W. Stachowiak, The effects of particle characteristics on three-body abrasive wear, Wear 249 (2001) 201-207.

[21] J. Williams, Engineering Tribology, Cambridge University Press, New York, 2005.

[22] K. H. Zum Gahr, Microstructure and Wear of Materials, Elsevier, Amsterdam, 1987.

[23] G. Herdan, Small particle statistics, second ed., Butterworth \& Co., London, 1960.

[24] W.C. Krumbein, Measurement and geological significance of shape and roundness of sedimentary particles, J. Sediment. Res. 11 (2) (1941) 64-72.

[25] T. Al-Rousan, E. Masad, E. Tutumluer, T. Pan, Evaluation of image analysis techniques for quantifying aggregate shape characteristics, Constr. Build. Mater. 21 (2007) 978-990.

[26] D.V. de Pellegrin, N.D. Corbin, G. Baldoni, A.A. Torrance, Diamond particle shape: Its measurement and influence in abrasive wear, Tribol. Int, no. 42, pp 160-168, 2009.

[27] T. Tinga, Application of physical failure models to enable usage and load based maintenance, Reliab. Eng. Syst. Safe. 95 (2010) 1061 - 1075.

[28] J.F. Archard, Contact and rubbing of flat surfaces, J. Appl. Phys. 24 (8) (1953) 981-988.

[29] E. Rabinowicz, L.A. Dunn, P.G. Russell, A study of abrasive wear under three-body conditions, Wear 4 (1961) 345-355. 
A-21 


\section{Paper B}

The influence of abrasive body dimensions on single asperity wear, M. Woldman, E. Van Der Heide, T. Tinga and M.A. Masen, Wear, 2013, Volume 301, Issues 1-2, Pages 76-81.

B-1 


\section{B-2}




\title{
The Influence of Abrasive Body Dimensions on Single Asperity Wear
}

\author{
M. Woldman $\cdot$ E. Van Der Heide $\cdot$ T. Tinga $\cdot$ M.A. Masen
}

\begin{abstract}
This work focuses on the relation between the properties of abrasive bodies and the wear they cause. By performing single asperity scratch tests to simulate abrasive wear, the wear process takes place in a controlled environment, allowing the properties of the abrasive body to be isolated and studied independently. The setup used is a pin-on-flat machine, enabling scratching along a straight line and under active load control. The abrasive bodies were generalized by using single crystal $\mathrm{SiO}_{2}$ tips to scratch DIN St-52 steel samples. The tip radius was varied to study the influence of the abrasive body size on the abrasive wear process. The normal load was varied as well to obtain its influence. Using confocal microscopy, the scratches were analysed to identify the abrasion mechanisms, such as ploughing and cutting and to determine the volumetric wear.
\end{abstract}

As expected, the results show an expected increase in the wear volume with increasing load. More interestingly, the wear rate varies significantly as a function of the size of the abrasive, enabling the prediction of the wear rate based on the abrasive body size. It is observed that, contrary to earlier reported size effects, smaller tips cause more wear than larger tips do. Moreover, at the low values for the degree of penetration studied in this work, a regime of limited plastic deformation was identified, based on the observation that the degree of wear parameter decreases with increasing degree of penetration.

Keywords Abrasive wear $\cdot$ Wear rate $\cdot$ Single asperity scratch tests

\section{Highlights}

- $\quad$ Single asperity scratch tests were employed with three different tip sizes to study the influence of the size.

- The wear rate decreases with increasing size of the abrasive body.

- Testing at low loads revealed a new regime for the relation between the degree of penetration and the degree of wear. For low values of the degree of penetration the degree of wear tends to decrease with increasing degree of penetration. 


\section{Nomenclature}

$\begin{array}{ll}A_{g}=\text { Groove area } & {\left[\mathrm{mm}^{2}\right]} \\ A_{s}=\text { Shoulder area } & {\left[\mathrm{mm}^{2}\right]} \\ D_{p}=\text { Degree of penetration } & {[-]} \\ D_{p, k}=\text { Degree of penetration, according to Kato } & {[-]} \\ D_{p, m}=\text { Degree of penetration, measured } & {[-]} \\ d=\text { Depth of indentation } & {[\mathrm{mm}]} \\ H_{v}=\text { Hardness, Vickers } & {\left[\mathrm{N} / \mu \mathrm{m}^{2}\right]} \\ k=\text { Specific wear rate } & {\left[\mathrm{mm}^{3} / \mathrm{N} \cdot \mathrm{m}\right]} \\ l=\text { Scratch length } & {[\mathrm{mm}]} \\ N=\text { Normal load } & {[\mathrm{N}]} \\ R=\text { Tip radius } & {[\mu \mathrm{m}]} \\ R^{2}=\text { Coefficient of determination } & {[-]} \\ R_{a}=\text { Surface roughness } & {[\mu \mathrm{m}]} \\ R_{g}=\text { Groove radius } & {\left[\mu \mathrm{m}^{2}\right]} \\ s=\text { Sliding distance } & {[\mathrm{m}]} \\ V_{g}=\text { Groove volume } & {[\mathrm{mm}]} \\ V_{s}=\text { Shoulder volume } & {\left[\mathrm{mm}^{3}\right]} \\ w=\text { Groove-width } & {[\mathrm{mm}]} \\ \beta=\text { Degree of wear } & {[-]} \\ \theta=\text { Angle describing the geometry of the abrasive tip } & {[-]}\end{array}$

\section{$1 \quad$ Introduction}

Excessive wear can occur in machines, because of the abrasive action of for instance sand particles in the contact between steel machine components. To prevent such equipment from failing, detailed knowledge on the abrasive wear process is required. This work focuses on the relation between the geometrical properties of abrasive bodies and the wear they cause.

In two- and three-body abrasive wear processes the properties and characteristics of the abrasive bodies are an important aspect. These abrasive bodies can be either hard particles such as sand or wear debris that is present in the system, or hard protuberances on one of the surfaces, for instance due to embedding into a soft surface of before mentioned particles or surface roughness asperities. Properties such as the size and the geometry of these abrasive bodies have an influence on the predominant wear mechanisms, meaning that there is not necessarily a straightforward relation between the size and shape of the abrasive body and the resulting wear volume. Examples are described by [1-5], who state that in two-body abrasion, abrasive particles or protuberances with a size below approximately $100 \mu \mathrm{m}$ show a proportionate relation between size

$$
\text { B-4 }
$$


and wear caused, whereas for larger particles the wear caused is independent of size. Explanations of this size effect range from the scale dependent bluntness of particles and the benefits of work hardening to the wear resistance of the topmost nano- or micrometres of a surface. Even though the explanation for the observed size effect in abrasion is lacking, it can be concluded that the geometrical aspects of the abrasive particles play an important role. In the present work the basic mechanisms behind abrasive wear are studied by focusing on the abrasive wear of DIN St-52 samples caused by single protuberances made of quartz $\left(\mathrm{SiO}_{2}\right)$ as a function of their size and normal load.

In the literature, several models have been described to calculate abrasive wear [6-11]. However, improvements are needed for abrasion to be quantified to a reasonable extent, e.g. by incorporating the shape and motion of the abrasive body into the model. Besides the abrasive body characteristics, external conditions like the normal load influence the abrasive wear rate too. According to Archard's wear equation [12], the abrasive wear volume increases linearly with increasing normal load.

The aim of the work presented in this paper is to study the influence of the abrasive medium size on the wear process, in particular when the abrasive medium is sand. To clearly separate the size effect, this property needs to be isolated from other properties like shape, hardness and number of particles. Experimental methods that are often applied to study the particle size effect are using a multiple-particle setup, e.g. a pin-on-disk setup with a disk of abrasive paper. This enhances a coupling between particle size and the number of particles on the contact and the applied normal load, making it difficult to capture the actual size effect. Further, because of the multiple pass situation in such tests, the scratches will overlap, thereby influencing the wear rate $[9,13]$. Hence, the original contribution of the work presented in this paper is that the particle size effect is studied by performing single pass, single asperity scratch tests employing a pin-on-flat setup. Using various tip radii the influence of the size on the abrasive wear can be studied directly. Moreover, rather than quantifying the abrasive wear resistance of the counter material, this paper focuses on the properties of the abrasive itself; by utilizing quartz tips the test conditions will resemble a wear process where sand particles are the abrasive medium.

Using this method for studying the particle size effect is considered an essential starting point, to describe the scratching behaviour of particles in a situation of sliding contact. Later, multiple particle and multiple pass situations will be included to approach the real abrasive wear situation as much as possible. 


\section{Single asperity scratch tests}

One common way of studying abrasion in a controlled way is by sliding a pin or prismatic specimen over a surface [e.g. 6, 14]. Sliding the pin over a softer surface at a constant normal load and sliding speed enables the study of the wear process by examination of the wear scar. The setup used in this research is of the pin-on-flat type. A photograph of the setup is shown in Fig. 1. The tip is mounted in a sample holder, suspended in elastic hinges and connected to a $z$ stage to make sure the pin moves in the vertical $/ z$-direction only. The sample to be scratched is mounted on a linear $x y$-stage. The loads and displacements are controlled by piezo-electric actuators, force transducers and a PID (ProportionalIntegral-Derivative) control system.

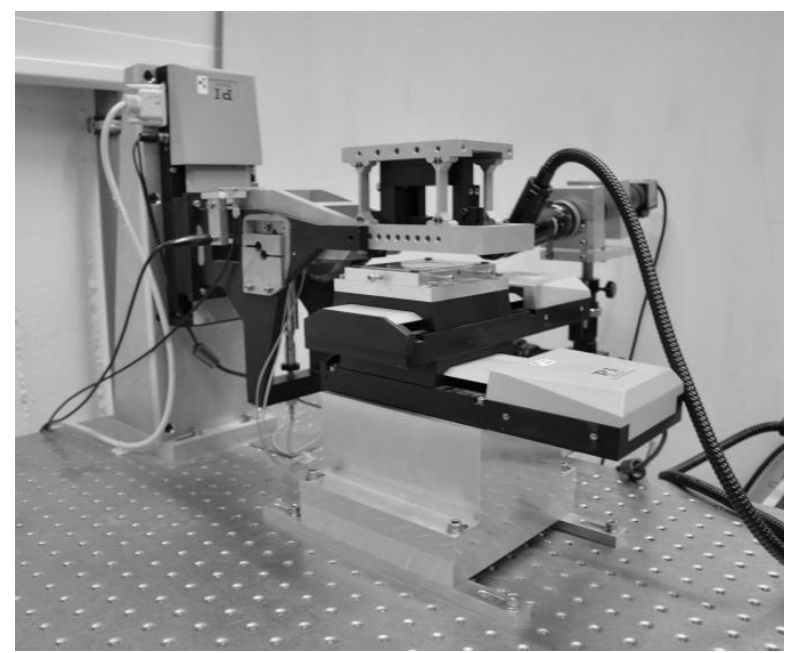

Fig. 1 Photograph of the experimental setup.

At the onset of a scratch test, the tip is lowered slowly towards the surface until contact is achieved. Then, the predefined normal load is applied and the $x$-stage is moved to provide the scratching motion. The PID system controls the applied normal load within $+/-0.05 \mathrm{~N}$. The $y$-stage is used to perform consecutive scratches.

Sand is a typical abrasive medium that causes considerable wear issues in many practical applications. Current research into abrasive wear, however, mainly focuses on either steel or diamond abrasive bodies and, hence, knowledge about abrasion by sand is lacking. The use of sand to study abrasion experimentally 
causes some issues though. Firstly, sand particles have random shapes, while the shape of the abrasive should be known and unambiguously described to investigate the basic geometrical effects on wear effectively. Secondly, it is difficult to properly mount individual sand particles. Hence, in this work scratches are made using tips produced of mono crystalline quartz $\left(\mathrm{SiO}_{2}\right)$. The quartz tips have a cone angle of $60^{\circ}$ and tip radii of 50, 100 and $200 \mu \mathrm{m}$. Fig. 2 shows photographs of the tips with the three sizes used, the photographs are obtained with a stereo microscope.

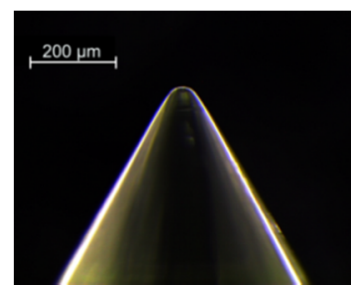

(a)

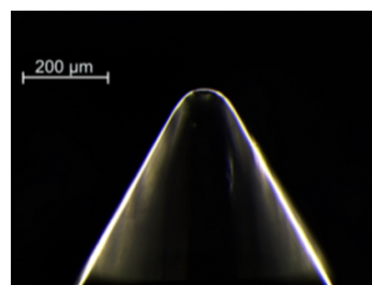

(b)

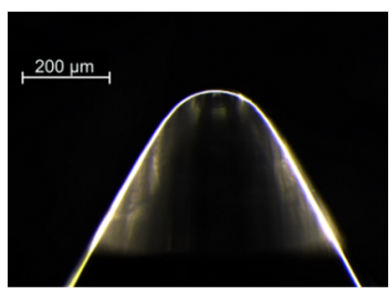

(c)

Fig. 2 Examples of quartz tips used, (a) $R=50 \mu \mathrm{m}$, (b) $R=100 \mu \mathrm{m}$, (c) $R=200 \mu \mathrm{m}$.

As the counter material, standard DIN St-52 steel is selected as it is commonly used in machine components. The steel specimen contact surfaces are polished to a roughness value of $R_{a}=6 \mu \mathrm{m}$. The mechanical properties of both the quartz and the steel used are reported in Table 1.

\begin{tabular}{|l|c|c|c|c|}
\hline Material & $\begin{array}{l}\text { Hardness } \\
(\mathrm{GPa})\end{array}$ & $\begin{array}{l}\text { Young's } \\
\text { Modulus }(\mathrm{GPa})\end{array}$ & $\begin{array}{l}\text { Density } \\
\left(\mathrm{kg} / \mathrm{mm}^{3}\right)\end{array}$ & $\begin{array}{l}\text { Poisson's } \\
\text { ratio (-) }\end{array}$ \\
\hline $\begin{array}{l}\text { Quartz } \\
\left(\mathrm{SiO}_{2}\right)\end{array}$ & 9.8 & $72-74$ & 2200 & 0.17 \\
\hline $\begin{array}{l}\text { Steel } \\
\text { (DIN St-52) }\end{array}$ & 0.2 & 210 & 7800 & 0.30 \\
\hline
\end{tabular}

Table 1 Mechanical properties of the materials tested.

Experiments are performed using the three different tip sizes with normal loads between 0.1 and $11 \mathrm{~N}$ and a constant sliding speed of $0.5 \mathrm{~mm} / \mathrm{s}$. By visual inspection in between tests it was verified that the geometry of the tips did not change progressively. Moreover, the tips were cleaned using a fine brush in between tests to remove possible steel wear debris. The created scratches are analysed using a confocal microscope, measuring the groove to determine the mechanism (scratching, ploughing) and the amount of wear. A schematic cross section of a typical wear scar is shown in Fig. 3 , with $A_{g}$ the groove area, $A_{s}$ the area of the shoulders, $w$ the groove-width and $d$ the depth of indentation.

\section{B-7}




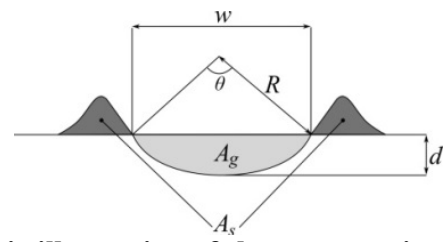

Fig. 3 Schematic illustration of the cross section of a wear scar.

Multiplication of $A_{g}$ and $A_{s}$ with the scratch length $l$ gives the groove volume $V_{g}$ and shoulder volume $V_{s}$. Then, the total amount of removed material is equal to $V_{g}-V_{s}$ and the degree of wear is determined using the following equation [15]:

$$
\beta=\frac{V_{g}-V_{s}}{V_{g}}
$$

with $\beta=1$ meaning ideal material removal (pure cutting and no ploughing) and $\beta=0$ indicating ideal ploughing or no material removal. Using this parameter, the specific wear rate $k\left(\mathrm{~mm}^{3} / \mathrm{N} \cdot \mathrm{m}\right)$ derived by Archard [12] can be expressed as:

$$
k=\beta \frac{V_{g}}{N \cdot s}
$$

with $N$ the normal load $(\mathrm{N})$ and $s$ the sliding distance $(\mathrm{m})$. Finally, the relative indentation depth can be characterized with the degree of penetration $D_{p}(-)$, which is equal to the ratio of the indentation depth and the half-width of the groove. When obtained from measured data, the degree of penetration $\left(D_{p, m}\right)$ is equal to:

$$
D_{p, m}=\frac{d}{w / 2}=\frac{2 d}{w}
$$

From this definition, Hokkirigawa and Kato [14] derived a theoretical equation for the degree of penetration, based on the geometry of the scratching tip:

$$
D_{p, t}=R \sqrt{\frac{\pi H_{v}}{2 N}}-\sqrt{\frac{\pi H_{v}}{2 N} R^{2}-1}
$$


with $R$ the tip radius $(\mu \mathrm{m})$ and $H_{v}$ the hardness of the wearing material $\left(\mathrm{N} / \mu \mathrm{m}^{2}\right)$. Note that higher values of $D_{p}$ are linked to cutting wear and lower values indicate ploughing wear.

\section{$3 \quad$ Results and discussion}

\subsection{Particle size effect}

The correlation between the experimentally determined and theoretical degree of penetration is verified in Fig. 4, plotting the degree of penetration predicted by Eq. 4 against the measured degree of penetration according to Eq. 3. Fig. 4 shows that the measured values are lower than the predicted ones. Although the data points could be represented by a straight line, its slope clearly deviates from the value of 1 represented by the dotted line in Fig. 4. The theoretical parameter represents the degree of penetration when the indenter is in the material, while the experimental parameter is based on the groove after removal of the indenter. As the elastic deformation of the counter material disappears upon load removal, that part of the indentation depth cannot be retrieved from the groove [16]. As a result, the measured degree of penetration is lower than the theoretical value that includes the elastic part. Since the elastic deformation has a linear relation with the applied load, the relative difference between the two parameters is constant and either of the two parameters can be used. The scratch results in this paper will be compared to $D_{p, t}$ rather than $D_{p, m}$. Note that to give an indication of the accuracy of the experiment, repeated scratch tests were performed under identical conditions (tip radius $R=100 \mu \mathrm{m}$ ). Moreover, the accuracy of the wear volume measurements with the confocal microscope was established by repeating confocal measurements on 1 wear track. This is why Fig. 4 shows multiple results at a value of $D_{p}$ of around 0.14 (repeated confocal measurements) and 0.21 (repeated scratch tests), corresponding with normal loads of 1 and $5 \mathrm{~N}$. The variation is expected to be caused by a transitional region for the active wear regime (alternating between ploughing and scratching) at higher loads. Referring to Fig. 4, this would explain the relative high variation at a value of $D_{p}$ of around 0.21 , indicating that certainly in the higher load regime location for the confocal measurement is important. Note that in the following figures, the average values for the two abovementioned conditions will be used. 


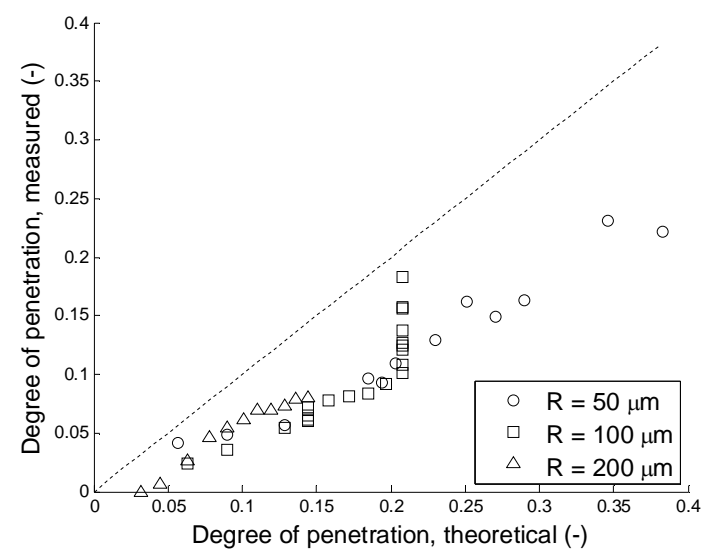

Fig. 4 Measured degree of penetration against theoretical degree of penetration as defined by Hokkirigawa and Kato [14].

When the measured wear volume is plotted against the corresponding normal load, Fig. 5 (a) is obtained. In consecutive experiments, the normal load was increased until the tip failed due to brittle fracture. This explains why the maximum applied loads are smaller for the smaller tip radii, because they fail at a lower load.

Assuming linear behaviour according to Eq. 2 (i.e. taking that $k, \beta$ and $s$ are constant), the data points for the different tip radii are fitted with straight lines and the slopes of the lines then are equal to the specific wear rate values $k$ reported in Table 2 . The differences in the wear rate values indicate a size effect: the wear rate of the steel caused by tips with a small radius is about twice the wear rate for the larger tips.

\begin{tabular}{|c|c|c|}
\hline Tip radius $(\mu \mathrm{m})$ & \multicolumn{2}{|l|}{ Wear rate } \\
\cline { 2 - 3 } & $\left(\cdot 10^{-4} \mathrm{~mm}^{3} / \mathrm{Nm}\right)$ & $\mathrm{R}^{2}$ \\
\hline 50 & 4.3 & 0.87 \\
\hline 100 & 1.8 & 0.92 \\
\hline 200 & 2.2 & 0.94 \\
\hline
\end{tabular}

Table 2 Specific wear rates for the different tip radii. 


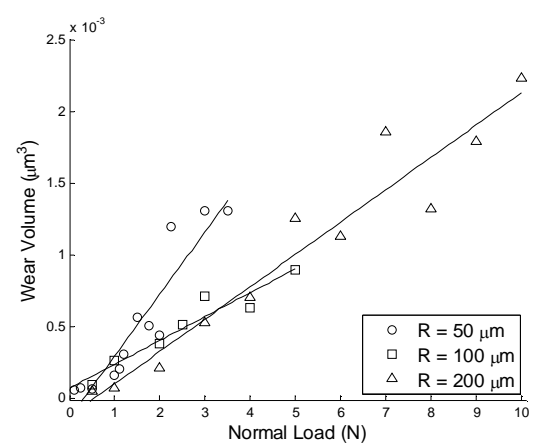

(a)

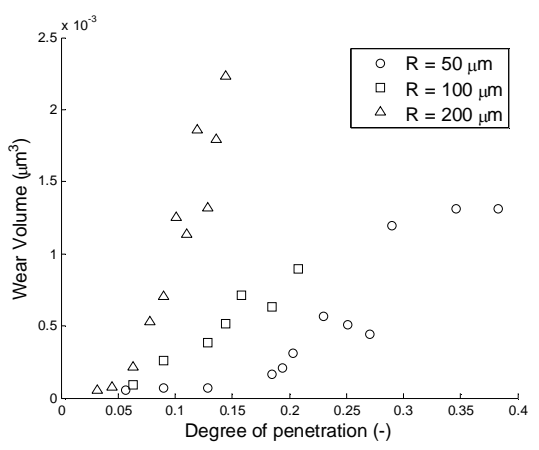

(b)

Fig. 5 Representative wear volume versus the normal load (a) and the degree of penetration (b).

To study the development of the different wear modes over the load regime, the total wear volume is plotted against the degree of penetration in Fig. 5 (b). Also here different trends are observed for the different tip radii. For all tip radii the wear volume increases with increasing degree of penetration, following parabolic trends. The wear volume increases with increasing tip size, because for constant $D_{p}$ the cross-sectional area of the groove is larger for larger tips.

Figs. 5 clearly illustrate the effects of size on the wear volume. The slopes for the fitted curves for the tips with radius 100 and $200 \mu \mathrm{m}$ are comparable, whereas the line for the tip with $R=50 \mu \mathrm{m}$ is different. From the literature, indeed a size effect has been described for abrasive bodies with sizes up to around $100 \mu \mathrm{m}$. Similarly, the wear rate is expected to increase with particle size. According to Fig. 5 (a) however, the smaller tip results in a higher wear rate than larger tips do. This can be explained with a geometrical analysis. The cross-sectional area $A_{g}$ of the groove can be expressed as:

$$
A_{g}=\frac{R_{g}^{2}}{2}(\theta-\sin \theta)
$$

with $R_{g}$ the groove radius, which is approximately equal to the tip radius and $\theta$ the angle between the left- and right contact point as shown in Fig. 6. 
Angle $\theta$ is equal to:

$$
\theta=2 \cos ^{-1}\left(\frac{R-d}{R}\right)
$$

with Eq. 5, the wear volume can be calculated theoretically, depending on the tip radius $R$ and indentation depth $d$.

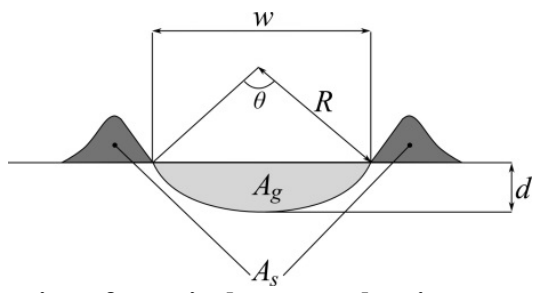

Fig. 6 Schematic cross section of a typical groove, showing contact radius $R$ and angle $\theta$.

In plastically deforming contacts, the contact pressure equals the hardness of the deforming material and thus the size of the contact area can be expressed as the ratio of the applied normal load and the hardness. This means that the contact area is independent of the tip radius, and the resulting wear volume can be plotted against the contact area for the different tip radii as in Fig. 7. This figure shows that for a constant contact area, and thus a constant load, the volume of the resulting groove increases with decreasing tip radius. Therefore, the wear rate increases with decreasing tip radius at a constant load.

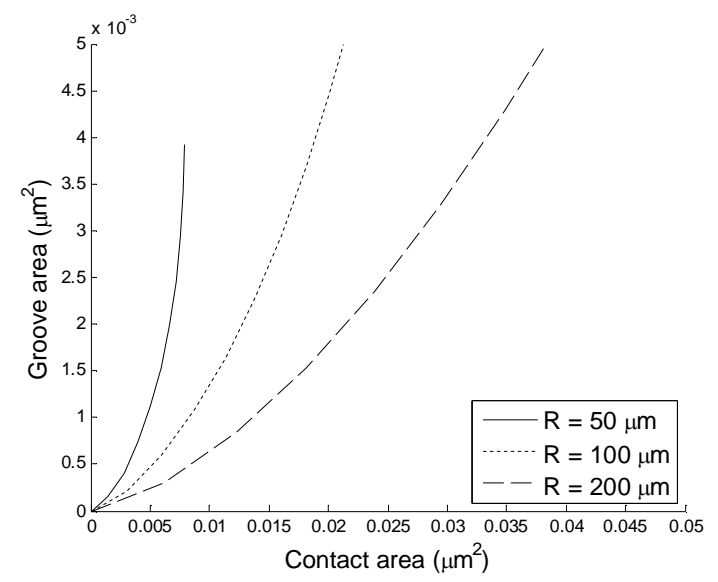

Fig. 7 Contact area versus groove area, calculated. 
Note that this effect opposes the size effect reported in the literature, where it is observed that the abrasive wear rate increases with increasing size. A possible explanation is that in the literature, see e.g. [5], the particle size effect is commonly studied using a grid of particles or tips, while in this paper the effects of only one tip are studied.

When using a grid and a constant total normal load, the load per tip decreases with decreasing tip size since the number of tips per unit area increases for smaller tips when the height distribution of the bearing area curve of the grid is kept constant. This results in a decreased amount of wear caused by each single tip. It is expected that the results of the present work, combined with earlier work [17], can be used to thoroughly examine the real three-body wear process and predict the associated wear rates.

\subsection{Wear mechanisms}

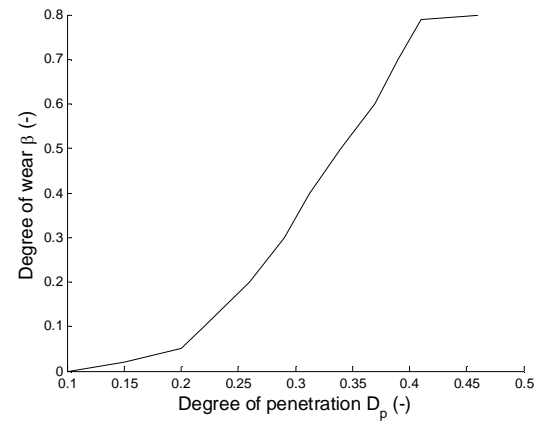

(a)

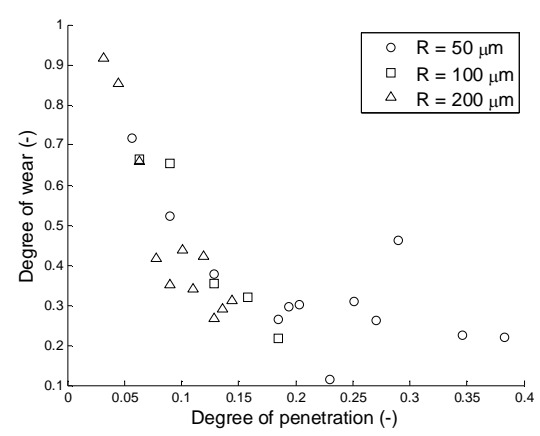

(b)

Fig. 8 Degree of wear versus degree of penetration adapted from Hokkirigawa and $\mathrm{Li}$ [18] (a) and according to the measurements (b)

According to literature, plotting the degree of penetration (Eq. 4) against the degree of wear (Eq. 1) should result in an S-shaped curve, as shown in Fig. 8 (a) based on the work of Hokkirigawa and Li [18]. The curve shows a degree of wear of 0 at low degrees of penetration, and an increase with increasing $D_{p}$ following an S-shaped curve. Typically, results at degrees of penetration below 0.1 are not reported, possibly because of limitations of the accuracy of the measurement equipment: the typical lateral dimensions of the wear scratch at such low values for $D_{p}$ are in the order of microns and the depth is in the order of nanometres. By employing a confocal microscope with a height resolution of less than $1 \mathrm{~nm}$ it is possible to measure the resulting wear scratches obtained at low degrees of penetration. Fig. 8 (b) shows degrees of wear obtained for low 
values of $D_{p}$. At very low values of the degree of penetration, a value of almost 1 is observed for the degree of wear and with increasing indentation depths the degree of wear drops towards 0 . The figure is an expansion of the existing curves, showing that that the degree of wear first decreases with increasing degree of penetration. This is because of plastic deformation of the counter surface. At low loads, and thus low degrees of penetration, the counter material tends to deform plastically, pushing the deformed material downwards rather than into the shoulders. This means that the groove volume $V_{g}$ has a relatively high value while no shoulders are formed and thus the shoulder volume $V_{s}$ is practically zero, leading to a high value for the degree of wear parameter $\beta$. As the degree of penetration increases, the material will no longer be pushed down but will go upwards and sideways, causing shoulders to form along the scratch and decreasing the degree of wear value.

The load range that could be used in the current set of experiments is limited because of brittle fracture of the quartz tip material. This means the degrees of penetration at which the wear has been studied are limited too. Note that the fracture of abrasive sand particles at high indentation depths and significant shear loads also occurs in practical applications.

\section{Conclusions}

The influence of abrasive body size on the abrasive wear in single asperity scratch tests has been studied. The work presented in this paper demonstrates the benefits of performing single pass, single asperity scratch tests in helping to understand the particle size effect. Contrary to the commonly applied wear tests using a multi-particle setup (e.g. by running a tip against a grid of particles), performing single asperity scratch tests with different tip radii enables to isolate and quantify a tip size effect. It has been found that both the amount of wear and the wear mechanism vary with size at a given load. Smaller tips cause more wear than larger tips do, because at constant load, the groove volume increases with decreasing tip radius. This observed size effect opposes the size effects reported by others.

At very low values for the degree of penetration it has been observed that plastic deformation causes high values of the degree of wear parameter. At these low loads and indentation depths the surface damage mechanism is not wear, but plastic deformation, without shoulder formation. 


\section{Acknowledgements}

The authors wish to thank Walter Lette and Erik de Vries from the supporting staff of the Laboratory for Surface Technology and Tribology at the University of Twente for their help running the experiments.

\section{$6 \quad$ References}

[1] A. Misra, I. Finnie, On the size effect in abrasive and erosive wear, Wear 65 (1980) $359-373$.

[2] I.M. Hutchings, Tribology: Friction and Wear of Engineering Materials, Edward Arnold, London, 1992.

[3] D.V. de Pellegrin, A.A. Torrance, E. Haran, Wear mechanisms and scale effects in two body abrasion, Wear 266 (1-2) (2009) 13-20.

[4] H. Sin, N. Saka, N.P. Suh, Abrasive wear mechanisms and the grit size effect, Wear 55 (1) (1979) 163-190.

[5] R. Gåhlin, S. Jacobson, The particle size effect in abrasion studied by controlled abrasive surfaces, Wear 258 (1-4) (1999) 118-125.

[6] M.A. Masen, M.B. de Rooij, D.J. Schipper, Micro-contact based modelling of abrasive wear, Wear 258 (1-4) (2005) 339-348.

[7] K.H. Zum Gahr, Modelling of two-body abrasive wear, Wear 124 (1) (1988) $87-103$.

[8] A.A. Torrance, Modelling abrasive wear, Wear 258 (1-4) (2005) 281-293.

[9] Y. Xie, J.A. Williams, The prediction of friction and wear when a soft surface slides against a harder rough surface, Wear 196 (1-2) (1996) 21-34.

[10] L. Fang, W. Liu, D. Du, X. Zhang, Q. Xue, Predicting three-body abrasive wear using Monte Carlo methods, Wear 256 (7-8) (2004) 685-694.

[11] Y. Xie, B. Bhushan, Effects of particle size, polishing pad and contact pressure in free abrasive polishing, Wear 200 (1996) 281-295.

[12] J.F. Archard, Contact and rubbing of flat surfaces, J. Appl. Phys. 24 (8) (1953) 981-988.

[13] A.A. Torrance, A new approach to the mechanics of abrasion, Wear 67 (1981) 233-257.

[14] K. Hokkirigawa, K. Kato, An experimental and theoretical investigation of ploughing, cutting and wedge formation, Tribology International 21 (1988) 5157.

[15] K. Kato, Wear mechanisms, New Dir. Tribol., published at the First World tribology congress (1997) 39-56.

[16] A.A. Torrance, The correlation of abrasive wear tests, Wear 63 (1980) 359370 . 
[17] M. Woldman, E. Van Der Heide, D.J. Schipper, T. Tinga, M.A. Masen, Investigating the influence of sand particle properties on abrasive wear behaviour, Wear 294-295 (2012) 419-426.

[18] K. Hokkirigawa, Z.Z. Li, The effect of hardness on the transition of abrasive wear mechanisms of steels, proc. Wear of Materials (1987) 585-593. 


\section{Paper C}

Classification of Particle Shapes in 3D, M. Woldman, E. Van Der Heide, T. Tinga and M.A. Masen, submitted to Applied Mathematical Modelling (52013).

C-1 


\section{C-2}




\title{
Classification of Particle Shapes in 3D
}

\author{
M. Woldman $\cdot$ E. Van Der Heide $\cdot$ T. Tinga $\cdot$ M.A. Masen
}

Abstract The study of particle shape is an important topic in several research fields, ranging from construction technology to pharmaceutics. Most of those studies generalize the shape of the particles by assuming spheres or by using two dimensional sharpness parameters such as roundness. To attain a reasonable description, a more adequate three dimensional characterisation for the shape of particles has been derived.

Particle shape properties can be defined on three levels; as shape on the global level, sharpness on the local level and roughness on the micro level. In this work, two methods for quantifying particle shape on the global and the local level are proposed. The shape can be defined based on either the variation in the outward normal direction along the particle's surface or the average distance from the particle's centroid to its surface.

The definitions are tested by comparing standard regular convex polyhedrons (Platonic solids) with well-defined decreasing sharpness, i.e. ranging from a tetrahedron to an icosahedron. By superimposing irregularities to these polyhedron shapes the method is assessed on the local level (sharpness) as well. By using a combination of the methods derived in this work, the shape of a particle can be adequately classified on both the global and local levels.

Keywords Particle $\cdot$ Shape definition $\cdot$ Regularity $\cdot$ Sharpness

\section{Nomenclature}

$a=$ the amplitude or bump height

$D=$ the diameter of the particle

$\bar{d}=$ the average distance from the centroid to the particle surface [-]

$\vec{d}=$ the direction of a triangle

$\vec{d}_{j}=$ the outward normal direction of the object triangle

$\hat{d}_{j}=$ the normalized distance between the centroid and the centre of the object triangle [-]

$\vec{d}_{k}=$ the outward normal of the surrounding triangles

$\hat{d}_{k}=$ the normalized distance between the centroid and the centre of the triangles surrounding the object triangle

$[-]$

$e_{r e g}=$ the threshold value for the regularity parameter

$e_{\text {sharp }}=$ the threshold value for the sharpness parameter 
$\bar{h}_{j}=$ the average absolute difference in the distance between the centroid and the object triangle and the distance between the centroid and the surrounding triangles [-]

$i=$ index over the number of points in the discretized point set [-]

$j=$ the index over the number of triangles

$[-]$

$k=$ the index over the surrounding triangles

$l=$ the number of points on a particles' cross section

$[-]$

$m=$ the total number of triangles

$n=$ the number of points in the discretized point set

$p=$ the index over the triangles that remain after comparing the average absolute deviation to the threshold

$\mathbb{R}=$ the set of real numbers

$r=$ the half-width of the bump

$[-]$

$r_{g}=$ the global regularity parameter

$r_{l}=$ the local regularity parameter

$s_{l}=$ the local sharpness parameter

$t=$ the index over the three points defining each triangle

$\vec{t}_{t}=$ the points defining a triangle

$\overline{\vec{t}}=$ the position of the centroid of a triangle on the particles' surface [-]

$w=$ the number of bumps

$[-]$

$x=$ the location of the bump

$\overline{\vec{x}}=$ position of the centroid

$\vec{x}_{i}=$ points in the discretized particle set

$z_{s}=$ function for the protrusion

$[-]$

$\theta_{j}=$ the angle between the outward normal vector of the object triangle and the outward normal vector of a surrounding triangle

$\bar{\theta}_{j}=$ the average sharpness angle

$\tau=$ the tolerance to the discretisation error

$\varphi=$ the phase shift

\section{$1 \quad$ Introduction}

The influence of the shape of particles on their behaviour has been well recognized and studied extensively. Particle shape plays a role in different research fields, among which tribology, pharmaceutics, powder technology, sediment research and construction technology are examples.

In tribology, the surface damage and wear that result from hard particles scratching through the surface is a major factor reducing lifetime and reliability of mechanical components. The influence of the shape of such abrasive particles on the wear has been has been well recognized and studied extensively [1-5]. 
The shape of the particles determines their orientation in the contact zone and whether they will be rolling or embedding in one of the contacting surfaces. Moreover, sharper particles will cause more wear.

In pharmaceutics, it is observed that the roundness of particles influences the filterability, flowability and bioavailibity [6] as well as the dissolution rate [7] of medicine. There are similarities with powder technology, where the regularity (or roundness) plays a role in the settling, flow, packing and rolling friction of the particles [8-11]. Sediment research is related to this as well, but includes the dependence of the deformational behaviour on the sphericity (or roundness) and roughness of particles [12]. Krumbein derived several methods to quickly quantify particle roundness or shape [13].

Lastly, one of the points of interest in construction technology is the influence of particle shape on the rheological properties [14] and material density [15] of mixtures containing particles.

Interestingly, the same characteristics describe the influence of shape in all these fields; form or regularity on the global level, angularity on the local level and texture or roughness on the micro level. However, a lot of work has been done in all of these fields, a method to sufficiently define the shape or sharpness of particles still lacks. Partly, this is because particle shape can be defined on different levels; shape itself on the global level (e.g. round, rectangular), sharpness, like irregularities or protrusions, on the local level and roughness on the micro level. This means that a good definition of shape should either capture all three levels, recognize the dominant one or describe the three levels separately. Moreover, particle shape is a three dimensional property, so any parameter should take all three dimensions into account. Current particle shape definitions are often $2 D$ and are often based on defining some kind of deviation from a standard shape like a circle [1-4].

This paper describes two methods for defining particle shape, based on the three dimensional discretized surface of the particle. The shape definitions are worked out, including any alterations that enable studying the shape on both the global and local levels defined above. Finally, the derived parameters are tested against both standard regular convex polyhedrons with varying sharpness and scans from actual particles.

\section{Particle shape parameters}

The particle shape will be defined on both the global and local level. On the global level, the general shape of the particle is considered. Global parameters are typically termed roundness or regularity, giving a measure for the deviation of the actual particle shape from a spherical particle. In this work, this measure will be termed regularity. On the local level, local distortions (like spikes or 
bumps) are taken into account by calculating the sharpness or angularity of the particle. Sharpness can only reasonably be defined on the local level, therefore a global definition for sharpness is not derived. The particle shape can also be described on the micro level using roughness or texture parameters. Because roughness can already be calculated with existing parameters like $R_{a}$ and $R_{q}$ though, the micro level is not considered in this work.

The definitions derived below are based on a discretisation of the shape of the particle. The particle is discretized by sampling the outer surface, yielding a set of surface points. Then, using a Delaunay triangulation, the surface points are combined into a mesh of triangles, where each triangle is appointed an outward normal direction. In a Delaunay triangulation no points in the set are present in the circles circumscribing the triangles, making sure all points are taken into account.

\subsection{Global regularity}

The variation in the distance between the centroid of the particle and the surface is a measure for the shape of the particle. When this variation is negligible, i.e., the distance is a constant for every point on the surface, the shape is spherical and regular, whilst varying values indicate that the shape is irregular. To calculate a global shape definition based on this regularity, first the position of the centroid $\overrightarrow{\vec{x}}$ of the discretized particle set with points $\vec{x}_{i}$ in $\mathbb{R}$ is determined:

$$
\overline{\vec{x}}=\frac{\sum_{i=1}^{n} \vec{x}_{i}}{n}
$$

with $n$ the number of points in the point set and $i$ the index over this number of points. The position of the centroid $\overline{\vec{t}}$ of a triangle on the particles' surface is:

$$
\overline{\vec{t}}=\frac{\sum_{t=1}^{3} \vec{t}_{t}}{3}
$$

with $t$ the index over the three points defining each triangle $\vec{t}_{t}$. The vector between $\overline{\vec{t}}$ and $\overline{\vec{x}}$ describes the direction $\vec{d}$ of the triangle:

$$
\vec{d}_{j}=\overline{\vec{t}}_{j}-\overline{\vec{x}}
$$

with $j$ the index over the number of triangles on the outer surface of the particle. After taking the norm of $\vec{d}_{j}$, the average distance from the centroid to the surface of the particle is calculated: 


$$
\bar{d}=\frac{\sum_{j=1}^{m}\left\|\vec{d}_{j}\right\|}{m}
$$

with $m$ the total number of triangles. Following this, the average absolute deviation of the distance $\vec{d}_{j}$ is derived, which will be termed the global regularity $r_{g}$ :

$$
r_{g}=\frac{\sum_{j=1}^{m}\left|\hat{d}_{j}-\bar{d}\right|}{m}
$$

\subsection{Local regularity}

On the local level, similar techniques as used for the global definition are applied, only now they focus on specific regions along the particle's outer surface. The regularity of a particle on this more local level also contains information about the particle's behaviour on the local scale.

The approach checks for differences in the distances from the centroid to the centre of an object triangle and those from its surrounding triangles:

$$
\bar{h}_{j}=\frac{1}{3} \sum_{k=1}^{3}\left|\hat{d}_{j}-\hat{d}_{k}\right|
$$

with $\bar{h}_{j}$ the average absolute difference in the distance between the centroid and the object triangle and the distance between the centroid and the surrounding triangles, $\hat{d}_{j}$ the normalized distance between the centroid and the centre of the object triangle, $\hat{d}_{k}$ the same distance for the triangles surrounding the object triangle and $k$ the index over the surrounding triangles. A high value of $\bar{h}_{j}$ thus indicates that triangle $j$ is at a considerably larger or smaller distance from the particle centroid than its surrounding triangles, and therefore constitutes a local shape irregularity. The definition for the local regularity $r_{l}$ for the complete particle then becomes:

$$
r_{l}=\frac{\sum_{j=1}^{m} \bar{h}_{j}}{m}
$$




\subsection{Local sharpness}

The approach for the local sharpness parameter is similar to the local regularity parameter, though the definition is significantly different. For sharpness the outward normal directions of the surrounding triangles are compared to that of the object triangle. The angle between these directions is a measure for the sharpness; when the angle approaches zero the shape is spherical and when the angle increases the shape starts deviating from spherical, increasing the sharpness. The inner product of the outward normal vector of the object triangle and the outward normal vector of a surrounding triangle equals:

$$
\vec{d}_{j} \cdot \vec{d}_{k}=\left\|\vec{d}_{j}\right\|\left\|\vec{d}_{k}\right\| \cos \theta_{j}
$$

Because both $\vec{d}_{j}$ and $\vec{d}_{k}$ have been normalized, the angle can be expressed as:

$$
\theta_{j}=\operatorname{acos}\left(\vec{d}_{j} \cdot \vec{d}_{k}\right)
$$

The average sharpness angle $\bar{\theta}_{j}$ for one object triangle is equal to:

$$
\bar{\theta}_{j}=\frac{1}{3} \sum_{k=1}^{3} \operatorname{acos}\left(\vec{d}_{j} \cdot \vec{d}_{k}\right)
$$

with $\vec{d}_{j}$ the outward normal of the object triangle and $\vec{d}_{k}$ the outward normal of its surrounding triangles.

Because the methods proposed in this work are based on the discretisation of the particles under study, there will always be some deviation from the actual particle shape. This for instance induces that the distance calculated with Eq. 4, which for a perfectly smooth spherical particle should give the same value for all triangles, turns out to not be constant. The regularity parameter will thus deviate from the expected value of zero. To prevent that this discretization effect largely affects the various shape parameters, a threshold is proposed to make sure the small deviations due to the discretisation are discarded. For simplicity, this is explained for the 2D case: regularity can be represented as the comparison between two adjacent points on a circular surface. Assuming a circular shape, the distance from the centroid to the surface should be constant. When the circular shape is approximated by a series of straight lines (i.e. the discretization), the resulting small deviations in distance should not affect the shape parameters. Therefore, differences in distances not exceeding a certain threshold value will be neglected. 
The threshold is defined as:

$$
e_{\text {reg }}=\tau \cdot|\bar{d}-\bar{d} \cos (\pi / l)|
$$

with $e_{\text {reg }}$ the threshold value, $\tau$ the tolerance to the error (set to 1.5) and $l$ the number of points on a $2 \mathrm{D}$ cross section of the $3 \mathrm{D}$ point set. In case of a circular cross section, $l$ is related to the total number of points $n$ in the point set:

$$
l=\sqrt{n}
$$

Note that the value of $\tau$ is obtained from a test on a discretized sphere with a number of points typical to real particle discretisations.

In the case of sharpness the threshold is defined by the change in the direction of the outward normal between two consecutive points on a circle. For a circle, the angle between such two directions is equal to $2 \pi$ divided by the number of points along the circle's surface:

$$
e_{\text {sharp }}=\tau \cdot \frac{2 \pi}{l}
$$

Only an angle larger than this normal angle would represent local regularity. Therefore, calculating $\theta_{j}$ for all triangles along the surface of a particle, comparing them to the threshold value, summing and averaging gives an estimate for the local sharpness $s_{l}$ of the particle:

$$
s_{l}=\frac{\sum_{j=1}^{p} \bar{\theta}_{j}}{p}
$$

with $p$ the index over the triangles that remain after comparing the average absolute deviation to the threshold.

\section{$3 \quad$ Application and Verification}

\subsection{Platonic solids}

On a global level, the methods described above can be verified by applying them to standard shapes. These shapes give an objective and intuitive indication of the sharpness; a tetrahedron is sharper than a sphere. The standard shapes used are regular convex polyhedrons (Platonic solids), ranging from a tetrahedron, cube (hexahedron), octahedron and dodecahedron to an icosahedron. A sphere is also

$$
\text { C-9 }
$$


included in the analysis, with varying grades of discretisation, to confirm the calculated sharpness indeed approaches the expected zero values. Pictures of the discretized geometries tested are shown in Fig. 1.
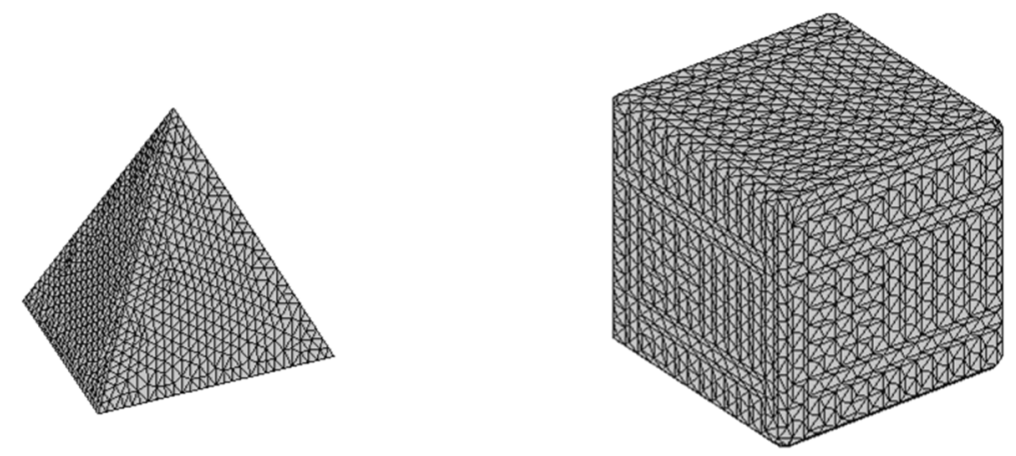

Tetrahedron

Hexahedron
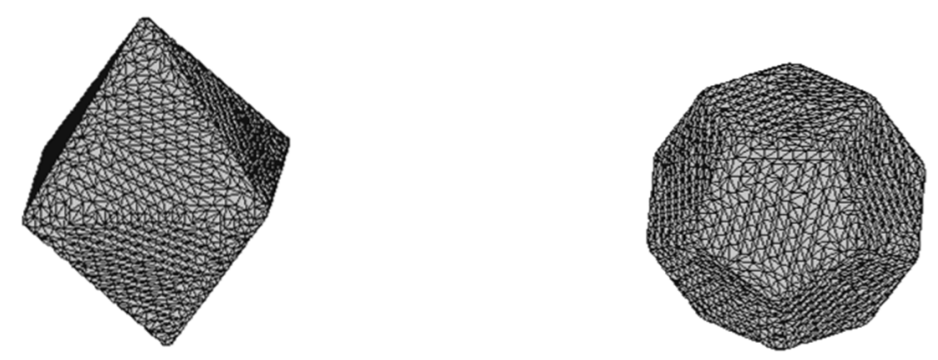

Octahedron

Dodecahedron
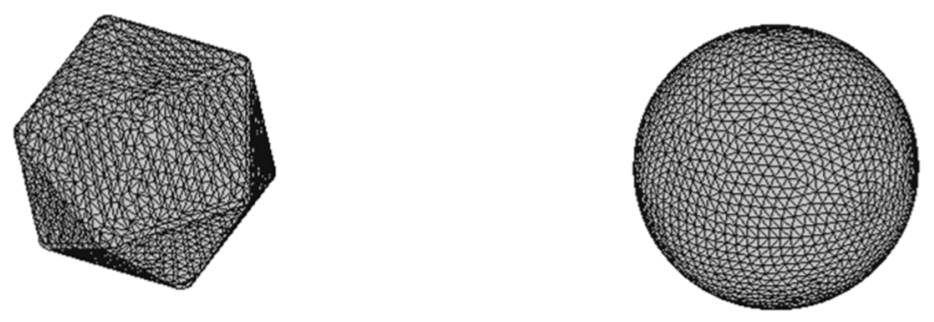

Icosahedron

Sphere

Fig. 1, Discretized standard 'particle' shapes.

C-10 


\begin{tabular}{|l|c|c|c|}
\hline \multirow{2}{*}{ shape } & global & \multicolumn{2}{l|}{ local } \\
\cline { 2 - 4 } & regularity & sharpness & regularity $\left(\cdot 10^{-3}\right)$ \\
\hline sphere & 0.00 & 0.00 & 0.14 \\
\hline icosahedron & 0.04 & 0.44 & 2.7 \\
\hline dodecahedron & 0.05 & 0.50 & 3.0 \\
\hline octahedron & 0.10 & 0.60 & 4.4 \\
\hline hexahedron & 0.10 & 0.71 & 5.3 \\
\hline tetrahedron & 0.21 & 1.91 & 14.5 \\
\hline
\end{tabular}

Table 1, Quantified shape definitions for various particles.

The results show a steady increase in the parameter values when the shapes get more irregular. The small (nearly zero) values for the local regularity parameter are expected, since the standard shapes do not have local irregularities. The sharpness parameter is more sensitive to changes than the regularity parameters. According to Figs. 2, plotting the parameter values against the number of faces on the solids tested, both global regularity and local sharpness give good predictions of the global shape. Note that the first five values represent the platonic solids and the last five the spheres with decreasing element size, proving the parameter values indeed approach zero when the shape gets more spherical. Moreover, the jumps in the parameter values reported in Table 1 and observed in Figs. 2 can be explained by looking at Figs. 1. The shapes of the tetrahedron and the hexahedron are significantly different, resulting in a big jump. The hexahedron and octahedron have more similar shape, causing a smaller jump. The big difference in shape between the octahedron and dodecahedron again gives a big jump and because the dodecahedron and icosahedron look similar the jump is smaller. 


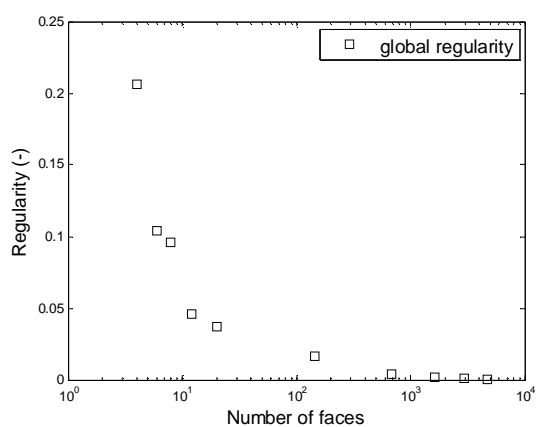

(a)

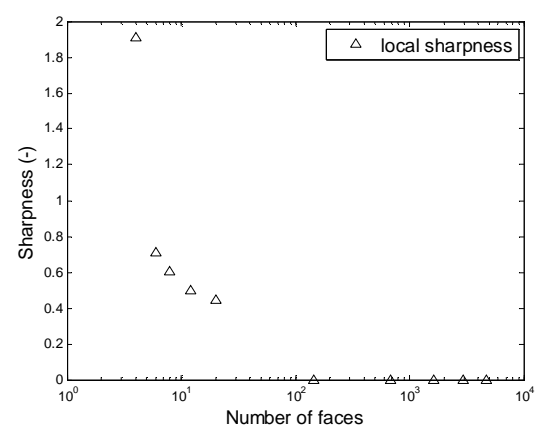

(c)

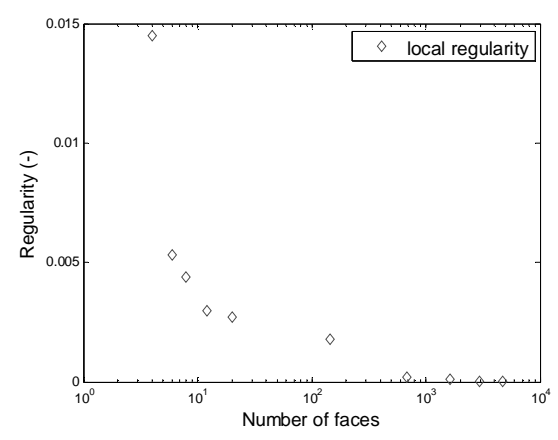

(b)

Fig. 2, Regularity $(a, b)$ and sharpness (c) parameter values against the number of faces on the solids tested.

\subsection{Shape variations}

For platonic solids, the sharpness changes significantly due to a change in the number of faces on the surface. The global shape, however, can also change without changing this number of faces, e.g. evolving a sphere into an ellipsoid. To test whether the shape parameters appropriately capture these shape changes, they are calculated for ellipsoids with different major semi-axis length and constant minor semi-axis length. The results are shown in Fig. 3, plotting the parameter value against the eccentricity of the ellipsoid and indicating the global regularity recognizes the changes, while the local regularity and sharpness parameters, as expected, do not. This implies that a combination of the global regularity and the local sharpness is a good way of describing global particle shape. Referring to Table 1, the octahedron for instance has a relative high value of $r_{g}$ and low value of $s_{l}$ compared to the values for the ellipsoid shown in Fig. 3. This indicates that higher values of both parameters represent an

\section{C-12}


increase in global sharpness, and when the local sharpness stays relatively low the particle deviates from a sphere but does not really get sharper (as for the ellipsoid).

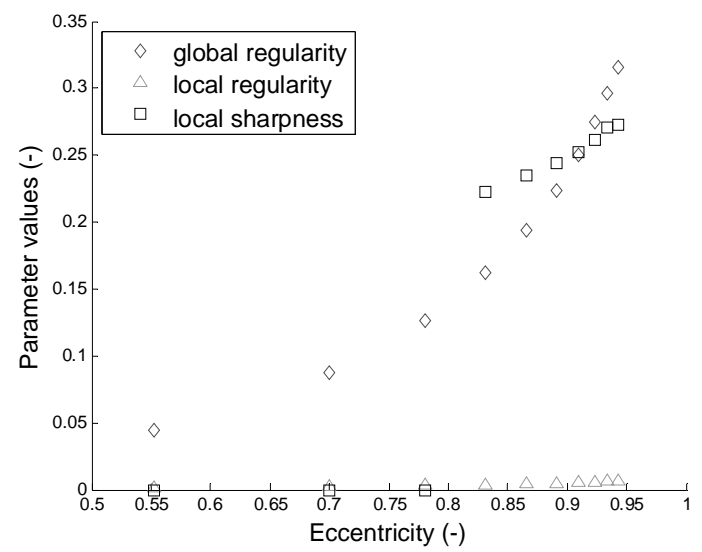

Fig. 3, Effect of changing the aspect ratio of an ellipsoid on the values of the three shape parameters.

\subsection{Local sharpness}

To analyze the defined parameters on the local level, a small protrusion is added to a spherical particle. The width and height of this protrusion $z_{s}$ are varied and can be described by a half-period sinusoidal function:

$$
z_{s}=\frac{a}{2} \sin (w \cdot x+\varphi)+\frac{a}{2}\left\{\begin{array}{l}
a=0: D / 50: D / 5 \\
w=1 \\
x=0: \pi / r: \pi \\
r=3,5,7 \\
\varphi=1.5 \pi
\end{array}\right.
$$

with $a$ the amplitude or bump height, $D$ the diameter of the particle, $w$ defining the number of bumps (with a value of 1 giving 1 bump), $x$ the location of the bump, $r$ the half-width of the bump and $\varphi$ the phase shift. By varying the values for $a$ and $r$ the sharpness of the bump can be changed. To give an overview, Figs. 4 show the resulting local particle sharpness for several values of $a$ and $r$ for $D=5$. 


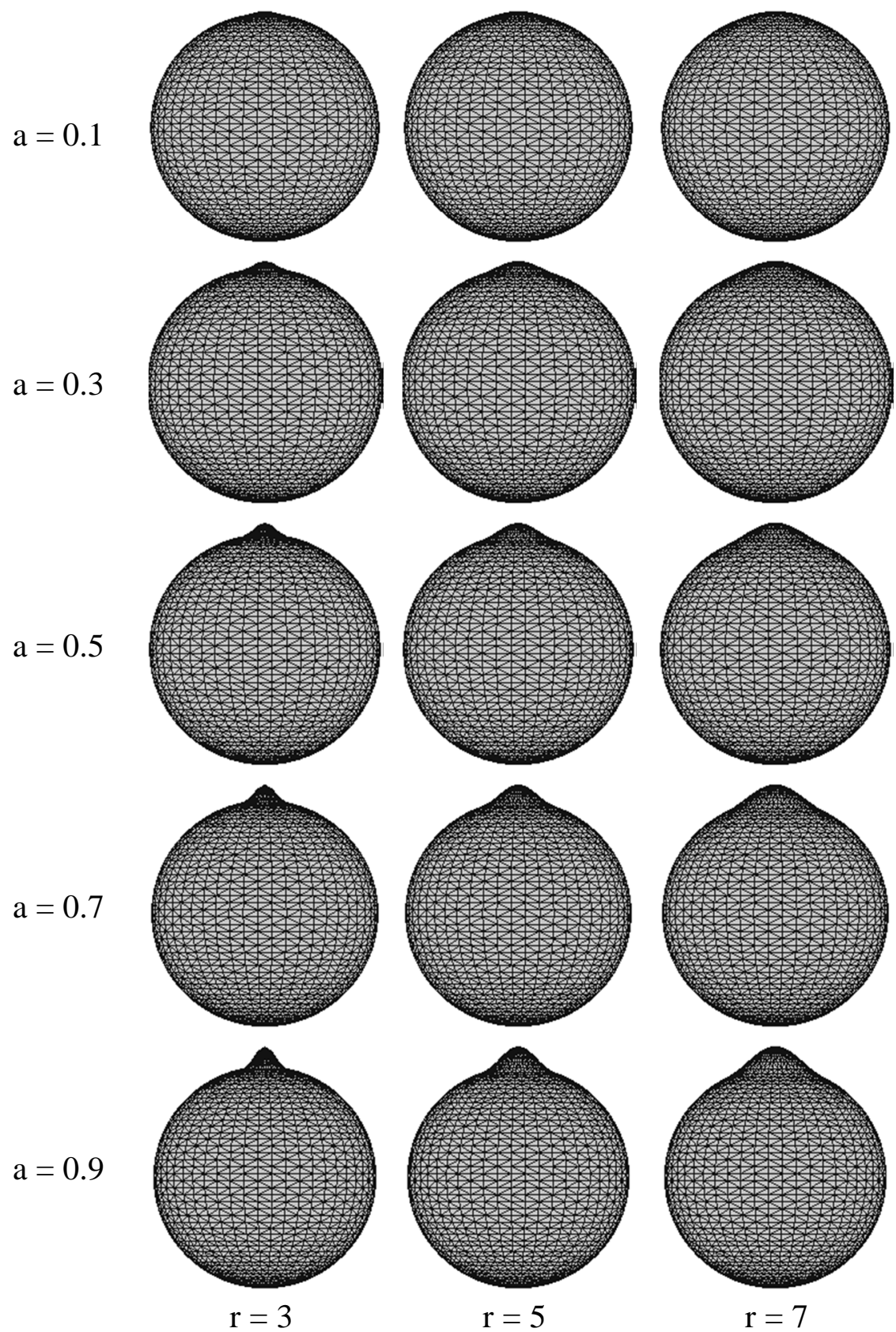

Fig. 4, Protrusions on a spherical particle for different values of the protrusion's amplitude and half-width.

$$
\text { C-14 }
$$


The local sharpness parameter is very well suited for identifying this protrusion. Fig. 5 shows the results for $r=7$, illustrating that the local sharpness parameter is sensitive to changes in the height of the bump, whereas the local and global regularity parameters are not. Similar trends to those observed in Fig. 5 are seen for other values of $r$ as shown in Fig. 6. Lower values of the bump height induce more of a change in the global shape rather than a local sharpness, which is therefore not recognized by the local sharpness parameter. Only when the bump is high and sharp enough, the sharpness parameter value will be unequal to zero. The small changes in geometry at small bump heights are however quantified by the regularity parameters, since they do show a slight increase with increasing bump height.

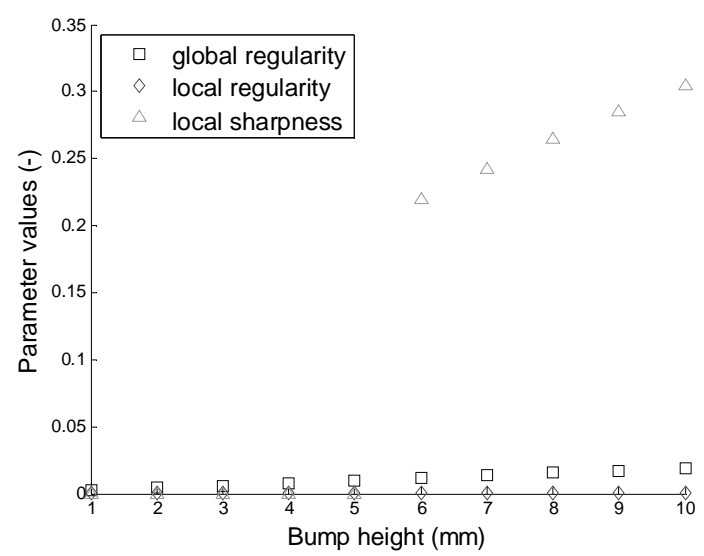

Fig. 5, Effect of bump height on the calculated global and local shape parameters.

In Fig. 6, the influence of the bump width $r$ is investigated by plotting the local sharpness parameter $\left(s_{l}\right)$ against the bump height for different values of $r$. It proves that lower values for $r$ and thus higher sharpness, expectedly gives higher values for $s_{l}$. Note that the sharpness values for $r=5$ first approach those of $r=3$ and then shift to those of $r=7$. Referring to Figs. 4 it is thought that this is because for lower bump heights, the bump shape for $r=5$ is similar to that of $r=3$, while for higher bump heights it is more similar to the one for $r=7$. 


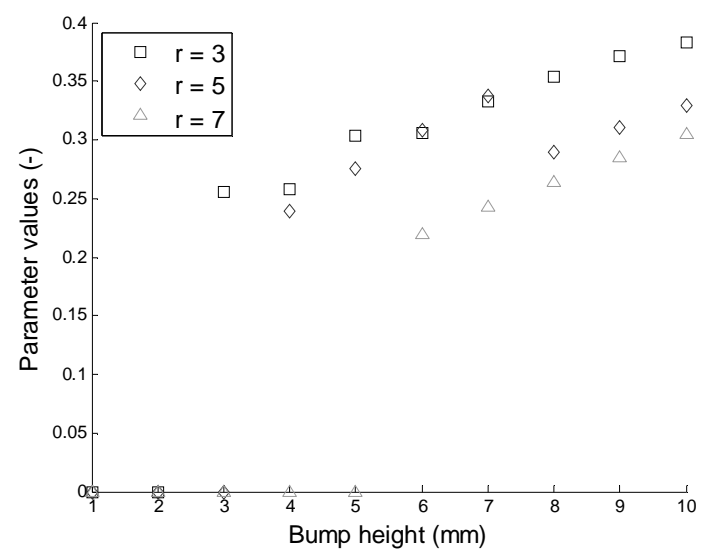

Fig. 6, Effect of bump radius on the calculated local sharpness parameter.

\section{Conclusions}

A method has been derived to quantify particle shape in $3 D$. Based on a discretized description of a particle, three types of parameters have been defined to describe its shape on both the global and local level. These methods are either based on the change in the distance between the particle's center and its surface (global and local regularity) or the change in normal outward direction along the particle's surface (local sharpness). To describe overall particle shape, a combination of the global regularity parameter and the local sharpness parameter is recommended. The local sharpness parameter is a good means of recognizing local irregularities. In future work, the parameters derived here will be related to the wear caused by the abrasive action of particles.

\section{Acknowledgements}

The authors wish to thank Axel Homborg for his assistance and fruitful discussions. 


\section{References}

[1] A.A. Torrance, Modelling abrasive wear, Wear 258 (1-4) (2005) 281-293.

[2] D.V. de Pellegrin, G. Stachowiak, Simulation of three-dimensional abrasive particles, Wear 258 (1-4) (2005) 208-216.

[3] T. Al-Rousan, E. Masad, E. Tutumluer, T. Pan, Evaluation of image analysis techniques for quantifying aggregate shape characteristics, Constr. Build. Mater. 21 (2007) 978-990.

[4] D.V. de Pellegrin, N.D. Corbin, G. Baldoni, A.A. Torrance, Diamond particle shape: Its measurement and influence in abrasive wear, Tribol. Int 42 (2009) 160-168.

[5] M. Woldman, E. Van Der Heide, D.J. Schipper, T. Tinga, M.A. Masen, Investigating the influence of sand particle properties on abrasive wear behaviour, Wear 294-295 (2012) 419-426.

[6] M. Kempkes, J. Eggers, M. Mazzotti, Measurement of particle size and shape by FBRM and in situ microscopy, Chem. Eng. Sci. 63 (2008) 4656-4675.

[7] M. Mosharraf, C. Nyström, The effect of particle size and shape on the surface specific dissolution rate of microsized practically insoluble drugs, Int. J. Pharm. 122 1-2 (1995) 35-47.

[8] F. Podczeck, A shape factor to assess the shape of particles using image analysis, Powder Technol. 93 (1997) 47-53

[9] K. Yamamoto, T. Inoue, T. Miyajima, T. Doyama, M. Sugimoto, Measurement and evaluation of three-dimensional particle shape under constant particle orientation with a tri-axial viewer, Adv. Powder Technol. 132 (2002) 181-200.

[10] M.A. Taylor, Quantitative measures for shape and size of particles, Powder Technol. 124 1-2 (2002) 94-100.

[11] P.W. Cleary, M.L. Sawley, DEM modelling of industrial granular flows: 3D case studies and the effect of particle shape on hopper discharge, Appl. Math. Model. 262 (2002) 89-111.

[12] I. Kock, K. Huhn, Influence of particle shape on the frictional strength of sediments - A numerical case study, Sediment. Geol. 196 (2007) 217-233.

[13] W.C. Krumbein, Measurement and geological significance of shape and roundness of sedimentary particles, J. Sediment. Res. 11 (2) (1941) 64-72.

[14] S.T. Erdoğan, N.S. Martys, C.F. Ferraris, D.W. Fowler, Influence of the shape and roughness of inclusions on the rheological properties of a cementitious suspension, Cem. Concr. Compos. 305 (2008) 393-402.

[15] P.Stroeven, J. Hu, Z. Guo, Shape assessment of particles in concrete technology: 2D image analysis and 3D stereological extrapolation, Cem. Concr. Compos. 311 (2009) 84-91. 



\section{Paper D}

A Finite Element approach to Modelling Abrasive Wear Modes, M.Woldman, E. van der Heide, T. Tinga, G. Limbert and M.A. Masen, submitted to Tribology Transactions (1-2014).

D-1 
D-2 


\title{
A Finite Element approach to Modelling Abrasive Wear Modes
}

\author{
M. Woldman - E. Van Der Heide - T. Tinga - G. Limbert • \\ M.A. Masen
}

\begin{abstract}
Abrasive wear causing damage to e.g. steel machine components is a serious problem. Performing maintenance timely can prevent such equipment from failing because of this wear, but this requires the amount of wear to be predicted to a reasonable extent. Hence, the aim is to derive a model to predict the amount of wear caused by the abrasive action of sand particles.
\end{abstract}

An important aspect to this model is the influence of the essential particle properties on abrasive wear. It however is difficult to study the wear behaviour of a sliding third body experimentally and hence, this is done with a numerical analysis. Finite element (FE) simulations were run with ABAQUS/Explicit, modelling a tip scratching a smooth surface.

The model is verified by comparing the results with a set of experiments performed earlier [1], wherein single asperity scratch tests were performed to isolate the influence of particle size. The first results indicate that the mechanisms observed in the wear experiments can be reproduced with the model, giving confidence that a model for the prediction of abrasive wear rates caused by sand particles can be derived.

Keywords Abrasive wear $\cdot$ Wear modelling

\section{$1 \quad$ Introduction}

Abrasive wear caused to machine components is a problem for equipment operating in sandy environments. The damage inflicted on e.g. plain and roller bearings affects the performance of the machine, reducing maintenance intervals and ultimately leading to failure. In order to optimize the maintenance strategy and prevent failure from arising, it has to be possible to understand and predict the abrasive process. In this work, a model is proposed to predict third body abrasive wear rates and to help understand the abrasive wear process.

Abrasion is a rather complex process, influenced by a variety of parameters, ranging from the contacting material properties to environmental and operating

$$
\text { D-3 }
$$


conditions like applied loads and the relative humidity. In third-body abrasion, a major part of the influential parameters are the properties of the particles that cause the wear. According to e.g. [2, 3], the most important particle properties influencing abrasive wear are the size, the shape and the hardness. Although a lot of research effort has been put into establishing the relationships between these parameters and abrasion [4-11], the mechanisms are still not fully understood and more in-depth knowledge is required to be able to define and quantify the relationships in a more general way. One way of doing this is with the help of a model. In earlier work by the authors the influence of particle size and -shape were studied experimentally [1, 12]. More specifically, in [1] the influence of particle size on abrasion was studied by performing single asperity scratch tests. Spherical $\mathrm{SiO}_{2}$ tips with varying radii were used to scratch smooth steel surfaces. In real applications, however, particles will not be spherical but have a more random shape, which has to be taken into account to be able to predict the wear arising to a reasonable extent. In [13] particle shape definitions were derived, quantifying the shape of random particles as a deviation of a spherical particle and thus to describe to shape of a particle. They however need to be verified in order to be able to state the influence of particle shape on abrasive wear. This can be done by modelling the experimental procedure used in [1] and extending this to situations with various tip sizes. In this way, the particle shape effect can be verified and a more general model for the wear caused by the abrasive action of particles can be derived.

This paper treats a finite element model for the ploughing and scratching action of a $\mathrm{SiO}_{2}$ tip with a predefined radius over a smooth steel surface. By using a selection of tips with their geometry varying from spherical to pyramidal and verifying them with the results from [1], both the shape parameters from [13] can be verified and a general model for a ploughing and scratching asperity can be obtained. The set-up of the model will be discussed in the following section. After this the model is verified and applied to different tip shapes.

\section{$2 \quad$ Model definition}

The abrasive wear finite element model is developed using Abaqus/Explicit. The explicit option is used to include the plastic deformations and material removal involved in abrasive wear processes. The model consists of a discrete rigid tip and a flat deformable surface. In the simulations the tip is constrained in all directions, while the surface is positioned under the tip and moves so that a groove is formed on the surface. 


\subsection{Tip geometry and properties}

The abrasive medium is initially modelled based on the tip used in the single asperity scratch tests described in [1]. The tip used is shown in Fig. 1. To minimize the number of elements and thereby the computational time, the base of the tip is not modelled entirely. This can be done without introducing errors because the base is only used for clamping and does not influence the scratching behaviour.

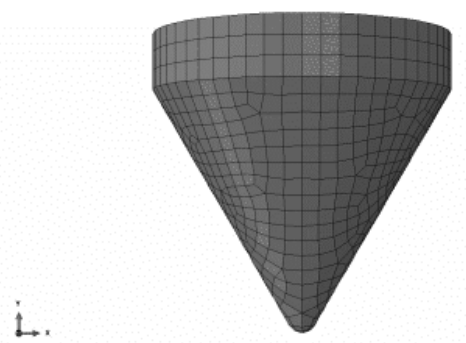

Fig. 1 Representation of the tip used in the numerical simulations, spherical $R=50 \mu \mathrm{m}$.

The tip material is quartz, Table 1 gives the relevant properties of this material. During abrasive wear the surfaces deform plastically and, because the tip is much harder than the steel surface and practically does not wear during the scratching movement, it is considered rigid, reducing the computation time. The reference point for the rigid body, where in Abaqus the possible boundary conditions, loads and displacements and material properties are applied, is defined as the apex of the tip. Although the tip has to be modelled accurately in order to maintain the spherical geometry, the mesh is kept as coarse as possible to decrease the computational time. The total number of elements on the tip is 1200 , the approximate element size around the apex is 0.005 .

Although a rigid body will not deform and therefore no material properties need to be specified, in Abaqus/Explicit a mass needs to be specified. The average mass of the tips that were employed in the single asperity scratch tests discussed in [1] is $18 \mathrm{mg}$ and therefore this value is used in the numerical model. The tip is fully constrained to prevent it from moving during the simulation. 


\begin{tabular}{|c|c|c|}
\hline Material & Steel (DIN St-52) & Quartz $\left(\mathrm{SiO}_{2}\right)$ \\
\hline Hardness $(\mathrm{GPa})$ & 2 & 9.8 \\
\hline Young's Modulus $(\mathrm{GPa})$ & 210 & 73 \\
\hline Density $\left(\mathrm{kg} / \mathrm{m}^{3}\right)$ & 7800 & 2200 \\
\hline Poisson's ratio $(-)$ & 0.30 & 0.17 \\
\hline
\end{tabular}

Table 1 Mechanical properties of the materials tested.

\subsection{Specimen geometry and material behaviour}

The surface to be scratched is modelled similar to the steel specimens used in the single asperity scratch tests. The specimen material is St. 52, for which the relevant properties are listed in Table 1. The specimen used in Abaqus is shown in Fig. 2 (a). It is not a representation of the complete specimen as used in the experiments in [1], but only the region that is influenced by the scratching movement of the tip is included. By applying symmetry boundary conditions to the sides, the rest of the specimen is still simulated, but elements do not need to be appointed. This is done to decrease the total number of elements and thus the computational time. Typical wear grooves in [1], resulting from the scratching of a tip with a radius of $50 \mu \mathrm{m}$ is up to a few micrometres deep, with a width in the order of several tens of micrometres, and therefore the dimensions of the modelled scratched specimen are $300 \times 200 \times 15 \mu \mathrm{m}$, whilst the dimensions of the individual elements are $1 \mu \mathrm{m}$, which is small enough to ensure that minor changes in the geometry can be simulated.

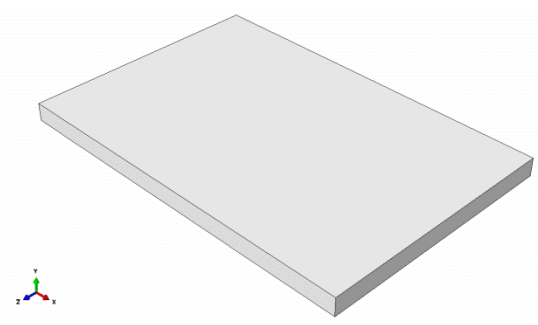

(a)

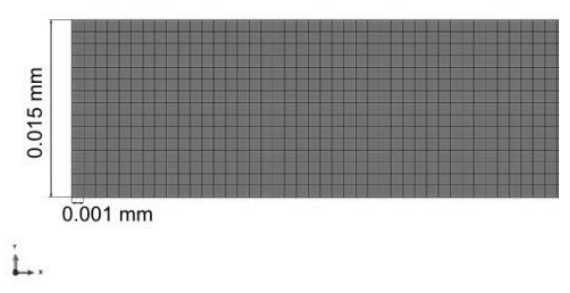

(b)

Fig. 2 Representation of the specimen used in the numerical simulations (a) with a cross section to show the element size in (b).

The material model for the specimen includes wear in the form of plasticity as well as element removal. The plastic material behaviour is modelled by extending the linearly elastic part of the stress-strain curve with a plastic part 
beyond the yield point. In Abaqus this is done by defining tables with values for the stress depending on the plastic strain for various values of the strain rate, see Fig. 3, which has been adapted from [14] for a St. 52 steel alloy similar to the one that was applied in the single asperity scratch tests.

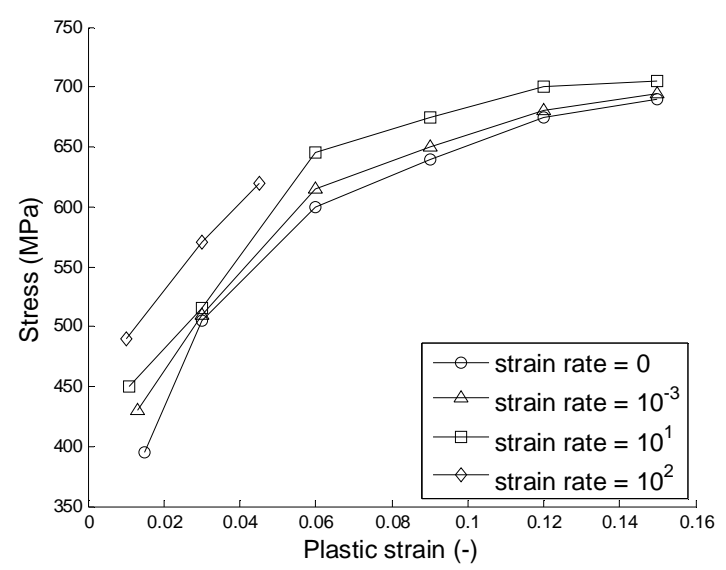

Fig. 3 Plastic material behaviour of the steel specimen at different strain rates $\left(\mathrm{s}^{-1}\right)$.

To account for damage under compressive stress conditions, the Johnson-Cook failure model is used [15]. With this model the fracture strain is calculated based on the pressure, strain rate and temperature. Damage is quantified by the damage parameter $D$ :

$$
D=\sum \frac{\Delta \varepsilon}{\varepsilon^{f}}
$$

with $\Delta \varepsilon$ the increment of equivalent plastic strain during an integration cycle and $\varepsilon_{\varepsilon}^{f}$ the equivalent plastic fracture strain [15]. Fracture will occur when the damage parameter $D$ is equal to 1 . The fracture strain at room temperature is defined as:

$$
\varepsilon^{f}=\left[D_{1}+D_{2} \cdot e^{D_{3} \cdot \sigma^{*}}\right]\left[1+D_{4} \cdot \ln \dot{\varepsilon}^{*}\right]
$$

with constant values for $\mathrm{D}_{1}-\mathrm{D}_{4}$, the pressure-stress ratio $\sigma^{*}$, the dimensionless strain rate $\dot{\varepsilon}^{*}$ and $\sigma^{*} \leq 1.5$. These parameters are defined as:

$$
\begin{gathered}
\sigma^{*}=\frac{\sigma_{\mathrm{m}}}{\bar{\sigma}} \\
\dot{\varepsilon}^{*}=\frac{\dot{\varepsilon}}{\dot{\varepsilon}_{0}}, \text { with } \dot{\varepsilon}_{0}=1 \mathrm{~s}^{-1}
\end{gathered}
$$


with $\sigma_{\mathrm{m}}$ the average normal stress, $\bar{\sigma}$ the equivalent von Mises stress and $\dot{\varepsilon}$ the actual strain rate. The material parameters $D_{1}-D_{4}$ have been obtained empirically for steel by [15], as listed in Table 2.

\begin{tabular}{|c|c|}
\hline Parameter \# & Parameter value, steel \\
\hline $\mathrm{D}_{1}$ & 0.05 \\
\hline $\mathrm{D}_{2}$ & 3.44 \\
\hline $\mathrm{D}_{3}$ & -2.12 \\
\hline $\mathrm{D}_{4}$ & 0.002 \\
\hline
\end{tabular}

Table 2 Parameter values for the Johnson-Cook model.

The Johnson-Cook model induces that the element will be removed when the strain in an element exceeds the fracture strain as defined in Eq. 2. This leads to volume loss of the surface and thus to wear of the scratched material.

Whilst the Johnson-Cook model applies to damage under compressive stress conditions, damage may also be caused by shear stresses acting in the deforming material. Certainly when large deformations arise, local shear bands may form; zones of large shear strains causing damage to the material and ultimately leading to failure. In Abaqus, a shear criterion can be included in the material model to predict the onset of damage due to this formation of shear bands. Referring to [16], the equivalent plastic strain at the damage initiation can be calculated as a function of the shear stress ratio and the strain rate. If the incremental increase in the equivalent plastic strain yields the total plastic strain to exceed this limit, failure will take place and the element for which this criterion is met will be removed.

\subsection{Simulations}

As stated in the previous section, the required geometrical features of the model are quite detailed as the radius of the tip and the scratch depth are in the order of micrometres. In order to appropriately describe these features, the element size needs to be of the same order or even smaller. 
In Abaqus/Explicit simulations the critical time increment $\Delta t_{\text {cr }}$ above which the simulation becomes unstable is related to the element size according to:

$$
\Delta t_{\mathrm{cr}}=\frac{l}{c}
$$

with $l$ the smallest element length (m) and $c$ the wave speed along an element $(\mathrm{m} / \mathrm{s})$ :

$$
\mathrm{c}=\sqrt{\frac{E}{\rho}}
$$

with $E$ Young's modulus (MPa) and $\rho$ the material density $\left(\mathrm{kg} / \mathrm{m}^{3}\right)$. According to Eq. 5.4, the required small element size induces a small critical time step. In combination with the typically low sliding speeds of the indenter contact (less than $1 \mathrm{~mm} / \mathrm{s}$ ) this means that the calculation times for the simulations become very long, in the order of weeks, even when running the simulations on multiple processors. To speed up the calculation time, some computational tricks may be performed.

Firstly, the calculation time can be decreased by increasing the sliding speed, which is an option when the materials are not strain rate dependent or when the strain rate dependency can be changed in order to account for material behaviour at lower speeds. As shown in Fig. 3, in the current situation the material is strain rate dependent, and thus the material's strain rate dependencies are artificially changed to account for increased sliding speeds. In practice this means that the $\mathrm{x}$-axis of the curves in Fig. 3 is increased to match the range of the sliding speed. Thus, the artificial increase of the sliding speed from $1 \mathrm{~mm} / \mathrm{s}$ to $9000 \mathrm{~mm} / \mathrm{s}$ to speed up the calculation requires the strain rates to vary accordingly. A comparison between the results of a slow simulation with the original material stain rate dependencies and a fast simulation with altered material properties indeed did not show any significant differences and hence the computational speeding up is applied in the present work.

Second, mass scaling can be performed to increase the critical time step. As discussed by [17] a higher wave speed results in a reduction of the critical time above which the calculation becomes unstable. This can be achieved by artificially increasing the material density, as long as the kinetic energy in the material remains small compared to the internal energy. Fig. 4 shows the ratio of the internal energy and the kinetic energy as a function of the simulation time when the density of the scratched sample is increased ten-fold (from $7800 \mathrm{~kg} / \mathrm{m}^{3}$ to $78000 \mathrm{~kg} / \mathrm{m}^{3}$ ). The figure shows that this artificially increased density does 
not influence the simulation results. Artificially changing the strain rate sensitivity and the material density, allows an increase of the time step and thus a decrease of the computational time from around one day to around three hours.

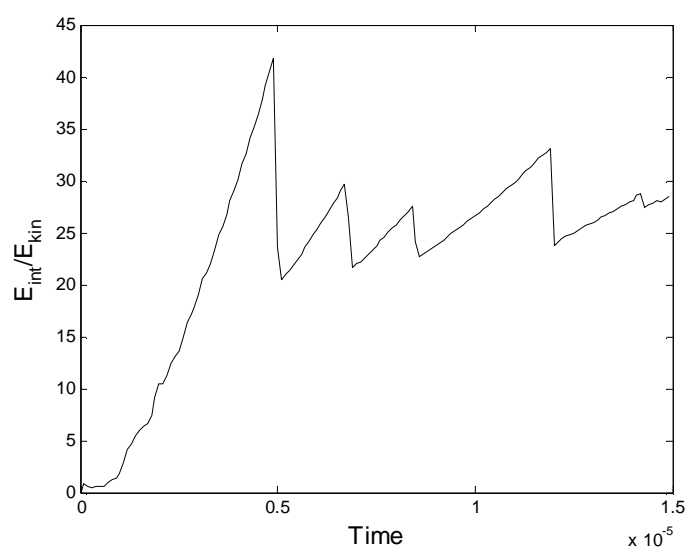

Fig. 4 Energy ratio.

The modelled scratching movement simulates the single asperity scratch tests described in [1]; the tip is fixed and the specimen is translated through under the tip. An important difference, however, is that the Abaqus/Explicit simulations are performed using displacement controlled conditions, whilst the experiments were done with a controlled normal load. The reason for this is that when simulations that possibly imply disconnected bodies are load-controlled, the stiffness matrix becomes singular [18]. In displacement control this is not possible and hence, displacement control is used in the simulations described in this paper. 


\section{$3 \quad$ Single asperity wear mechanisms}

The result of a single asperity scratch test is a groove formed on the specimen by the sliding movement of the tip across the surface, an example of which is shown in Fig. 5.

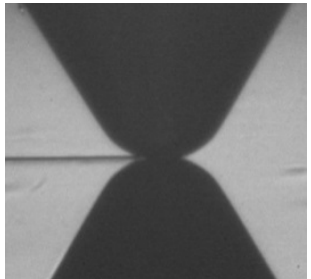

(a)

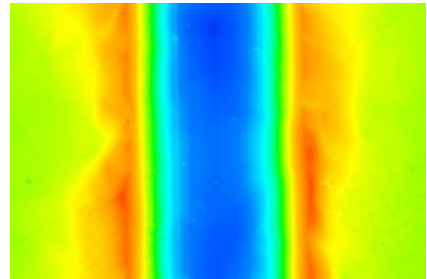

(b)

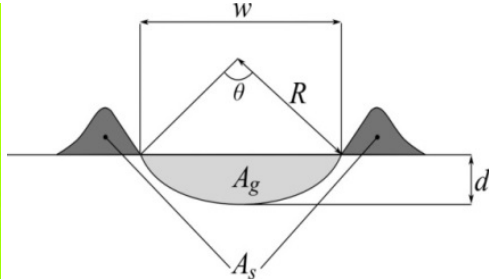

(c)

Fig. 5 Example of a groove resulting from a single asperity scratch test, (a) during the experiment, (b) result of a confocal microscope height profile measurement (blue is low, red is high) (c) Schematic illustration of the cross section of a wear scar.

Based on experiments and inspired by the slip line models of Challen and Oxley [19], [20] showed that there are three primary abrasive mechanisms that may occur in the contact between a scratching tip and a scratched surface, with the predominant mechanism depending on the conditions, such as the applied load or the indentation depth, quantified by the degree of penetration, and the friction or the shear strength of the contacting interface between the two materials.

\section{Ploughing}

At low loads and thus at low values for the degree of penetration the tip will plough the surface, forming a groove with a cross section as shown in Fig. 6. In this situation no actual material loss takes place, the material is rather pushed downwards and into the shoulders.

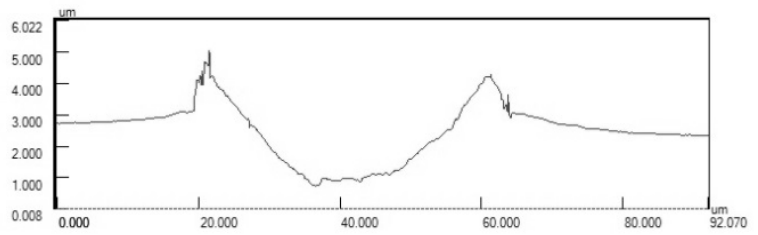

Fig. 6 Example of an experimental groove, $R=100 \mu \mathrm{m}, \mathrm{d}=0.002 \mu \mathrm{m}$.

D-11 


\section{Cutting}

The most severe mechanism of abrasive wear is cutting. In this case (almost) all material from the groove is removed completely in the form of a chip, and no or hardly any shoulders develop along the sides of the groove. In abrasion, this process is typically only observed under extreme conditions, such as high loads and very sharp particles.

\section{Wedge formation}

Wedge formation is a non-steady state mechanism that involves a groove to be formed and the displaced material from the groove to be collected in a 'bow' in front of the moving tip. During scratching the bow will grow and ultimately break off (i.e. wear will occur) after which the process of bow initiation and growth restarts again.

A scratch can be quantified using the degree of wear parameter, which is the fraction of the material from the groove that is actually removed from the surface. Referring to the idealized schematic cross section of a wear scar shown in Fig. 5 (c), the degree of wear $\beta$ is defined as:

$$
\beta=\frac{A_{g}-A_{s}}{A_{g}}
$$

with $A_{g}$ the groove area and $A_{s}$ the shoulder area. A value of $\beta$ close to 0 means ploughing, whereas a value close of $\beta$ is indicative of cutting and severe wear. [21] studied the properties of such grooves and showed that the wear is a function of the degree of penetration $D_{p}$ of the scratching tip into the scratched material, which is defined as:

$$
D_{p}=\frac{2 d}{w}
$$

Fig. 7 shows an adaption of one of the curves presented by [21], showing the degree of wear to increase with increasing degree of penetration following an Sshaped curve. The dotted lines indicate the ploughing, wedging and cutting wear mechanisms. 


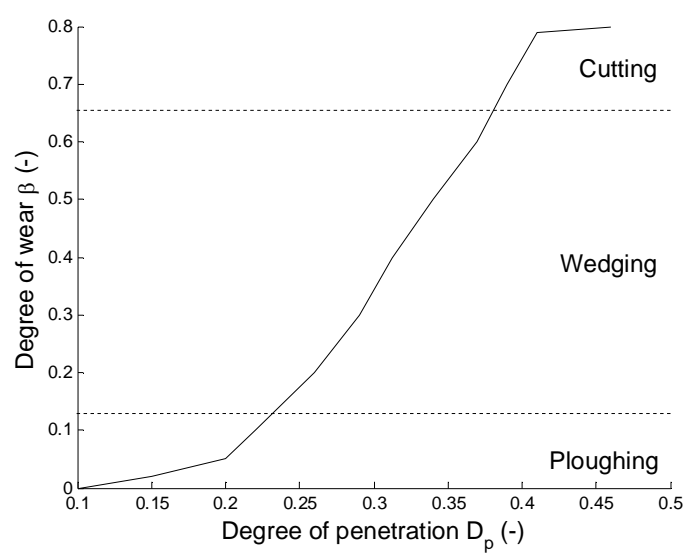

Fig. 7 Degree of wear versus degree of penetration adapted from Hokkirigawa and $\mathrm{Li}$

[18].

The degree of wear parameter is the measure for wear and the degree of penetration quantifies the relative depth of the groove and thus the severity of the contact.

In [1], single asperity scratch tests were performed on steel surfaces using quartz tips with predefined radii to study the effects of the indenter size on abrasion. The performed experiments are relatively easy and well controllable; the geometries are prescribed and all system parameters like the applied load and the resulting indentation depth are either known or can be calculated, which enables simulating them in Abaqus. In these single asperity scratch experiments, ploughing was observed for most values of the indentation depth, whereas cutting was only observed at extreme loads and typically resulted in brittle failure of the quartz tips. The aim of the present work is to employ the developed numerical model to reproduce Hokkirigawa's experimental curve of Fig. 7. A correct reproduction will demonstrate that the model is capable of simulating the three mechanisms for different values of the degree of penetration and friction.

\section{$4 \quad$ Model verification}

The numerical model is simulated using the explicit method, i.e. the simulations are numerically unconditionally stable. This means that the simulation will always complete and produce a result, even when the outcomes are physically not feasible. It is therefore extra important to verify the results and to make sure they are reasonable. In this section, a curve similar to the curve shown in Fig. 7

$$
\text { D-13 }
$$


will be obtained using the numerical model. The different wear mechanisms will be treated separately.

\subsection{Ploughing}

In Fig. 8, some results are shown for the ploughing situation by plotting the cross section of a simulated groove and its corresponding experimental groove.

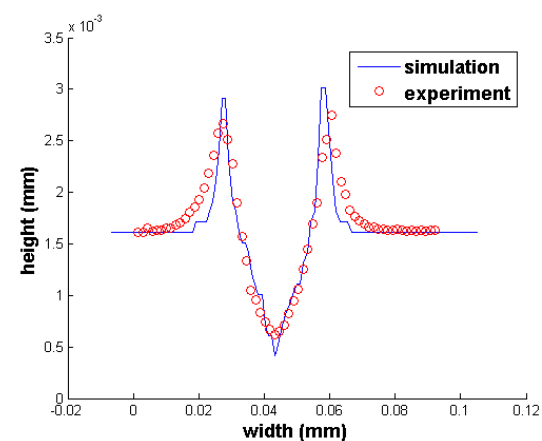

(a)

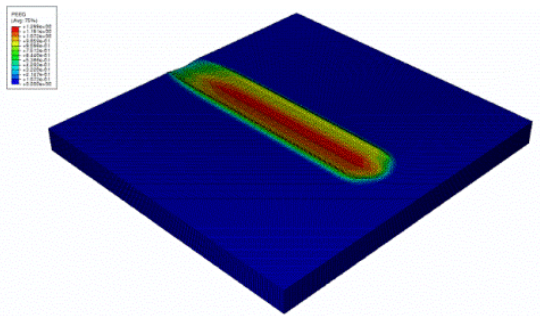

(b)

Fig. 8 Ploughing results, $R=50 \mu \mathrm{m}, \mathrm{d}=0.001 \mathrm{~mm}$, (a) cross section and comparison with experiment and (b) overview of the simulated groove.

The results in Fig. 8 indicate that the ploughing behaviour of a tip sliding over a surface can be modelled. Ploughing is a predominantly plastic process, without wear or loss of elements in the model. The simulated groove is similar to the experimental groove, both the depth of the groove and the shape of the groove closely resemble each other.

\subsection{Wedging}

For both the wedge formation and cutting mechanisms, actual wear occurs and elements are removed from the mesh. An example of a simulated wedging groove is shown in Fig. 9. The non-steady state repetitive behaviour of initiation and bow growth is visible. Although the model is capable of modelling the wedge formation mechanism to a reasonable extent, more work is required to improve the modelled material behaviour and simulate the correct morphology of the scratch. 


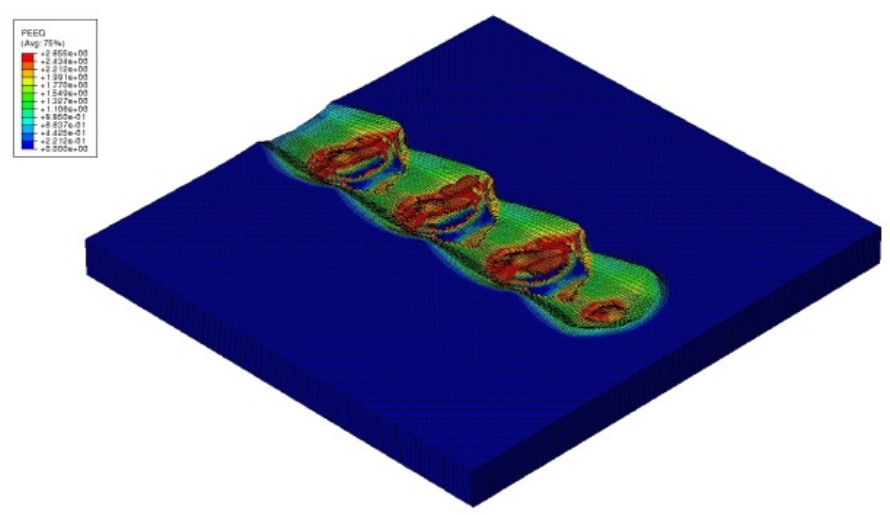

Fig. 9 Overview of a wedging groove, $R=50 \mu \mathrm{m}, \mathrm{h}=0.002 \mathrm{~mm}$.

\subsection{Cutting}

Cutting typically takes place for values of the degree of wear parameter larger than 0.7, resulting in a clear groove with hardly any shoulders. The shear strength of the indenter-surface interface is an important parameter in the onset of the cutting regime, and Challen and Oxley [19] showed that a reduced interfacial shear strength will result in an earlier onset of cutting. The reduced amount of sticking between the abraded material and the tip prevents the buildup of the bow and which facilitates the formation of a freely moving chip. By reducing the coefficient of friction in the model from 0.1 to 0.01 , a transition from wedge formation to the cutting regime is obtained in the simulation. This is shown in Fig. 10 where, after a start-up phase a groove without shoulders, as is typical for cutting can be observed. The value for the degree of wear for the fully developed part of the scratch is $\beta=0.7$.

This means that the cutting mechanism can also be simulated and the technique for element removal can be used to model wear mechanisms. 


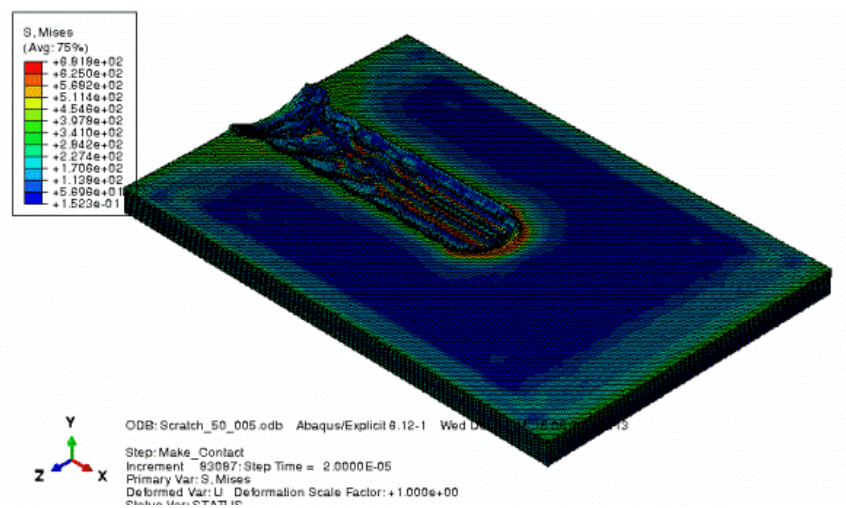

Fig. 10 Example of a groove created by cutting.

\subsection{Application of the model to conical tips}

Hokkirigawa and Li quantified abrasive wear by plotting the degree of wear as a function of the depth of indentation into the scratched material. A similar plot can now be produced based on the calculation outcomes of the developed model for the indenter with a radius of $50 \mu \mathrm{m}$, as presented in sections 4.1, 4.2 and 4.3. This graph is shown in Fig. 11. Indeed an approximate S-shaped curve can be observed, and regions for ploughing wedging and cutting can be distinguished.

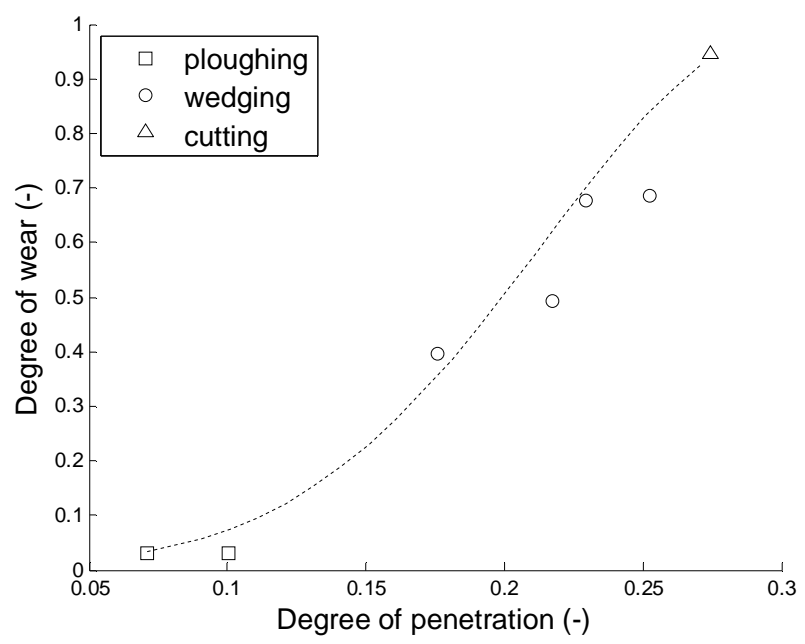

Fig. 11 Simulation results, degree of wear plotted against the indentation depth.

$$
\text { D-16 }
$$




\section{$5 \quad$ Conclusions}

A numerical model was derived for scratching a rigid tip with a predefined shape over a softer, deforming surface. The material model for the scratched material includes strain rate dependent elastic-plastic stress-strain behaviour. Volumetric wear is implemented by employing removal of elements using a shear damage criterion based on both fracture strains and equivalent plastic displacement. The model has been verified by reproducing the abrasive behaviour of a tip sliding over a surface. The three abrasive wear regimes that have been observed in experiments, ploughing, wedging and scratching, were observed with the model by varying the indentation depth of the tip and the friction between the tip and the surface and the characteristic S-shape curve as introduced by Hokkirigawa and $\mathrm{Li}$ has been re-created.

\section{$7 \quad$ References}

[1] M. Woldman, E. Van Der Heide, T. Tinga and M.A. Masen, The influence of abrasive body dimensions on single asperity wear. Wear, 301 (1-2): p.76-81, 2013.

[2] G.B. Stachowiak and G.W. Stachowiak, The effects of particle characteristics on three-body abrasive wear. Wear, 249(3-4): p. 201-207, 2001.

[3] J. Williams, Engineering Tribology. Cambridge University Press, Cambridge, 2005.

[4] I.M. Hutchings, Tribology: Friction and Wear of Engineering Materials, Edward Arnold, London, 1992.

[5] D.V. De Pellegrin, A.A. Torrance, and E. Haran, Wear mechanisms and scale effects in two-body abrasion. Wear, 266(1-2): p. 13-20, 2009.

[6] H. Sin, N. Saka, and N.P. Suh, Abrasive Wear Mechanisms and the Grit Size Effect.

Wear, 55(1): p. 163-190, 1979.

[7] A. Misra, and I. Finnie, On the size effect in abrasive and erosive wear. Wear, 65(3): p. 359-373, 1981.

[8] D.V. De Pellegrin and G.W. Stachowiak, Simulation of three-dimensional abrasive particles. Wear, 258(1-4): p. 208-216, 2005.

[9] R. Gåhlin, and S. Jacobson, The particle size effect in abrasion studied by controlled abrasive surfaces. Wear, 224(1): p. 118-125, 1999.

[10] D.V. De Pellegrin and G.W. Stachowiak, Assessing the role of particle shape and scale in abrasion using 'sharpness analysis': Part I. Technique development. Wear, 253(9-10): p. 1016-1025, 2002.

$$
\text { D-17 }
$$


[11] Y. Xie, and B. Bhushan, Fundamental wear studies with magnetic particles and head cleaning agents used in magnetic tapes. Wear, 202(1): p. 3-16, 1996. [12] M. Woldman, E. Van Der Heide, D.J. Schipper, T. Tinga and M.A. Masen, Investigating the influence of sand particle properties on abrasive wear behaviour. Wear, 294-295(0): p. 419-426, 2012.

[13] M. Woldman, E. Van Der Heide, T. Tinga and M.A. Masen, Classification of Particle Shapes in 3D, submitted to Applied Mathematical Modelling (52013).

[14] G.H. Majzoobi et al., Determination of materials parameters under dynamic loading. Part I: Experiments and simulations. Computational Materials Science, 49(2): p. 192-200, 2010.

[15] G.R. Johnson and W.H. Cook, Fracture characteristics of three metals subjected to various strains, strain rates, temperatures and pressures. Engineering Fracture Mechanics, 21(1): p. 31-48, 1985.

[16] Abaqus, Analysis User's Manual, 2011.

[17] L. Olovsson, K. Simonsson and M. Unosson, Selective mass scaling for explicit finite element analyses. International Journal for Numerical Methods in Engineering, 63(10): p. 1436-1445, 2005.

[18] R. De Borst et al., Nonlinear Finite Element Analysis of Solids and Structures. Wiley, 2012.

[19] J.M. Challen and P.L.B. Oxley, An explanation of the different regimes of friction and wear using asperity deformation models. Wear, 53(2): p. 229-243, 1979.

[20] K. Hokkirigawa and K. Kato, An experimental and theoretical investigation of ploughing, cutting and wedge formation during abrasive wear. Tribology International, 21(1): p. 51-57, 1988.

[21] K. Hokkirigawa, K. Kato, and Z.Z. Li, The Effect of Hardness on the Transition of the Abrasive Wear Mechanism of Steels. Wear, 123(2): p. 241$251,1988$. 


\section{Paper E}

Implementation of an abrasive wear model in a predictive maintenance concept for systems operated in sandy conditions, M. Woldman, T. Tinga, E. Van Der Heide and M.A. Masen, submitted to Engineering Failure Analysis (1-2014).

E-1 
E-2 


\title{
Implementation of an abrasive wear model in a predictive maintenance concept for systems operated in sandy conditions \\ M. Woldman $\cdot$ T. Tinga $\cdot$ E. Van Der Heide $\cdot$ M.A. Masen
}

\begin{abstract}
Machines operating in sandy environments typically are damaged by the abrasive action of sand particles entering the machine and becoming trapped between sliding surfaces in contact. Certainly in the case of the military services, the combination of a sandy environment and the variable task to be fulfilled make the conditions wherein such machines operate extreme and difficult to predict. Hence, maintenance intervals are difficult to be established beforehand, thereby increasing the risk of failure. To prevent from such problems, maintenance should be performed based on the actual conditions of the machine and its surroundings. Thus, monitoring the applied loads and the properties of the particles in the contact zone, the amount of wear can be predicted and maintenance performed when necessary. To be able to implement a predictive maintenance concept as described above, knowledge is required on the relation between the operating and environmental conditions and the dominant wear mechanism, in this case abrasive wear. In previous work $[1,2]$ these relations were derived for the particle properties size and shape. This paper treats the implementation of these recently derived relations into a predictive maintenance concept for systems that are operated in a sandy environment. This requires to connect the local parameters that govern the wear mechanism, like the normal force, sliding distance and specific wear parameter, to the system-level usage parameters like the terrain type and driving distance. The proposed concept is demonstrated on the specific case study of a military vehicle. The sprockets of these vehicles suffer from severe wear and, since the sprockets are critical to the system performance, a preventive maintenance policy is required. The proposed method can be used for a long term prediction of the maintenance intervals. This is demonstrated by applying the method to simulated test scenario's, which were specifically derived for the machines under investigation. These comprise a distance travelled under varying terrain conditions. Based on the scenarios, the maximum allowed driving distance until maintenance is required can be estimated.
\end{abstract}

Keywords Third-body abrasion - Usage based maintenance - Predictive maintenance $\cdot$ Particle properties 


\section{Highlights}

- A usage based maintenance setup was derived for machines working in sandy climates.

- The maintenance setup was optimized for machines suffering from abrasive wear.

- The maintenance setup includes the influence of particle properties on abrasion.

- The verification includes both usage profiles and actual usage of a machine.

\section{Nomenclature}

$\begin{array}{ll}A_{\mathrm{c}} & \mathrm{mm}^{2} \\ A_{\mathrm{p}} & \mathrm{mm}^{2} \\ B & \mathrm{~mm} \\ D & \mathrm{~m} \\ D & \mathrm{~mm} \\ E & \mathrm{MPa} \\ E^{\prime} & \mathrm{MPa} \\ F_{\mathrm{p}} & \mathrm{N} \\ F & \mathrm{~s}^{-1} \\ f_{\mathrm{t}} & - \\ f_{\mathrm{u}} & -\end{array}$

$H \quad \mathrm{~N} \mathrm{~mm}^{-2}$

$\begin{array}{ll}J & - \\ K & \mathrm{~mm}^{3} \mathrm{~N}^{-1} \mathrm{~m}^{-}\end{array}$

$K \quad-$

$K \quad-$

K

$l_{\mathrm{ft}} \quad-$

$l_{\text {fu }} \quad-$

$M \quad-$

$N \quad \mathrm{~s}^{-1}$

$N \quad \mathrm{~N}$

$N \quad-$

$P \quad-$

$P \quad$ W

Q $\mathrm{mm}^{3}$

$R \quad \mathrm{~mm}$

$R^{\prime} \quad \mathrm{mm}$ contact area

projected area of one particle

half contact width

machine life / distance

wheel diameter

Young's modulus

reduced modulus of elasticity

peripheral force

rotational frequency

fraction of the total distance travelled in certain terrain

fraction of the total distance travelled on certain uneven surface

(surface) hardness

Index

specific wear rate

Index

wear coefficient

sharpness of particle

load factor for terrain pavement

load factor for terrain gradient/unevenness

Index

feed rate of particles in contact

normal load

Poisson's ratio

packing fraction

engine power

volumetric wear

radius

reduced radius 


$\begin{array}{lll}S & \mathrm{~m} & \text { sliding distance } \\ T & \mathrm{~mm} & \text { width of a sprocket wheel } \\ T & \mathrm{~N} \mathrm{~m} & \text { driving torque } \\ V & \mathrm{~m} \mathrm{~s}^{-1} & \text { driving velocity } \\ \Omega & \mathrm{s}^{-1} & \text { angular velocity } \\ \Omega & \mu \mathrm{m} & \text { average particle size } \\ z_{\mathrm{m}} & - & \text { number of gear teeth in contact }\end{array}$

\section{Introduction}

During use, the condition of parts and machines deteriorates as the result of mechanical loading. This deterioration causes unwanted phenomena such as wear and fatigue. Ultimately, it will lead to failure of the mechanical component and reduced operation, inefficiency or even breakdown of the machine. In many situations the breakdown of machinery will result in unplanned standstill which disrupts the primary process, like a manufacturing process or transportation. In either case, the standstill has a multitude of rather costly consequences and it is therefore common practice to perform maintenance, i.e. repairing or replacing a machines' damaged or failed components, and thus decreasing the possible downtime of the machine. In general the objective is to perform maintenance before failure takes place, to prevent other components from being damaged. When machines operate under fluctuating conditions, the moment of maintenance is hard to predict. Generally, this uncertainty is covered by applying very conservative (i.e. short) maintenance intervals that are based on the most extreme conditions. However, it is also expensive and wasteful to replace components too early and therefore, to enable just-in-time maintenance, knowledge is required about the dominant failure mechanism and degradation rate [3]. Numerical analyses can then be performed to estimate the amount of degradation and the remaining lifetime before failure of components. In case of components failing due to a wear mechanism, this approach requires the tribological system to be known. This system comprises the surfaces in contact, the lubricant (if present) and the operational and environmental conditions.

A typical example can be found in military vehicles, which often operate in sandy environments like beaches and deserts and encounter continuously varying mechanical loading conditions. These variations are caused by velocities and accelerations, which depend on the situation at hand, such as training, patrolling and combat situations. The aggressive nature of the environmental conditions in which such machines operate and the worldwide deployment makes these conditions highly variable. The uncertainty and variability make it difficult to apply a static preventive maintenance concept in which intervals with a fixed length are used. However, particularly during military missions such as 
in the above sketched example, failure and down-time of the system can be very critical and failed components require maintenance as soon as possible. This requires a long term prediction of the maintenance interval to make sure that spare parts are available when needed.

One way of dealing with this problem is to establish variable maintenance intervals which are based on the actual usage (and associated degradation) of the machine including the driving velocity, applied motor power and environment in which the machine has been used. When the instantaneous amount of wear can be quantified and the total amount of wear at failure is known, the remaining lifetime of components can be determined based on the operational and environmental conditions. This enables the timely repair or replacement of the damaged components. This so-called predictive maintenance is increasingly gaining attention [4-7] and is a potential solution for improving the maintenance concept in situations in which the variability of operating conditions prevents the use of a more simple time or mileage based maintenance interval.

Several types of preventive maintenance can be distinguished, where Condition Based Maintenance and Usage Based Maintenance [3] are the most commonly used policies. Both methods monitor the system in order to establish the optimal maintenance intervals, but there is a significant difference as to the focus of the monitoring of these two methods. With Condition Based Maintenance the degradation is monitored more or less directly: the performance and condition of the machine components is measured, e.g. by counting the number of particles in the lubrication oil or by applying sensors for measuring the length of cracks in components. Maintenance will be performed when the condition of these components has reached a certain predefined threshold level [3]. In contrast, in a Usage Based Maintenance policy only the operational conditions of the machine are measured and recorded using sensors, and the degradation of the system is derived from these parameters. The classical usage based maintenance approach focuses on straightforward parameters like the number of operating hours or distance travelled. More advanced policies also take into account the severity of the usage, based on the operational conditions. One operating hour at a high power setting (or driving speed, harsh environment, etc.) can thus have a larger contribution to the degradation than one hour at a low power setting. Therefore, in these type of policies, the system condition is not monitored directly, but monitored usage parameters are utilized to predict the system degradation indirectly [3].

The objective of this paper is to propose a usage severity based maintenance concept for systems operating in sandy conditions, building on recent experimental and numerical work on third-body abrasive wear $[1,2]$. The 
experimental tests and numerical modelling work have resulted in a physical model that can be used to predict abrasive wear, and in the current work this model is implemented in a predictive maintenance framework. The framework will be demonstrated on a real life case study, concerning a Combat Vehicle 90 infantry fighting vehicle, with sprocket wheels that are damaged by abrasive wear. The novel combination of a physical model to describe abrasive wear and a predictive maintenance concept will improve the efficiency of the maintenance on components that are impacted by abrasive wear.

This paper is organized as follows. Firstly, section 2 describes the method for predicting the abrasive wear rates as a function of the operational conditions. Then section 3 describes the general physical model based predictive maintenance framework. Following this, section 4 will discuss the integration of the proposed wear model and predictive maintenance framework and its application to the case study of the military vehicle. In section 5, the analysis results will be presented and discussed and finally section 6 forwards some conclusions.

\section{Prediction of wear rates}

The implementation of a usage based maintenance strategy requires detailed knowledge of the predominant wear mechanism and the amount of wear as a function of the usage conditions. In this case, the components wear as the result of the scratching movement of sand particles. Hence the relations between this abrasive mechanism and the conditions under which the machine operates have to be established. First, the relevant operating conditions will be defined, after which the proposed wear prediction model is described.

\subsection{Conditions}

The system under consideration contains a data-logging system, keeping track of the operating conditions as well as a range of environmental parameters. Not all of these will have a significant influence on abrasion and therefore the most critical parameters have to be distinguished. This is achieved by considering the operational and environmental conditions.

According to Archard's wear law [8] the total amount of abrasive wear $Q$ is influenced $[9,10]$ by the hardness $H$ of the contacting surfaces, the applied loads $N$ and the sliding distance $s$ :

$$
Q=\frac{K \cdot N \cdot S}{H}
$$


Often, the specific wear rate $k=K / H\left(\mathrm{~mm}^{3} / \mathrm{Nm}\right)$ is used rather than the dimensionless wear coefficient $K$ :

$$
Q=k \cdot N \cdot s
$$

The specific wear rate depends on a multitude of system parameters [9], including the sand variety and the hardness of the abraded material, as shown in [1]. Thus, to be able to predict abrasive wear on a component the applied normal load and the sliding distance have to be monitored.

The specific wear rate comprises the properties of the wearing surface, the particles causing the wear, i.e. the particle size and shape, as well as any other influential conditions. These could include environmental parameters such as the temperature, humidity and wind speed under which the vehicle has been used. Where the particle properties will influence the abrasive wear mechanism directly because they are the source of abrasion, the ambient conditions have a more indirect influence in the sense that they potentially affect the number and variety of the particles entering the contact. For instance, particles are more prone to stick to the contacting surfaces when the humidity increases [11]. Moreover, the wind may influence the amount and size of the particles entering the contact, for instance when an aerosol is encountered by the machine. However, these are secondary to the particle properties themselves and in the present work these secondary conditions are neglected.

\subsection{Specific wear rates}

In [1] the influence of sand particle shape and size on abrasive wear has been studied by using six distinct types of sand. Five of these sand samples were obtained from geographical locations and the sixth was a commercially available 'reference' sand that is used as the standard sand in dry sand rubber wheel tests. Dry sand rubber wheel tests were performed on Fe 510 (1.0570) steel samples to quantify the abrasive wear resulting from these sand particles. Fig. 1 shows the volumetric wear of the steel samples as a function of time for the various sands, illustrating that the sand properties have a significant influence on the resulting wear. 


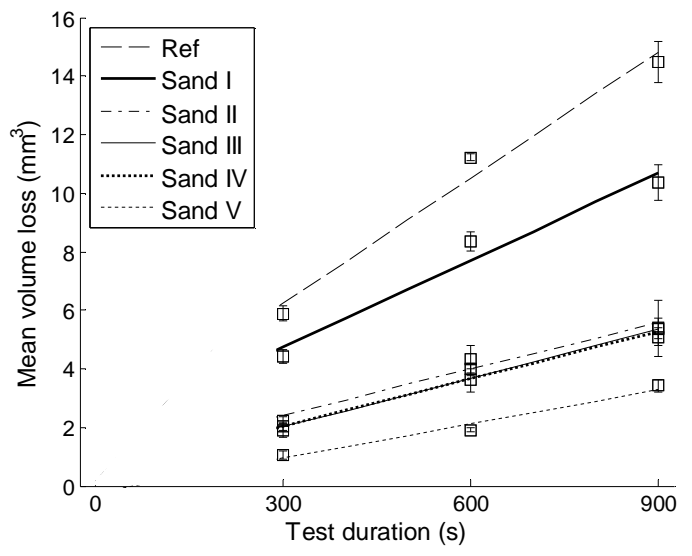

Fig. 1, Results of dry sand-rubber wheel tests, mean volume loss plotted against the test duration, reproduced from [1].

As the normal load and sliding speed during the experiments were kept constant, the slopes of the fitted lines in the figure represent the specific wear rates $k$ as obtained for each sand variety, shown in Table 1. This table also shows the respective particle sizes $\Omega$ (equivalent diameter), the feed rate $n$ and the sharpness $\kappa$ values, which will be used as input parameters for the abrasive wear model. The size represents the average size of a sample of the particles, as determined using a visual analysis. The sharpness parameter is also quantified using a visual analysis, as discussed in [2]. The particle feed rate $n$ represents the number of sand particles in the contact between the two sliding surfaces at any time, as discussed in [1]:

\begin{tabular}{|c|c|c|c|c|}
\hline \multirow{2}{*}{$\begin{array}{c}\text { Sand } \\
\text { variety }\end{array}$} & Size $\Omega$ & Feed rate $n$ & Sharpness $\kappa$ & Wear rate $k$ \\
\cline { 2 - 5 } & $(\mu \mathrm{m})$ & $(-)$ & $(-)$ & $\left(\cdot 10^{-4} \mathrm{~mm}^{3} / \mathrm{Nm}\right)$ \\
\hline Ref & 230 & 305 & 5.0 & 15 \\
\hline 1 & 80 & 3257 & 2.0 & 11 \\
\hline 2 & 226 & 302 & 2.5 & 5.7 \\
\hline 3 & 90 & 2269 & 2.5 & 5.7 \\
\hline 4 & 78 & 4733 & 1.7 & 5.6 \\
\hline 5 & 515 & 58 & 1.4 & 3.8 \\
\hline
\end{tabular}

Table 1 Experimental and measurement results for sand varieties tested. 
Based on these data an empirical relation between the sand particle properties and wear rate has been derived [1]:

$$
\begin{aligned}
& \frac{k}{k_{\text {ref }}}=\left(\frac{\Omega_{i}}{\Omega_{\text {ref }}}\right)^{3} \cdot\left(\frac{n_{i}}{n_{\text {ref }}}\right)^{1.5} \cdot\left(\frac{\kappa_{i}}{\kappa_{\text {ref }}}\right)^{2.5} \\
& \text { with } \begin{cases}\Omega_{i}=\Omega_{i} & \text { if } \Omega_{i}<100 \mu \mathrm{m} \\
\Omega_{i}=\Omega_{\text {ref }} & \text { if } \Omega_{i}>100 \mu \mathrm{m}\end{cases}
\end{aligned}
$$

with the index $i$ representing the particle property values for the different sand varieties, and the index ref representing the particular values for silversand, which is taken as the reference, $k_{\text {ref }}$. Using Eq. 3 allows the prediction of the specific wear rate for any combination of sand particle properties.

For real applications other than this testing environment the approach is to collect a sample of sand where the machine under consideration will be employed. This sample is analysed as discussed in [1] to give typical values for the particle size and shape and the feed rate, which are used as input for the wear model.

\section{$3 \quad$ Predictive maintenance concept}

The generic concept of a physics-based predictive maintenance method was proposed by Tinga [3]. The basic premise of this approach is that the relation between usage of the system and its degradation can be quantified with a physical model. This is illustrated in Fig. 2, showing that the system remaining life can generally not be obtained directly from the monitored usage. A physical failure model is required, using the local loads (e.g. stress, strain, temperature) as input and providing the damage accumulation or consumed service life. The challenge in this approach is twofold: $i$ ) finding the (numerical) relation between the usage of the system and the local loads on the selected component, and ii) finding the critical failure mechanism (e.g. fatigue, creep, corrosion, wear) and defining the associated failure model. These two relations are indicated in Fig. 2 by the numbers 1 and 2 respectively. 


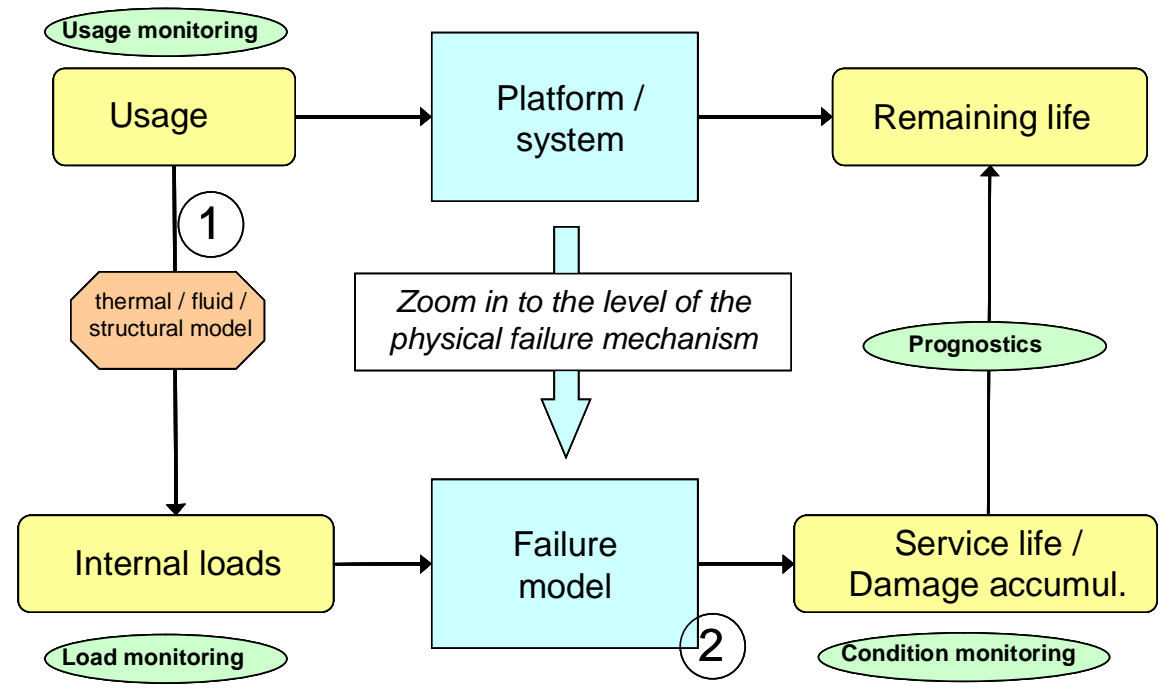

Fig. 2, Schematic representation of the relation between usage, loads, condition and life consumption.

In the present work, the focus is on one specific failure mechanism, i.e. abrasive wear. The previous section described the numerical model that has been derived for this mechanism, and also showed which local loads govern this failure mechanism. The sliding distance $(s)$, normal force $(N)$ and specific wear rate $(k)$ appeared to be the local load parameters for this failure mechanism. In a generic sense, for any variation in these three load parameters, the associated degradation or service life consumption can be assessed. However, the specific application determines how these local load parameters (on the component level) are associated to the usage parameters on the system level (nr. 1 in Fig. 2). Only if this relation can be quantified, the optimal maintenance interval for any fluctuating usage pattern can be assessed.

In the next section, it will be demonstrated for a specific case study how these two levels can be related and how the predictive maintenance concept can be applied. 


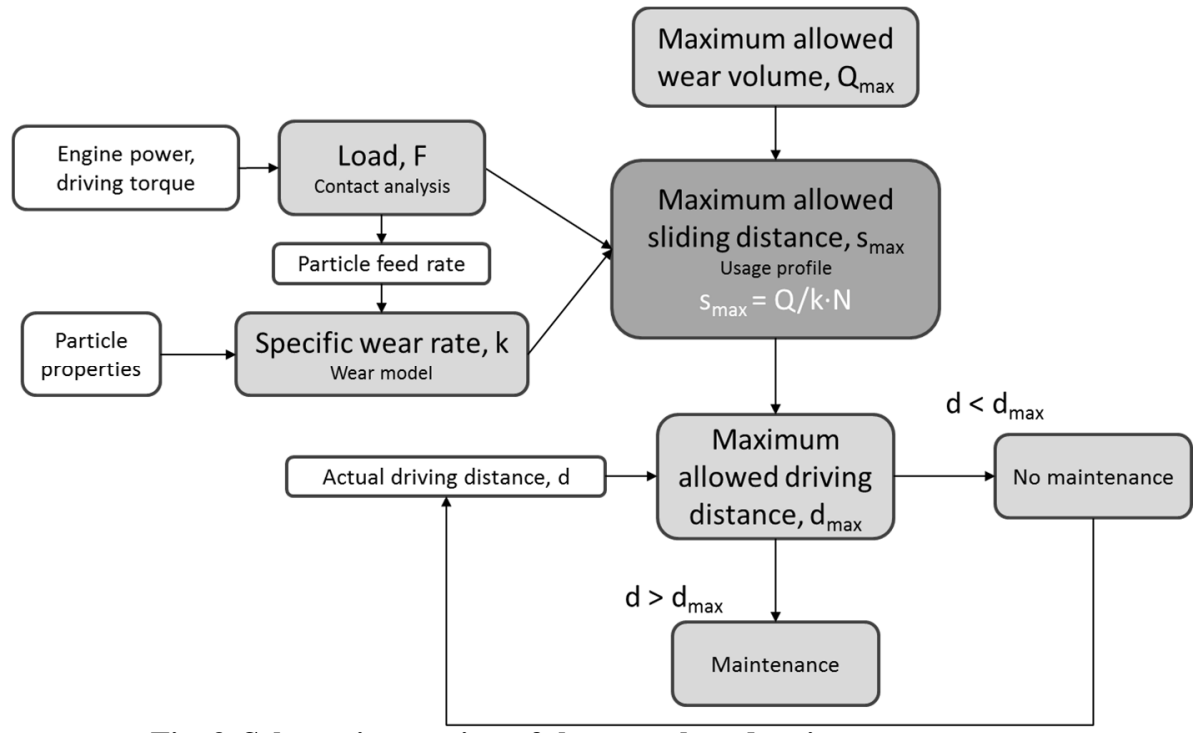

Fig. 3, Schematic overview of the usage based maintenance concept.

\section{$4 \quad$ Case study}

In this section, the generic approach introduced in the previous section will be applied to a specific case study. To establish and quantify the maintenance intervals, the developed model for third body abrasive wear from section 2 will be incorporated in the framework presented in section 3. The input to this wear model consists of the local loads, which in this case are the normal force $N$, the specific wear rate $k$ and the sliding distance $s$ in the contact zone. The wear volume $Q$ can then be calculated from Eq. 2.

However, these local loads must be related to the usage parameters on the system level. The usage of the vehicle is defined primarily as a combination of driving distance and driving conditions. The latter is defined in terms of surface type (e.g. asphalt) and terrain roughness, which could be used to assess the engine power setting (i.e. engine torque) and the amount of sand in the contact. Also the operation location is typically known, which means that the sand variety is known.

The aim is then, for a given variation in usage parameters and a predefined maximum allowed wear volume $Q_{\max }$, to assess the service life of the machine, expressed in distance travelled $d_{\max }$. This procedure is schematically illustrated in Fig. 3. The next subsection will introduce the case study subject, the infantry vehicle, while subsection 4.2 discusses the usage profiles. Section 4.3 describes

\section{E-12}


the failure behaviour of the component to be studied, the sprocket wheel. Finally, section 4.4 provides the details of the sprocket wheel. The results of a number of scenario analyses will be presented and discussed in section 5 .

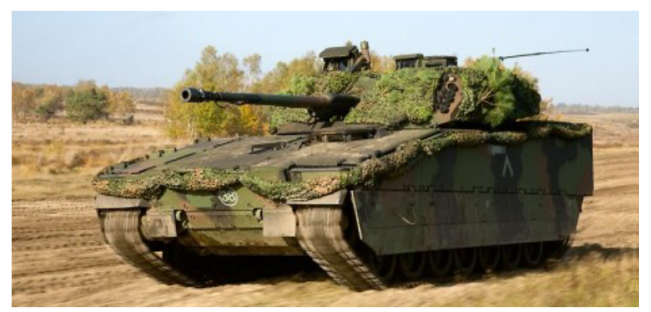

(a)

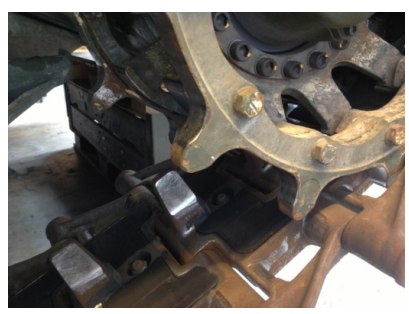

(b)

Fig. 4, (a) the CV90 infantry vehicle, operating in a sandy environment (left, source: defensie.nl) and (b) the sprocket wheel.

\subsection{Case study description}

Much of the equipment owned by the armed forces is regularly deployed in sandy environments. One example is the Dutch CV9035NL, or Combat Vehicle 90, as shown in Fig. 4 (a), an infantry fighting vehicle that has been used by the Dutch army since 2008. The CV90 is fitted with continuous tracks, to enable operation on unpaved terrain both during training missions and military operations. The vehicle typically operates in heavy terrain and at full power, and has a range of several hundreds of kilometres. This makes the operating conditions quite demanding for the system and some of the machine parts are damaged by wear. This particularly applies to the tracks, the driving sprocket shown in Fig. 4 (b) and the guiding and tension idler wheels, because sand is free to enter the contact between the track stops and the wheels. Because the replacement of the stops that connect the sprocket wheel to the track is very time consuming, the stops are constructed from a material with a higher hardness than the wheels, which makes them more durable than the wheels. Hence this case study focuses on the sprocket wheels, see Fig. 4 (b), whilst the wear on the stops is neglected. Moreover, since the wheels are critical to the functioning of the vehicle, their service life limits the lifetime of the vehicle. 


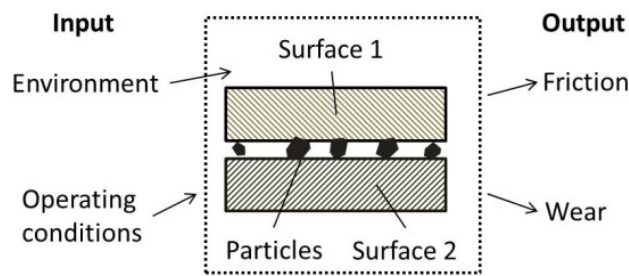

Fig. 5, The tribological system for the abrasive wear on the sprocket wheel.

The generic tribological system for third-body abrasion is shown in Fig. 5. The input is formed by operating conditions of the vehicle, which translate into the sprocket-stop contact conditions i.e. the applied load, the sliding distance and the environmental conditions like the sand variety. Although a lubricant such as water may be present in some instances during use, the majority of the time the vehicle operates under dry conditions. The presence of hard particles in the contact can cause two types of mechanisms to be active, i.e. surface fatigue and abrasion. Surface fatigue manifests itself as (micro-) pitting and delamination of the surface, whereas abrasion results in scratches and grooves in the sliding direction. Because primarily the latter are found on the wheel, as depicted in Fig. 6, the present approach focuses on failure due to excessive material loss by scratching, and neglects the surface fatigue mechanism. 


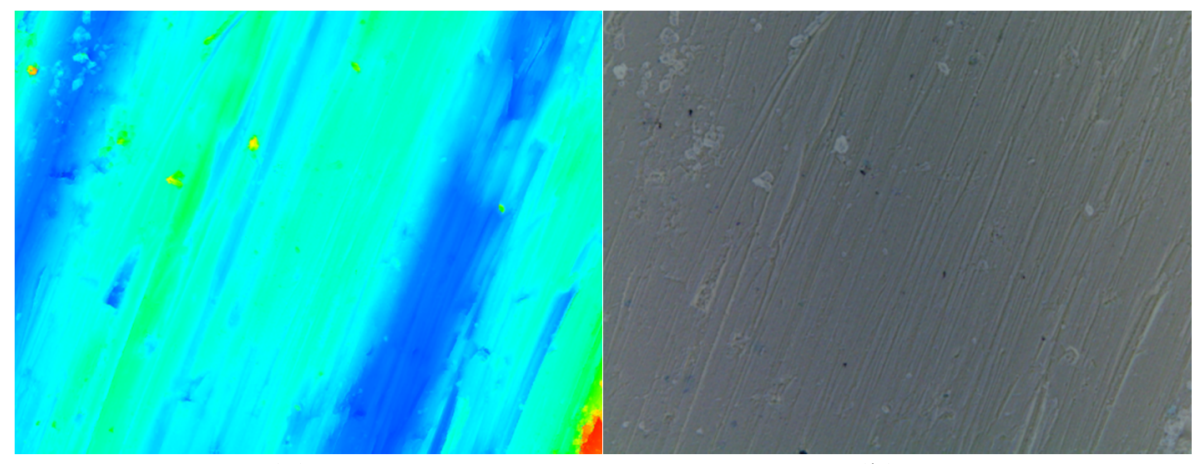

(a)

(b)

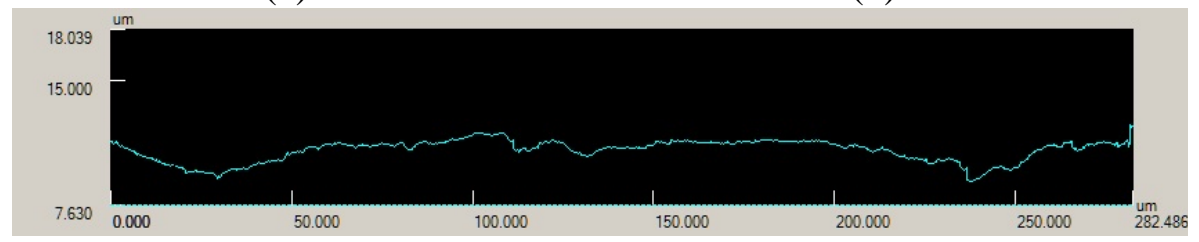

(c)

Fig. 6, Typical wear scar on a sprocket wheel, (a) height information on the surface, (b) actual surface, (c) cross section along the surface.

The CV90 is typically operating in a sandy environment and the sand varieties used for the dry sand-rubber wheel tests performed in [1] were selected with this application in mind. This means that the sand varieties listed in Table 1 can be encountered in practical situations, except the silversand that only acted as a reference during the testing work.

The sprocket wheel of the CV90 is equipped with so-called wear indicators: a number of blind holes along the outline of the gear teeth as schematically indicated in Fig. 7. The indicators provide a reference location to determine the amount of wear of the teeth. For new undamaged wheels the distance from the contact surface of the teeth to the indicators is known and the amount of wear on a tooth can be quantified by the distance between the indicators and the worn tooth surface. The maximum allowable wear is reached when the surface contour reaches an indicator hole. From that moment, the track might run off the sprocket, making the machine stop running.

In fact, these markers could enable a condition based maintenance policy, as the condition of the component can be monitored by periodically measuring the remaining distance between the surface and the marker. Maintenance could then be triggered when less than a certain distance is left. However, in practice there is no periodic assessment of the remaining distance. It would require regular inspections by the operators, which are not currently prescribed. Moreover, such

\section{E-15}


an approach would only be diagnostic, in a sense that action is only required when the present condition exceeds a certain threshold. Predictions of remaining useful life, which are much more valuable, cannot be obtained from such an approach. For that reason, the present work proposes a predictive method based on monitored usage parameters, enabling a usage based maintenance policy.

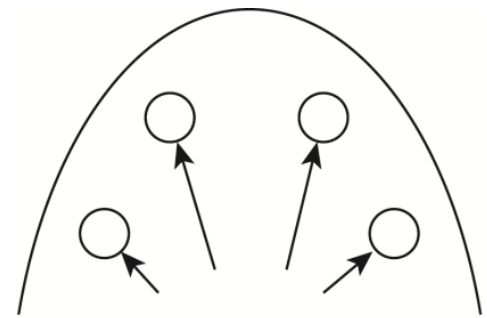

wear indicator

Fig. 7, Wear indicators on the sprocket teeth.

The remaining service life of the wheel can be predicted for any set of operating conditions by comparing the calculated wear volume to the maximum allowed total wear volume. The calculated wear volume is obtained by determining the condition and sand specific wear rate $k$ from Eq. 3 and inserting it, together with the other usage parameters, into Eq. 2. The maximum allowable volumetric wear on one tooth is the distance from the fresh surface of a new wheel to the wear indicators, multiplied by the width of the tooth and the contact length. When the actual wear volume exceeds the maximum allowed wear volume, maintenance has to be performed.

\subsection{Usage profiles}

The case study described above is analysed by applying usage profiles that have been established by the Royal Netherlands Army [12] in order to specify the requirements of the military vehicle during procurement. Two scenarios have been set up, one for a training mission, representing intensive usage, and one for a military operation. The CV90 vehicles are used for training missions during a large portion of their service life and the vehicles are impacted by abrasive wear during these training missions. Moreover, the training scenarios differ significantly from the operational scenario, mostly in their intensity. Because the conditions in the training mission scenario is typically more demanding than the scenario for the military operation, only the training mission scenario is considered here. 
The profiles described in [12] are based on distances travelled on a variety of terrains. The variation in the difficulty of the terrain forms the basis for the usage profiles in this case study. As specified in Table 2 a distinction is made between the surface types; for training missions these are "asphalt", "unpaved" and "heavy soil and loose sand". Furthermore, the gradients of these terrain varieties is considered "light", "medium" or "heavy". Table 2 shows the composition of the usage profile as the fractions of the distances travelled for each combination of surface type and terrain gradient.

\begin{tabular}{|l|c|c|c|c|}
\hline \multirow{2}{*}{ Unevenness } & \multicolumn{3}{|l|}{ Surface type } & \multirow{2}{*}{} \\
\cline { 2 - 4 } & Asphalt & Unpaved & $\begin{array}{c}\text { Heavy soil and loose } \\
\text { sand }\end{array}$ & \\
\hline Light & $2 \%$ & $6 \%$ & $12 \%$ & $20 \%$ \\
\hline Medium & $5 \%$ & $15 \%$ & $30 \%$ & $50 \%$ \\
\hline Heavy & $3 \%$ & $9 \%$ & $18 \%$ & $30 \%$ \\
\hline
\end{tabular}

Table 2, Usage profile for training missions, fractions of travelled distance.

Depending on these conditions, the transmitted power and the driving torque of the vehicle will vary, thereby varying the loads working on the sprocket wheels and hence on the contact. Also, the amount of sand particles depends on the terrain; whilst driving on asphalt fewer sand particles are encountered than whilst driving through the heavy soil conditions. The usage profile in Table 2 specifies travelled distances only and the additional effects of driving through heavier terrain and the unevenness or gradient have to be quantified before they can be taken into account. Tiddens [13] incorporated the effects of variations in the applied driving power and torque by introducing a load factor. The magnitude of this factor was determined in a rather subjective way by interviewing a number of experts. In addition to the effect of driving power, also the effect of the amount of particles in the contact needs to be accounted for. In this work, a more complete and physics based approach is followed to determine the load factors, as will be discussed below. Ultimately, taking the most severe condition, i.e. "heavy soil and loose sand" combined with "heavy unevenness", as a reference, the severity of the other situations can be scaled by multiplying them with a factor smaller than one. This means that for the reference situation the maximum transmitted torque and amount of sand in the contact (this is denoted the particle feed rate), are used and in the other situations they will reduce due to the load factors specified next.

While Tiddens [13] combined all influence factors into one scale factor, the present work aims to separate the different effects and provide a physical

$$
\text { E-17 }
$$


motivation for the magnitude of the factors, instead of relying on expert opinions. As was mentioned in the introduction of this section, the terrain type affects both the applied engine power (torque) and the amount of sand that is present in the contact between track and sprocket wheel. The former governs the normal load $N$ in the contact, while the latter affects the specific wear rate $k$ (see section 2). Assuming that a heavy soil surface type is the reference, the required power to drive on other surface types is estimated and the values are shown in Table 3. This means that driving on asphalt is estimated to take only $33 \%$ of the power of driving in heavy soil. Similarly, the values for the different terrain unevenness grades are provided in Table 4 . The effect of the surface type on the amount of sand in the contact is also estimated, as shown in the $2^{\text {nd }}$ column of Table 3. When driving on a paved road, hardly any sand will enter the contact, as is expressed by a 0.02 value in Table 3 . The values in both Table 3 and Table 4 are based on the interviews by Tiddens [13], with both experts and users of the CV90.

\begin{tabular}{|c|c|c|}
\hline Terrain & $\begin{array}{c}\text { Load factor } \\
\text { Force }\end{array}$ & $\begin{array}{c}\text { Load factor } \\
\text { Number of Sand particles }\end{array}$ \\
\hline Paved & 0.33 & 0.02 \\
\hline Unpaved & 0.5 & 0.2 \\
\hline Heavy soil & 1 & 1 \\
\hline
\end{tabular}

Table 3, Load factors for different terrains.

\begin{tabular}{|c|c|}
\hline Unevenness & Load factor \\
\hline Light & 0.67 \\
\hline Medium & 0.83 \\
\hline Heavy & 1 \\
\hline
\end{tabular}

Table 4, Load factors (force) for terrain unevenness.

Note that separating the different effects requires more factors, which cannot always be assessed very accurately. However, since the factors now have a clear physical meaning, quantifying the factors is easier, and more importantly, the sensitivity of the separate factors on the overall service life can now be assessed. Therefore, if the absolute value of the factors is not available, at least a relative analysis can be performed. 


\subsection{Failure behaviour}

The failure behaviour of the CV-90 tracks and sprocket can be analysed based on the data that has been collected for a whole fleet of 193 vehicles. The first vehicles were taken in operation in the year 2008, the remainder of the fleet followed in the years 2009 to 2012. This means that some vehicles already operated for 5 years, while others only accumulated one year of operation. Further, the vehicles are organized in four battalions divided over two geographical locations. In addition, the driver training facility also operates a small number of vehicles.

For those vehicles that needed a sprocket wheel replacement, the date of this replacement was registered in the computerized maintenance management system (CMMS). These dates, in combination with the estimated start of operation (only the year is known, not the exact date), enable the assessment of the mean time between failures (MTBF) for the sprocket wheels. These values are shown in Table 5. The failure data for the driver training fleet was not available. The number of days to failure is not a very precise measure of the service life, since it depends heavily on the usage of the system. Therefore, the usage of the vehicles at each battalion was quantified by calculating the average number of kilometres driven per year. Note that a detailed registration of the kilometres was not available. The usage is estimated from the present accumulated number of kilometres for each individual vehicle and the number of years the vehicle has been operated. This yields the possibility to estimate the MTBF in terms of kilometres, as is shown in the two final columns of Table 5.

\begin{tabular}{|c|c|c|c|c|}
\hline Battalion & Location & MTBF & Usage & MTBF \\
\cline { 3 - 5 } & & days & km/year & $\mathrm{km}$ \\
\hline 1 & $\mathrm{~A}$ & 262 & 945 & 679 \\
\hline 2 & $\mathrm{~A}$ & 457 & 963 & 1206 \\
\hline 3 & $\mathrm{~B}$ & 1036 & 678 & 1923 \\
\hline 4 & $\mathrm{~B}$ & 760 & 859 & 1788 \\
\hline Driver training & $\mathrm{A}$ & n.a. & 1396 & n.a. \\
\hline
\end{tabular}

Table 5, Failure behaviour of sprocket wheels at various battalions.

These results show that the usage of the vehicles varies across the battalions, but also the failure behaviour, both in terms of calendar time and kilometres. 


\subsection{Sprocket wheel analysis}

Whilst driving on heavy terrain with large gradients, the maximum driving torque of the engine of $2650 \mathrm{Nm}$ is used. With the help of a torque converter and a transmission with ratios of $1: 13.1$ and 1:4.2 this torque is increased to approximately $140 \mathrm{kNm}$, which is divided over the four sprocket wheels. The peripheral force $F_{p}$, which is the load transmitted by each sprocket wheel, then equals:

$$
F_{p}=\frac{0.25 \cdot P}{v}=\frac{0.25 \cdot T \cdot \omega}{\pi \cdot d \cdot f}=\frac{0.25 \cdot T \cdot 2 \cdot \pi \cdot f}{\pi \cdot d \cdot f}=\frac{0.5 \cdot T}{d}
$$

with $P$ the engine power (W), $v$ the driving velocity $\left(\mathrm{m} \cdot \mathrm{s}^{-1}\right), \omega$ the angular velocity $\left(\mathrm{rad} \cdot \mathrm{s}^{-1}\right), f$ the rotational frequency $\left(\mathrm{rev} \cdot \mathrm{s}^{-1}\right), T$ the driving torque $(\mathrm{Nm})$ and $d$ the wheel diameter (mm). Note that the power and torque are divided over four sprocket wheels, hence the engine power is multiplied with 0.25 in Eq. 4 . According to [14] the force per gear tooth $F_{t}$ is approximately equal to:

$$
F_{t}=\frac{F_{p}}{z_{m}}
$$

with $\mathrm{z}_{\mathrm{m}}$ the number of gear teeth in contact. It is assumed here that always half of the total number of teeth on the gear is in contact.

The contact between the stop (track) and the gear is a line contact, and the contact width can be approximated with Hertz's theory of elastic contact [15]. The equation for the half contact width $b$ of a line contact of length $t$ is:

$$
b=2 \cdot\left(\frac{2}{\pi}\right)^{1 / 2} \cdot\left(\frac{F_{t}}{t}\right)^{1 / 2} \cdot\left(\frac{R^{\prime}}{E^{\prime}}\right)^{1 / 2}
$$

with $R^{\prime}$ the reduced radius and $E^{\prime}$ the reduced modulus of elasticity:

$$
\begin{gathered}
\frac{1}{R^{\prime}}=\frac{1}{R_{1}}+\frac{1}{R_{2}} \\
\frac{1}{E^{\prime}}=\frac{1-v_{1}^{2}}{2 E_{1}}+\frac{1-v_{2}^{2}}{2 E_{2}}
\end{gathered}
$$

The contact area is equal to:

$$
A_{c}=2 \cdot b \cdot t
$$


Abrasive wear originates from sand particles inside the contact between the sprocket and the stop. Assuming that there is a full layer of particles between the two contacting surfaces, the particle feed rate $n$ is:

$$
n=\frac{p \cdot A_{c}}{A_{p}}
$$

with $p$ the packing fraction, which is equal to 0.605 for a close-packed monolayer of spherical particles, and $A_{p}$ the projected area of one particle.

The specific wear rates for the sand varieties under consideration for all four terrain conditions can now be calculated by inserting the values for the feed rate, which depends on the terrain type, and the particle size and shape into Eq. 3. The resulting values for the specific wear rates are shown in Table 6.

\begin{tabular}{|c|c|c|c|}
\hline \multirow{2}{*}{ Sand variety } & \multicolumn{3}{|c|}{ Terrain } \\
\cline { 2 - 4 } & Paved & Unpaved & Heavy soil \\
\cline { 2 - 4 } & $\left(\cdot 10^{-6} \mathrm{~mm}^{3} / \mathrm{Nm}\right)$ & $\left(\cdot 10^{-4} \mathrm{~mm}^{3} / \mathrm{Nm}\right)$ & $\left(\cdot 10^{-3} \mathrm{~mm}^{3} / \mathrm{Nm}\right)$ \\
\hline ref & 8.1 & 2.5 & 2.9 \\
\hline 1 & 0.5 & 0.2 & 0.2 \\
\hline 2 & 0.8 & 0.3 & 0.3 \\
\hline 3 & 1.4 & 0.5 & 0.5 \\
\hline 4 & 1.4 & 0.5 & 0.5 \\
\hline 5 & 0.5 & 0.2 & 0.2 \\
\hline
\end{tabular}

Table 6, specific wear rates, corrected for the terrain.

The maximum allowed volumetric wear on a sprocket tooth $Q_{\max }$ equals the product of the sprocket width, the length over which the tooth is in contact with the stop and the distance between the gear tooth surface and the wear indicator. In this case this value can be calculated to be $50 \cdot 25 \cdot 20=25 \cdot 10^{3} \mathrm{~mm}^{3}$. Rewriting Archard's wear equation (Eq. 2) and accounting for the different terrain and unevenness situations and load factors, the maximum allowable sliding distance between the stop and the sprocket can be calculated:

$$
s_{\text {max }}=\sum_{j} \sum_{m} \frac{f_{\mathrm{t}, j} \cdot f_{\mathrm{u}, m} \cdot Q_{\mathrm{max}}}{k_{r e f} \cdot l_{\mathrm{ft}, j} \cdot l_{\mathrm{fu}, m} \cdot F_{t}}
$$

with $k_{\text {ref }}$ the specific wear rate for the selected sand variety at the reference conditions, $f_{\mathrm{t}, j}$ the fraction of the total distance travelled in certain terrain, $l_{\mathrm{ft}, \mathrm{j}}$ the load factor for the terrain type, $f_{\mathrm{u}, \mathrm{k}}$ the fraction of the total distance travelled with E-21 
certain unevenness of the terrain, $l_{\mathrm{fu}, \mathrm{k}}$ the load factor for the unevenness of the terrain and $j$ and $m$ the indices over the terrain type and unevenness variations, respectively.

Finally, referring to Fig. 4 (b), the sliding distance under loaded conditions of the stop over a gear tooth during one rotation of the wheel is equal to half the semi-circular part of the perimeter of the stop. By dividing the maximum allowed sliding distance $s_{\max }$, as expressed by Eq. 11, by the single gear tooth contact length, the maximum allowed number of wheel rotations is found, from which the maximum allowed driving distance can be calculated. Comparing the actual travelling distance with the maximum allowed driving distance provides the fraction of the wheel service life that has been consumed. Based on this information, the maintenance schedule can be determined. The maximum allowable driving distance thus represents the service life of the wheel for the given conditions, as will be shown in the next section.

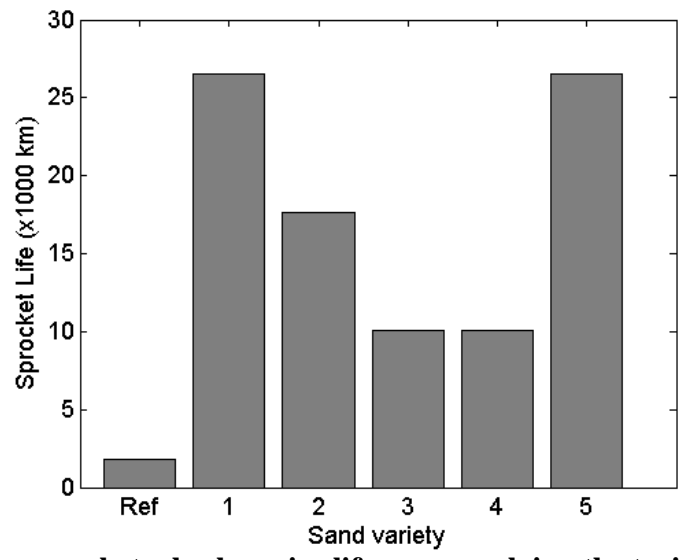

Fig. 8, Resulting sprocket wheel service life upon applying the training usage profile.

\section{$5 \quad$ Results and discussion}

The method proposed in the previous section can now be applied to calculate the sprocket service life under various operating conditions. The values for operation in the five different sand varieties and according to the assumed usage profile (Table 2) are shown in Fig. 8. The results indicate a large variation in service life of the sprocket as a function of the different sands. Typical values range from $10000 \mathrm{~km}$ to $25000 \mathrm{~km}$. Note that the standard sand used in dry sand rubber wheel testing is very abrasive, as can be concluded from the very short sprocket service life. However, this sand is not encountered in real applications. 
The calculated values for the sprocket service life can be compared to the values observed in practice. The date of replacement of the sprocket wheel for these vehicles is registered in the computerized maintenance management system (CMMS). The resulting mean times to failure for the various battalions were given in Table 5, showing typical values in the range of $1000-2000$ kilometres to failure. The sand variety encountered at the training locations is similar to variety 3 , which means that the sprocket service life as predicted by the model is $10.000 \mathrm{~km}$ (see Fig. 8). It can be concluded that the order of magnitude of the predicted service life is correct, but there is clearly a considerable difference between the predicted and actual value. This is not surprising, since a considerable number of assumptions have been made during the model set-up in section 4, e.g. concerning the load factors (in Table 3 and Table 4), the force transmission, the contact area and the amount of sand in the contact. Also the distribution of the driven kilometres over the various operating conditions has been estimated (Table 2). Since all these factors affect the calculated service life, the uncertainties prohibit the accurate prediction of a service life in an absolute sense.

Another possible explanation for the deviation between predicted and actual service life is the change in operating conditions after the first year of operation. The usage profile as defined in Table 2 is based on the regular training program for a vehicle that has completely finished the introduction period directly after starting service. However, during the introduction period (of about one year), the vehicle is used to train the driver and crew. This yields a usage profile that is completely different from the mission profile described in section 4.2 and takes place in a typically heavy and mostly sandy environment. This increase of the proportion of the total distance driven in sand would decrease the maximum allowed driving distance. Since a considerable fraction of the fleet is only in operation for a couple of years, this introduction period has a large influence on the average failure behaviour. To account for these different conditions, the usage profile is modified, as is shown in Table 7. 


\begin{tabular}{|l|c|c|c|c|}
\hline \multirow{2}{*}{ Unevenness } & \multicolumn{2}{|l|}{ Surface type } & \multirow{2}{*}{} \\
\cline { 2 - 4 } & Asphalt & Unpaved & $\begin{array}{c}\text { Heavy soil and loose } \\
\text { sand }\end{array}$ & \\
\hline Light & $1 \%$ & $1 \%$ & $18 \%$ & $20 \%$ \\
\hline Medium & $1 \%$ & $1 \%$ & $18 \%$ & $20 \%$ \\
\hline Heavy & $3 \%$ & $3 \%$ & $54 \%$ & $60 \%$ \\
\hline
\end{tabular}

Table 7, Modified usage profile for training missions under heavier circumstances.

Applying this usage profile to calculate the sprocket service life yields the results shown in Fig. 9. Also the results for the standard scenario from Fig. 8 are plotted in this figure as a reference. The results demonstrate that, by modifying the profile, the maximum allowed driving distances is halved, indicating that the more severe conditions during the introduction period indeed decrease the service life of the wheel sprockets.

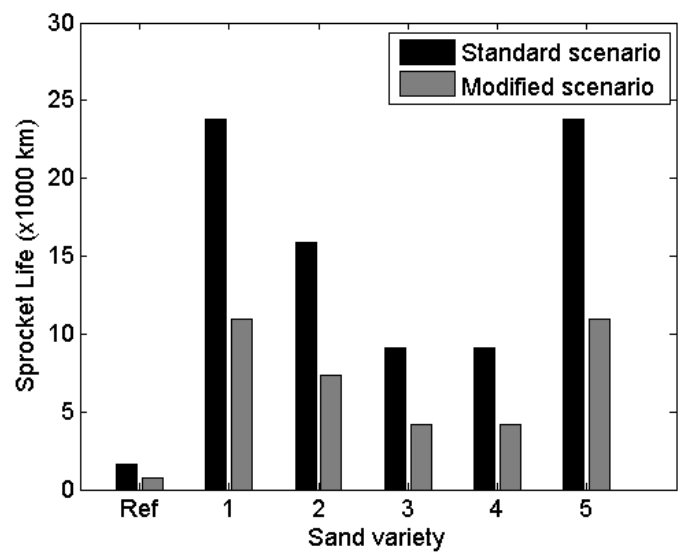

Fig. 9, Results of the standard and modified usage profile, sprocket wheel service life.

The most important benefit of the proposed concept is that it can be applied in scenario analyses, where it enables to quantify the effects of operating the system in a different way or at another location. This is possible since not only the variation in terrain type and unevenness can be included, but also the effect of the geographic location and associated sand variety is incorporated in the model. This is especially useful when deployment of the vehicles for a certain mission is considered. A simple assessment of the local sand properties and an estimate of the usage profile enables to predict the expected amount of wear and associated sprocket wheel service life. That information is very useful when the 
spare parts provisioning and maintenance planning must be decided upon. Moreover, also during training periods application of the developed method can be beneficial. For example, the failure data in Table 5 shows that a significant difference in mean time between failures exist between the two locations (A and B). The two battalions at location A have a MTBF in the range $600-$ $1200 \mathrm{~km}$, while the battalions at location B have a considerably longer MTBF in the range $1700-2000 \mathrm{~km}$. Inquiries at the staff revealed that no significant differences in training programs are recognized. Collection of more detailed information on the specific usage could confirm or reject that assumption. And if the usage indeed appears to be very similar, the difference in MTBF could also be due to different sand varieties at the two locations (which at the moment are assumed to be equal). If this information is available, the proposed method would enable to quantify and explain the observed differences, and support the associated maintenance decisions, e.g. in advising the appropriate maintenance intervals.

Finally, another striking observation from Table 5 is the difference in the amount of driven kilometres per year between the four battalions on the one hand and the drivers training facility vehicles on the other hand. Unfortunately, the failure data for the drivers training vehicles is not available. It is expected that the MTBF for these vehicles in terms of kilometres will be in the same range as these of the battalions (but based on the severe usage profile in Table 7), while the time to failure (in days) will be significantly lower. Again, the proposed method could be used to quantify these kind of effects.

\section{Conclusions}

A usage severity based maintenance concept was developed for systems operating in a sandy environment. This was achieved by implementing a recently developed abrasive wear model into a predictive maintenance framework. The method has been demonstrated by applying it to the specific case study of a military vehicle, for which the wear of the sprocket wheels is predicted. This required establishing relations between the local parameters that govern the wear mechanism, like normal force, sliding distance and specific wear parameter, and the system-level usage parameters like terrain type and driving distance. The method has been shown to support the determination of maintenance interval lengths for given usage profiles and sand varieties, and has proven to be valuable in scenario analyses. 
[1] M. Woldman, E. van der Heide, D.J. Schipper, T. Tinga, M.A. Masen, Investigating the influence of sand particle properties on abrasive wear behaviour, Wear 294-295 (2012) 419-426.

[2] M. Woldman, E. van Der Heide, T. Tinga, M.A. Masen, The influence of abrasive body dimensions on single asperity wear, Wear 301 (2013) 76-81.

[3] T. Tinga, Application of physical failure models to enable usage and load based maintenance, Reliab. Eng. Syst. Safe. 95 (2010) 1061-1075.

[4] C.S. Byington, M.J. Roemer, T. Galie, Prognostic enhancements to diagnostic systems for improved condition-based maintenance [military aircraft], Aerospace Conf. P. 6 (2002) 2815-2824.

[5] M.J. Roemer, C.S. Byington, G.J. Kacprzynski, G. Vachtsevanos, An overview of selected prognostic technologies with application to engine health management, ASME Turbo Expo 8-11 (2006) 707-715.

[6] C.R. Farrar, N.A. Lieven, Damage prognosis: the future of structural health monitoring. Philos. T. Roy. Soc. A 365 (2007) 623-632.

[7] T. Tinga, Predictive maintenance of military systems based on physical failure models. Chem. Eng. T 33 (2013) 295-300.

[8] J.F. Archard, Contact and Rubbing of Flat Surfaces, J. Appl. Phys. 24, (1953) 981-988.

[9] I.M. Hutchings, Tribology: Friction and Wear of Engineering Materials, Edward Arnold, London, 1992.

[10] M.A. Moore, Abrasive wear, Int. J. of Mater. in Eng. Ap. 1 (1978) 97-111.

[11] A. Fukunishi, Y. Mori, Adhesion force between particles and substrate in a humid atmosphere studied by atomic force microscopy, Adv. Powder Technol. 17 (2006) 567-580.

[12] Defence, M.o. Operationele scenario CV9035NL. Appendix 8 of Systeemplan Infantry Fighting Vehicle (2004).

[13] W. Tiddens, Towards improving maintenance performance in a military context (2012).

[14] J. van Gemerden, Technische informatie voor werktuigbouwkundigen, Wolters-Noordhoff, Groningen, the Netherlands, 2001.

[15] H. Hertz, Ueber die Berührung fester elastischer Körper, J. Rheine Angew. Math. 92 (1882) 156-171. 